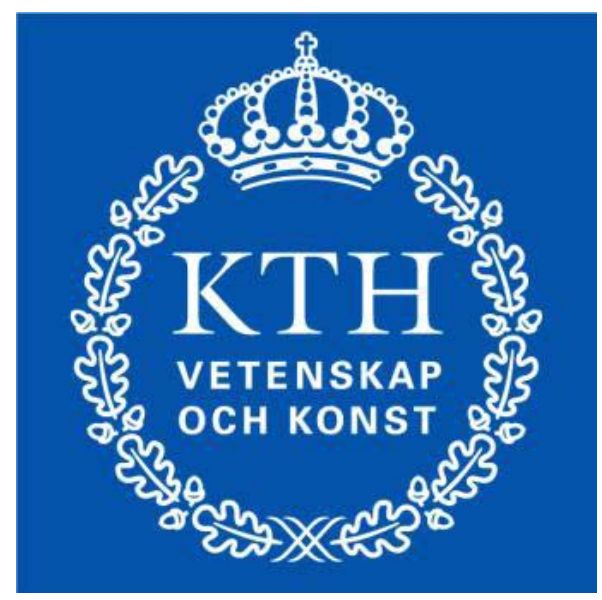

Royal Institute of Technology

TRITA-FYS 2012:49

ISSN 0280-316X

ISRN KTH/FYS/--12:49—SE

\title{
Validation of TRACE Code against ROSA/LSTF Test for SBLOCA of Pressure Vessel Upper-Head Small Break
}

\author{
MIAN XING \\ Master of Science Thesis \\ Division of Nuclear Power Safety \\ Stockholm, Sweden 2012
}




\section{Abstract}

OECD/NEA ROSA/LSTF project tests are performed on the Large Scale Test Facility (LSTF). LSTF is a full-height, full-pressure and 1/48 volumetrically-scaled two-loop system which aims to simulate Japanese Tsuruga-2 Westinghouse-type 4-loop PWR. ROSA-V Test 6-1 simulates a pressure vessel (PV) upper-head small break loss-of-coolant accident (SBLOCA) with a break size equivalent to $1.9 \%$ of the volumetrically scaled cross-sectional area of the reference PWR cold leg.

The main objective of present thesis is to build a TRACE calculation model for simulating thermal hydraulic behaviors in LSTF and PV upper-head SBLOCA, so as to assess different modeling options and parameters of TRACE code. The results show that TRACE code well reproduce the complex physical phenomena involved in this type of SBLOCA scenarios. Almost all the events in the experiment are well predicted by the model based on TRACE code. In addition, the sensitivity of different models and parameters are investigated. For example, the code slightly overestimates the break mass flow from upper head which affects the accuracy of the results significantly. The rising of core exit temperature (CET) is significantly influenced by the flow area of leakage between downcomer and hot leg. Besides, the effect of the break location, low pressure injection system (LPIS) and accumulator setup are also studied.

Key words: SBLOCA, LSTF, TRACE, thermal-hydraulics transient, safety analysis 


\section{Acknowledgements}

First of all, I would like to express my sincere gratitude to my supervisor Dr. Weimin Ma who guides my thesis work with his insight, patience and encouragement. I would also like to express my gratitude to Prof. Sevostian Bechta for his kind support and being my examiner.

I also want to express my gratitude to Liangxing $\mathrm{Li}$ and Shengjie Gong who give me a lot of comments about thesis writing in addition to the physical knowledge, experimental setup and pingpang technique, and Hua Li who teach me the convergence between SNAP and input deck, Sebastian who guide me familiar with the project and give me his model as template, and Sachin who shares his high speed computer, all this help me a lot during my thesis work.

Besides, I really appreciate the lab experience supported by Weimin Ma, Aram, Alexander and Storm.

I am very grateful to the whole department of Nuclear Power Safety who create such a harmony and hardworking circumstance in addition to all friendly and helpful staff here.

I want to show my thanks to all my friends in Stockholm: Chen Sisi, Zhang Youpeng, Chang Zhongwen, Shao Yiqiong, Zhong Huaqiang, Xu Zhenxiang, Li Gongzhuo, Sun Jing, Li Yang, Shi Chen, Zhu Yafeng, Liu Peng, Peng Lin and Zhang Zhongyuan, Paopao, Dingding etc.

Finally, I want to thank my parents who encourage and support my study here and my boyfriend, Hu Xiao who study and live with me every day, console and help me whenever I have difficulties. 


\section{Contents}

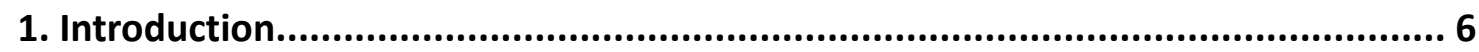

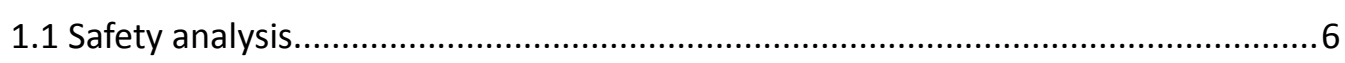

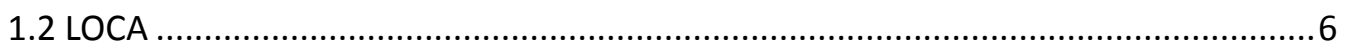

2. ROSA test 6-1

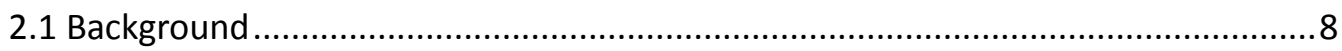

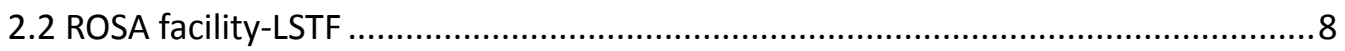

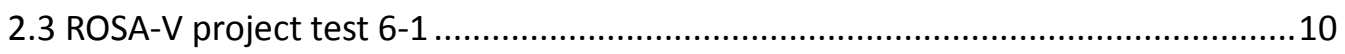

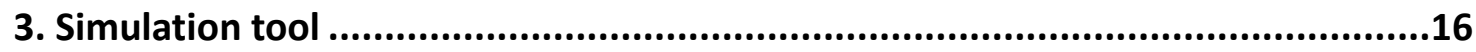

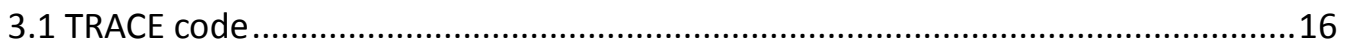

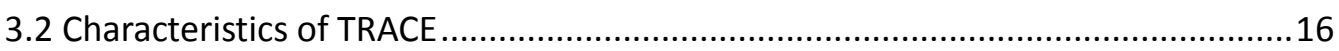

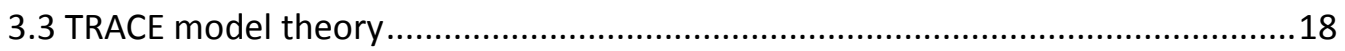

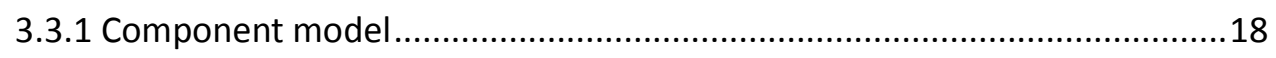

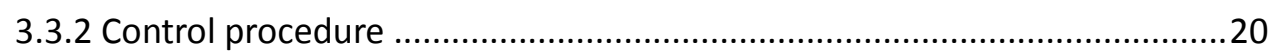

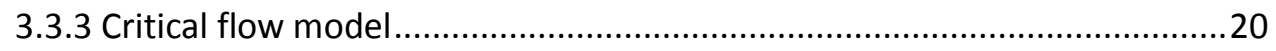

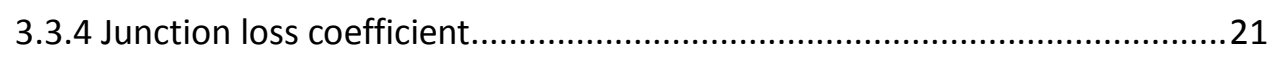

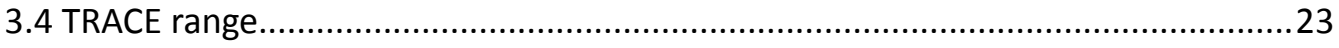

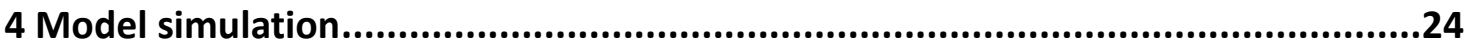

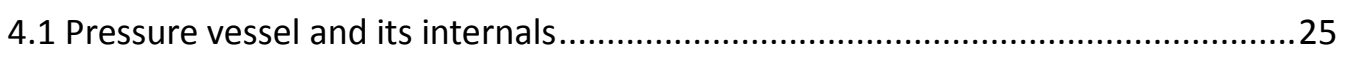

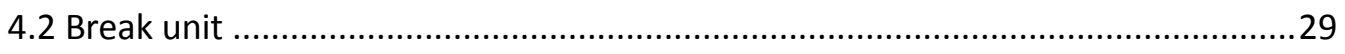

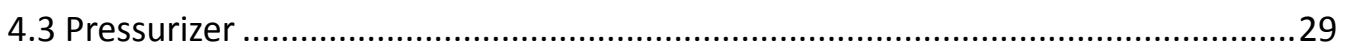

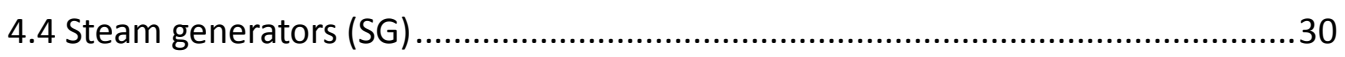

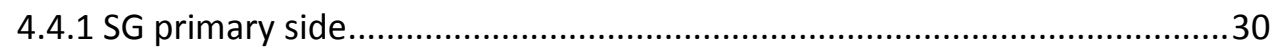

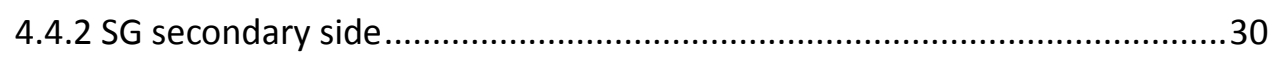

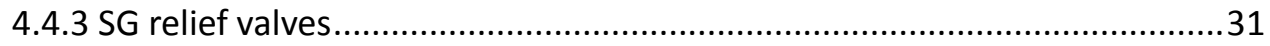

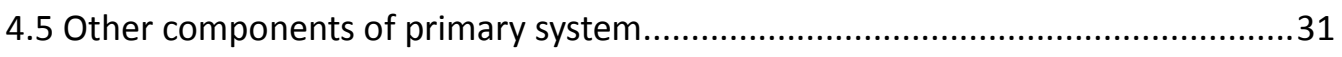

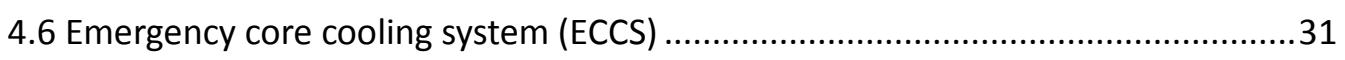

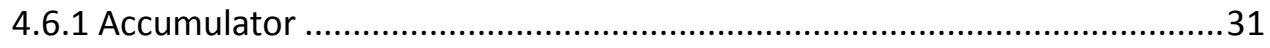

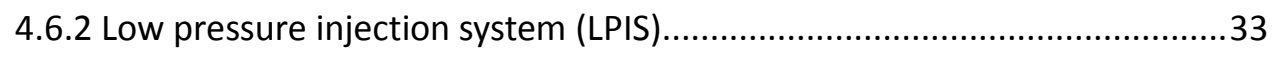

5. Results and discussions ....................................................................34

5.1 Model validation: components geometry comparison ..........................................

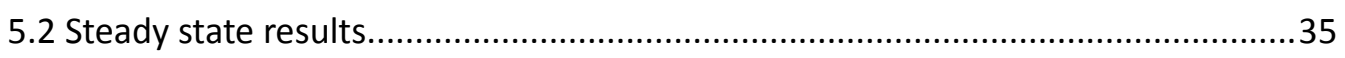

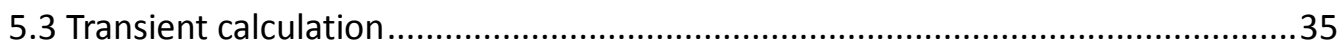

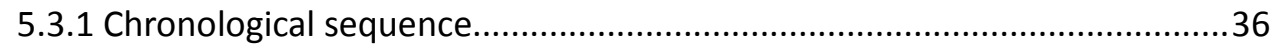

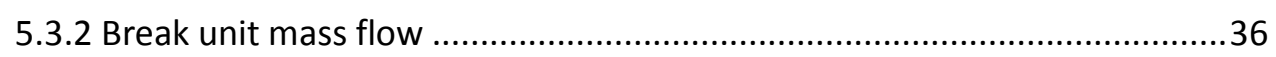

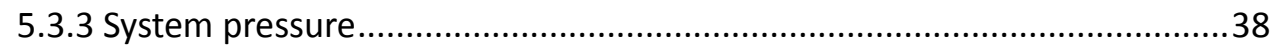

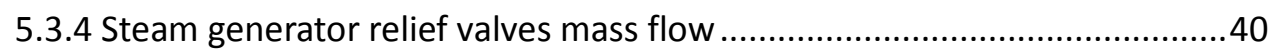

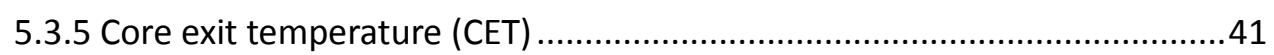

5.3.6 Maximum fuel rod surface temperature ................................................43

5.3.7 Primary loop mass flow rate..................................................................44

5.3.8 Collapsed liquid level in the core and upper head ...................................46

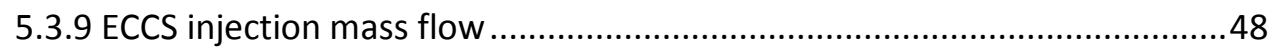

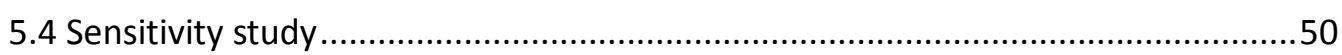




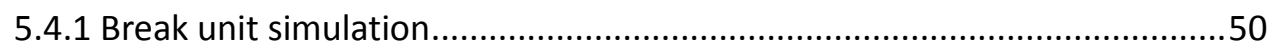

5.4.2 Leakage between downcomer and hot leg .............................................53

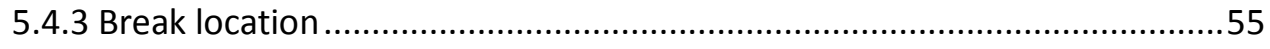

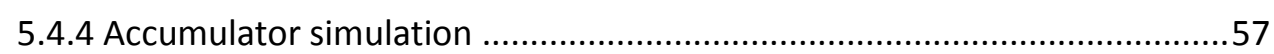

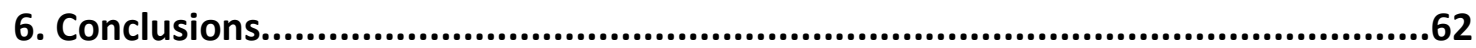

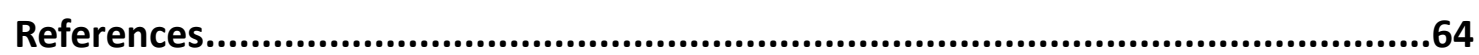




\section{Introduction}

\subsection{Safety analysis}

Nuclear power which uses nuclear fuel to generate heat and electricity is considered as a sustainable energy generation way. However, it also poses many threats to people and the environment and makes the nuclear safety analysis so significant. Nuclear safety analysis is the study of the reactor behaviors under the fault conditions. The events for safety analysis usually consist of the design basis accidents and beyond the design basis accidents [1]. Within the design basis accidents, required safety systems still work as intended under the malfunctions of the normal operating and control systems. However, during the events of beyond design basis, essential safety systems cannot be available as intended.

\subsection{LOCA}

Loss-of-coolant accident (LOCA) is one of the most important design basis accidents. The types of LOCA are characterized by different break flow area. Usually, a large LOCA has the flow area whose diameter is larger than $250 \mathrm{~mm}$, a medium LOCA is between 80 and $250 \mathrm{~mm}$, and small LOCA has a diameter of $10-80 \mathrm{~mm}$ [1]. In order to compensate the lost coolant, one or more emergency core cooling systems (ECCS) would be initiated, i.e. high-pressure safety injection, low-pressure safety injection and accumulators. High- and low-pressure safety injection systems and accumulator are actuated by different reactor pressure set points. For example, the accumulator will inject water to system as soon as the primary pressure drops to about 4.5 $\mathrm{MPa}$.

Before the Three-Mile Island accident, the large-break LOCA was considered as the design basis accident for PWR, which attacked most attention of the safety analysis of postulated accidents. However, the occurrence of TMI-2 accident reminded people the danger of small-break LOCA and lead to more and more detailed analysis of the small-break LOCA [2]. During a small-break LOCA, the reactor depressurization is much slower than the large-break LOCA which makes it impossible for LPIS to inject large rate of coolant flow at beginning. Besides, it is more likely to occur so it is worthy to study small-break LOCA (SBLOCA).

Typically, the sequence of events happened in SBLOCA proceeds as follows: control rods will be inserted into the core completely and the scram occurs within 20 to 60 seconds as soon as the reactor pressure drop is sensed. Then, the main coolant pump will be stopped and feed water will be also switched off. Although the fission power is shut down, the decay heat is still released. To take it away, the auxiliary feed water system is taken into operation. When the pressure drops to $10 \mathrm{MPa}$, the HPIS will pump water with a small flow rate to the core and it is the water phase in the core. After that, when the pressure falls below saturation pressure, the water inside the core turns to be saturated and it is the two-phase mixture of steam and water in the core. About $10-15$ minutes later, the pressure drops to about $4-4.5 \mathrm{MPa}$ and the 
accumulator will be initiated. Eventually, the pressure would be stabilized at about $1 \mathrm{MPa}$ and the low-pressure injection system could pump water into the primary system, so the core would be rapidly reflooded to be a cold condition [2]. The injection continues until the water in the storage tank is used up.

After the scram, the core is cooled by natural circulation. Firstly steam bubbles form and settle in PV. After the water level falls below the hot leg nozzle, the steam escapes to the steam generators (SG) and is condensed since the coolant temperature in SG secondary system is much lower. Then the condensed water will flow back to the reactor vessel in the opposite direction ('reflux condenser mode') [1]. Such a phenomenon happens in the condition that the secondary side has to be at low pressure, and at a correspondingly low saturation temperature. But when the primary pressure decreases below the secondary pressure, no condensation can take place [2].

During the SBLOCA, the depressurization is much slower than previous case and the pressure stabilizes at a higher value than the low-pressure safety injection initiation pressure. So the reactor operator should reduce the pressure and temperature to activate the LPIS by using steam generators, auxiliary feedwater and opening the steam relief valves. As an alternative, the operator could manually initiate the main feedwater systems in one loop and use the other heat sink, i.e. turbine condenser. Because in SBLOCA, the break flow is not sufficiently large to take out the decay heat, alternative heat sinks are required to discharge or damp the steam either on secondary side or to the turbine. Another method to reduce the reactor pressure is to open and close the pressure relief valves repeatedly in the pressurizer.

In this study, TRACE code is employed to estimate the thermal hydraulic responses after a SBLOCA of pressure vessel (PV) upper head under the assumption of total failure of high pressure injection system (HPIS). The computational calculation results will be compared with the experimental data: I) to interpret the transient thermal hydraulic performance of SBLOCA of PV upper head on LSTF; II) to assess the predictability of TRACE code against the complex phenomena during the transient; III) to conduct sensitivity study and find out the influence of some parameters or models. 


\section{ROSA test 6-1}

\subsection{Background}

The ROSA program was initiated in 70s of last century for the study of thermal-hydraulic phenomena of light water reactors (LWRs) during loss-of-coolant accidents ( both design basis LOCAs and small-break LOCAs) and operational transients, including fundamental blow down phenomena and effectiveness of emergency core cooling systems (ECCSs) by using scaled test facilities [3].

In 1991, ROSA project had progressed to ROSA-V program. The main objectives were defined to evaluate the effectiveness of Accident Management (AM) in the scenario of beyond design basis accidents (BDBAs), find out better solution to prevent severe accidents, and simulate passive safety systems simulation as well as the validate and improve computer codes [3].

\subsection{ROSA facility-LSTF}

During ROSA-V program, Large Scale Test Facility (LSTF) is the main test facility [3-4]. It was designed to model Japanese Tsuruga-2 $3423 \mathrm{MWt}$ (1160 MWe) Westinghouse-type 4-loop PWR by a full-height, full-pressure and $1 / 48$ volumetrically-scaled two equal-volume-loop system with a core of $10 \mathrm{MW}$ electrical heater. Hundreds of tests had been performed on LSTF to investigate various PWR plant behaviors and the effects of plant recovery methods for a wide spectrum of accident and transient conditions. In ROSA-V, LSTF is remodeled to have new fuel assembly design, full-height pressurizer and improved ECCS features which aims to confirm the effectiveness of various accident management (AM) measures for severe core damage prevention [3]. The effectiveness of passive safety systems could also be simulated and analyzed by using the device.

The main design features of remodeled LSTF and referred PWR are listed in Table 2.1. The core height, operation pressure and temperature are preserved. The geometry of single fuel rod is also in the same size, including rod diameter and the rod pitch. The power ratio between LSTF and referred PWR is $1 / 342$. It is realized by different rod bundle size and different number of rods. For the reference PWR, the rod bundle size is $7 \times 7$, while the LSTF is $17 \times 17$. Each loop contains an active $1 / 24$ volumetrically scaled steam generator (SG) and primary coolant recirculation system, since LSTF is designed to use 2-loop to simulate the 4-loop PWR with the $1 / 48$ volumetrical scale. The length of SG tube is kept while the U-tube number is cut down to be $1 / 24$ of the referred one. Besides, in order to better simulate the two-phase flow regime in the whole systems, the loop horizontal flow areas (i.e. the flow area of hot leg) are also sized to conserve the ratio between the length and square root of the diameter as following equation:

$$
\frac{L_{P W R}}{\sqrt[2]{D_{\text {PWR }}}}=\frac{L_{\text {LSTF }}}{\sqrt[2]{D_{\text {LSTF }}}}
$$


Figure 2.1 shows a general layout of the LSTF which consists of primary and secondary coolant system, including pressure vessel (PV), primary loop A with pressurizer (PZR) and symmetrical loop B without PZR, two steam generators, jet condenser, feedwater pump, auxiliary feedwater pumps and associated piping system. Besides, emergency core cooling systems (ECCSs) are made up by higher pressure injection system (HPIS), two accumulators (ACC-hot and ACC-cold) and low pressure injection system (LPIS).

Table 2.1 Main design features of LSTF and referred PWR.

\begin{tabular}{|l|l|l|l|}
\hline Items & PWR & LSTF & PWR/LSTF \\
\hline Core height $(\mathrm{m})$ & 3.66 & 3.66 & 1 \\
\hline Pressure $(\mathrm{MPa})$ & 16 & 16 & 1 \\
\hline Temperature $(\mathrm{K})$ & 598 & 598 & 1 \\
\hline Number of fuel rods & 50952 & 1008 & 50.55 \\
\hline Rod bundle size & $7 \times 7($ Square) & $17 \times 17$ & \\
\hline Rod diameter $(\mathrm{mm})$ & & & \\
\hline \multicolumn{1}{|c|}{ Heater rod } & 9.5 & 9.5 & 1 \\
\hline \multicolumn{1}{|c|}{ Non-heating rod } & 12.24 & 12.24 & 1 \\
\hline Rod pitch (mm) & 12.6 & 12.6 & 1 \\
\hline Total core power & $3423(\mathrm{t})$ & 10 & 342 \\
\hline Hot leg volume $\left(\frac{\pi}{4} \mathrm{D}^{2} \mathrm{~L}\right)$ & 2.98 & 0.124 & 24 \\
\hline Hot leg $\mathrm{L} / \sqrt{\mathrm{D}}$ & & & \\
\hline Number of primary loops & 8.14 & 8.11 & 1 \\
\hline Number of SGs & 4 & 2 & 2 \\
\hline Number of tubes in Steam Generator & 4 & 2 & 2 \\
\hline Length of Steam Generator tube (Average)(m) & 3382 & 141 & 24 \\
\hline
\end{tabular}




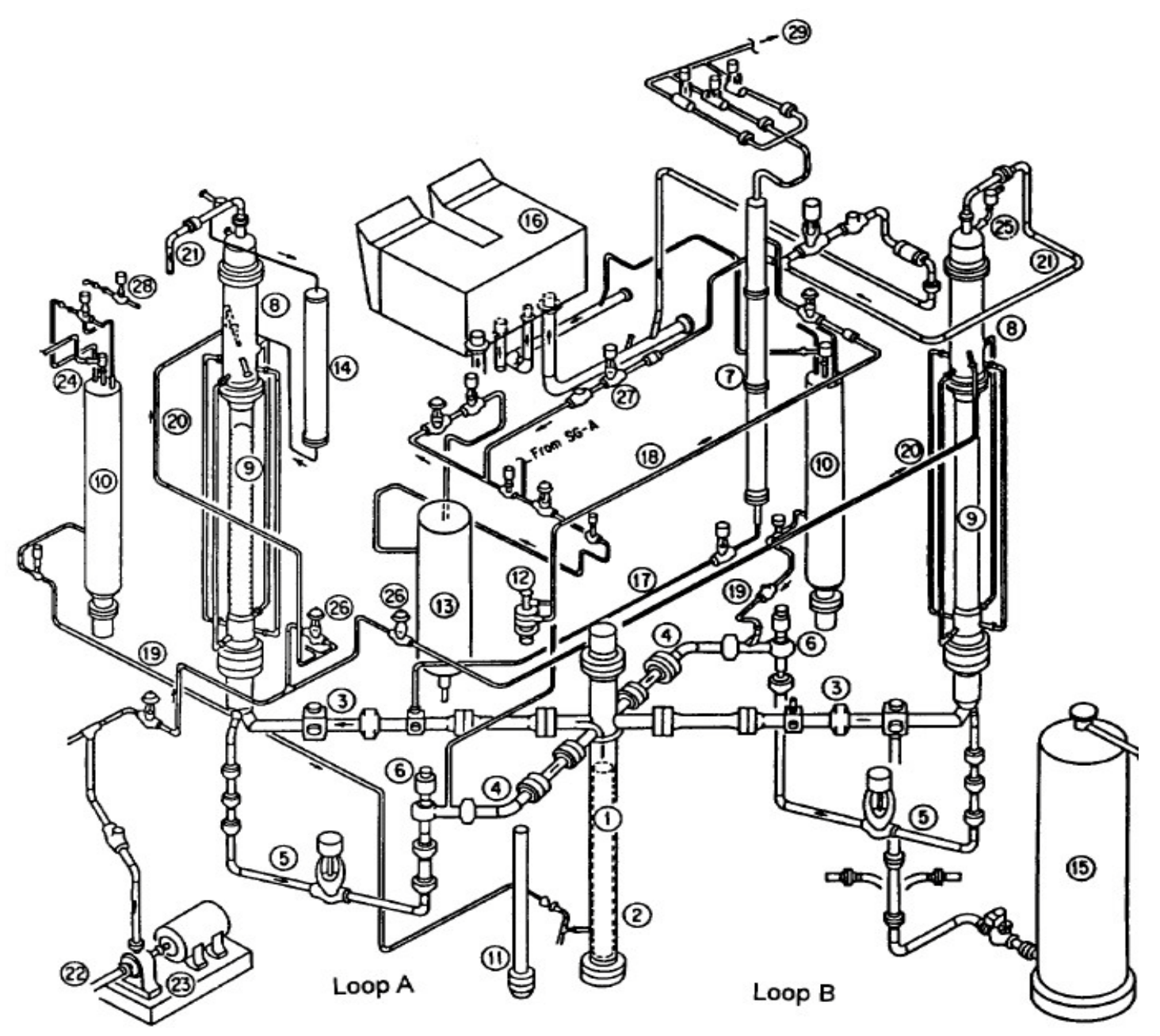

Figure 2.1 General view of LSTF.

\subsection{ROSA-V project test 6-1}

ROSA-V project test 6-1 simulates a pressure vessel (PV) upper head small break loss-of-coolant accident (SBLOCA) with a break size equivalent to $1.9 \%$ cold leg break, as shown in Figure 2.2. It has been reported from Davis-Besse Reactor that the coolant and operating conditions in the primary system of PWR plant may cause the stress corrosion cracking of control rod drive mechanisms (CRDM) and instruments which are made from nickel-based alloys (i.e. Alloy 600) related weld metal [4]. The cracking process is called primary water stress corrosion cracking (PWSCC) which could result in the pressure vessel head wall thinning and degradation, and impose a threaten to the safety concerning vessel structural integrity [5]. Due to the circumferential cracking of the penetration nozzles for CRDM, there might be some leakage or a small break loss of coolant accident (SBLOCA) at the upper head of PWR. So a SBLOCA with a break size equivalent to $1.9 \%$ cold leg break at the PWR pressure vessel (PV) upper head is simulated in Test 6-1.

In the test, the break unit contains a horizontal pipe and a break valve, as shown in Figure 2.3. The inner diameter of the pipe is $87.3 \mathrm{~mm}$ and it locates at $435 \mathrm{~mm}$ higher than upper head 
break nozzle. The break size is realized by the sharp-edge orifice fixed at the downstream of the pipe of $13.8 \mathrm{~mm}$ in diameter makes the orifice flow area correspond to $1.9 \%$ cross-sectional area of the cold leg in LSTF.

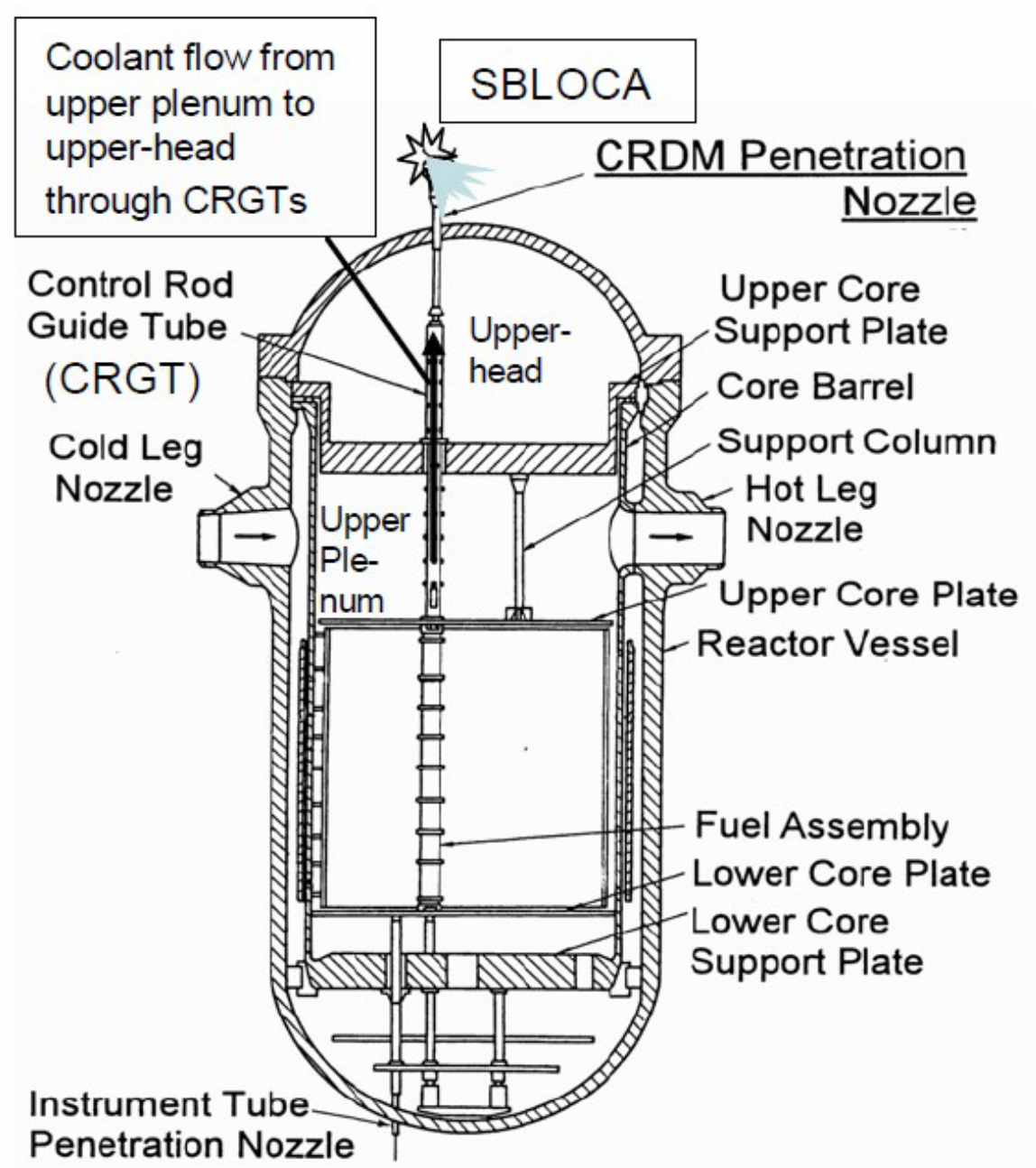

Figure 2.2 Location of SBLOCA at PWR PV upper head.

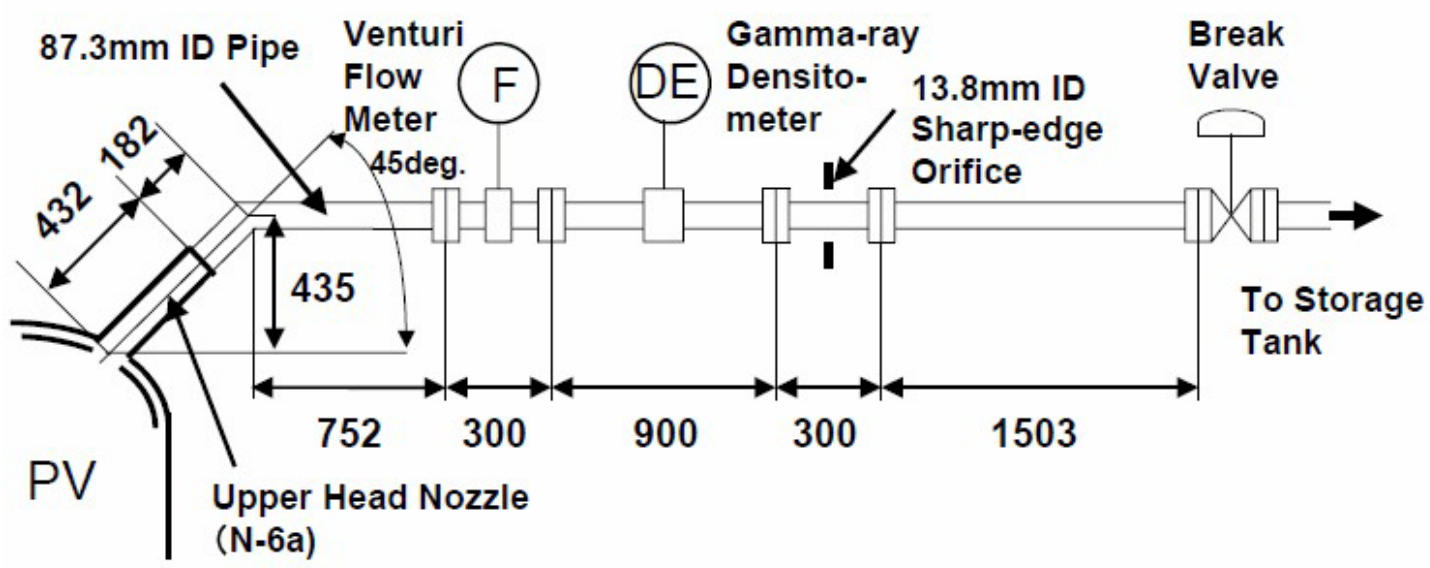

Figure 2.3 Experimental scheme of break units. 
The test chronology is summarized in Table 2.2. During the experiment, the transient scenario begins with the opening of a valve on the top of upper head to simulate the SBLOCA. Because of the break, the primary pressure suffers a slow drop. When the lower plenum pressure reaches the set point of $12.97 \mathrm{MPa}$, the scram signal is triggered. In the referred PWR, when the reactor scrams, the control rods are inserted without delay. However, in the LSTF experiment, since there is no real fuel or control rod, the core power is adjusted manually as the postulated core power decay curve, as shown in Table 2.3 [6]. Besides, the primary pump is also coasted down, following a pre-determined rational speed curve. When the break initiates, the rotational speed almost doubles from $85.1 \mathrm{rad} / \mathrm{s}$ to $161.85 \mathrm{rad} / \mathrm{s}$ and stabilizes at this level. Until the scram signal, the rotational speed begins to slow down and comes to a stop at about 275 s. Once, there was controversy about whether the main recirculation pump should be stopped or not during LOCAs. The current rule is to stop the pumps. Not only because that they would promote the loss of fluid by circulating if they were left in operation, but also due to the fact that they would fail due to vibration. In addition to the power decay and pump coast down, when the reactor scrams, main feedwater of steam generators (SG) would be stopped, and turbine will be tripped by closing main steam isolation valves (MSIVs) in the steam line in secondary system. However, the closure of main steam isolation valves results in a rise of the pressure in the secondary system.

Shortly after scram signal, safety injection (SI) is initiated, when the PV lower plenum pressure drops to $12.27 \mathrm{MPa}$. As a result, auxiliary feedwater is initiated to pump subcooled water (300K) into the SG. After the moment, the steam relief valves (SRV) in both loops will switch on and off alternately to maintain the secondary pressure between $7.65 \mathrm{MPa}$ and $7.95 \mathrm{MPa}$. At the same time, the pressure and temperature in the primary system will keep a relatively steady state because of the balance among the core power output, break loss and secondary side heat sink.

However, the balance will be broken as the upper plenum is depleted which leads to the phase change from two phase flow to single vapor in the break. There would be an immediate depressurization and a fast increase of temperature. When the core exit temperature (CET) is detected to reach $623 \mathrm{~K}$, the accident management (AM) will be initiated by fully opening of the SRVs in both SGs, which leads to a fast depressurization of the secondary system. But the AM action was ineffective in the early stage as long as the secondary pressure is higher than the primary pressure. As shown in Table 2.3, when the maximum fuel rod surface temperature or cladding temperature rises over 958K [4], specific core protection system logic would automatically reduce the core power to $10 \%$ of the actual decay power.

In LSTF ROSA test 6-1, accumulators are designed as the main cooling measure. When the PV lower plenum pressure drop down to $4.5 \mathrm{MPa}$, the subcooled water (320K) from accumulator tanks condenses the vapor in the primary system which enhances the core reflooding and thus helps the core quench. After that, the PV lower plenum pressure decreases to $1.2 \mathrm{MPa}$, and the low pressure injection system is activated.

An accumulator consists of an accumulator tank and a stand pipe. LSTF has two accumulator tanks with the same size. The whole volume is $4.8 \mathrm{~m}^{3}$. There is $0.46 \mathrm{~m}^{3}$ initial nitrogen gas and 
$1.12 \mathrm{~m}^{3}$ water at the top of the tank. Below, there is the stand pipe of $4.2 \mathrm{~m}$ height. The accumulator check valve will be opened to inject water when the primary pressure drops to $4.51 \mathrm{Mpa}$. Figure 2.4 illustrates the geometry and elevations of accumulator injection lines to the cold leg in both loops.

Table 2.2 Test chronology of the experiment.

\begin{tabular}{|c|c|c|c|}
\hline Signal variable & Setpoint & Trigger & Event \\
\hline Problem time & 0 & Break valve open & PV upper head break \\
\hline \multirow{5}{*}{$\begin{array}{l}\text { PV lower plenum } \\
\text { pressure }\end{array}$} & \multirow{5}{*}{$\begin{array}{l}12.97 \\
\mathrm{MPa}\end{array}$} & \multirow[t]{5}{*}{ Generation of Scram signal } & Initiation of core \\
\hline & & & power decay curve \\
\hline & & & $\begin{array}{l}\text { Primary pump } \\
\text { coastdown }\end{array}$ \\
\hline & & & $\begin{array}{c}\text { Main steam isolation } \\
\text { valve closure }\end{array}$ \\
\hline & & & $\begin{array}{c}\text { Termination of main } \\
\text { feedwater }\end{array}$ \\
\hline $\begin{array}{l}\text { PV lower plenum } \\
\text { pressure }\end{array}$ & $\begin{array}{l}12.27 \\
\mathrm{MPa}\end{array}$ & $\begin{array}{c}\text { Generation of safety injection } \\
\text { signal (SI) }\end{array}$ & $\begin{array}{l}\text { Auxiliary feedwater } \\
\text { start-up }\end{array}$ \\
\hline $\begin{array}{l}\text { Secondary side } \\
\text { pressure }\end{array}$ & $\begin{array}{l}7.95 \mathrm{MPa} \\
7.65 \mathrm{MPa}\end{array}$ & $\begin{array}{l}\text { Safety relief valve open and } \\
\text { close intermittently }\end{array}$ & $\begin{array}{c}\text { Secondary system } \\
\text { pressure oscillation } \\
\text { between determined } \\
\text { value }\end{array}$ \\
\hline Core exit temperature & $623 \mathrm{~K}$ & Accident management & $\begin{array}{l}\text { Steam relief valve } \\
\text { open permanently }\end{array}$ \\
\hline $\begin{array}{l}\text { Maximum fuel rod } \\
\text { temperature }\end{array}$ & $958 \mathrm{~K}$ & $\begin{array}{c}\text { Core protection system } \\
\text { activation }\end{array}$ & $\begin{array}{c}\text { Core power is } \\
\text { automatically } \\
\text { decreased to } 75 \%\end{array}$ \\
\hline $\begin{array}{l}\text { PV lower plenum } \\
\text { pressure }\end{array}$ & $4.5 \mathrm{MPa}$ & Accumlator valve open & $\begin{array}{l}\text { Accumulator } \\
\text { activates }\end{array}$ \\
\hline $\begin{array}{l}\text { PV lower plenum } \\
\text { pressure }\end{array}$ & 1.2 $\mathrm{MPa}$ & $\begin{array}{l}\text { Low pressure injection system } \\
\text { (LPIS) valve open }\end{array}$ & LPIS activates \\
\hline
\end{tabular}


Table 2.3 Predetermined core power decay curve.

\begin{tabular}{|l|l|l|l|l|l|l|l|}
\hline $\begin{array}{l}\text { Problem } \\
\text { time (s) }\end{array}$ & $\begin{array}{l}\text { Total } \\
\text { reactor } \\
\text { power } \\
\text { (W) }\end{array}$ & $\begin{array}{l}\text { Problem } \\
\text { time(s) }\end{array}$ & $\begin{array}{l}\text { Total } \\
\text { reactor } \\
\text { power } \\
(\mathrm{W})\end{array}$ & $\begin{array}{l}\text { Problem } \\
\text { time(s) }\end{array}$ & $\begin{array}{l}\text { Total } \\
\text { reactor } \\
\text { power } \\
\text { (W) }\end{array}$ & $\begin{array}{l}\text { Problem } \\
\text { time(s) }\end{array}$ & $\begin{array}{l}\text { Total } \\
\text { reactor } \\
\text { power } \\
\text { (W) }\end{array}$ \\
\hline 0 & 10119000 & 20 & 10121000 & 46 & 10124000 & 47 & 9295000 \\
\hline 48 & 7908000 & 49 & 7590000 & 50 & 7342000 & 70 & 4393000 \\
\hline 90 & 3523000 & 200 & 2391000 & 600 & 1886000 & 1200 & 1465000 \\
\hline 1201 & 1467000 & 1206 & 1348000 & 1207 & 1123000 & 1208 & 1103000 \\
\hline 1209 & 1100000 & 1215 & 1096000 & 1216 & 846000 & 1217 & 270000 \\
\hline 1218 & 189000 & 1219 & 170000 & 169900 & 162000 & 1300 & 159000 \\
\hline 1400 & 159000 & 1900 & 144000 & 2290 & 129000 & 2291 & 108000 \\
\hline 2292 & 100000 & 2293 & 96000 & 2671 & 98000 & 2706 & 119000 \\
\hline 2707 & 123000 & 2708 & 134000 & 3165 & 137000 & 3265 & 137000 \\
\hline
\end{tabular}

(a) Accumulator injection line to cold leg in loop without PZR

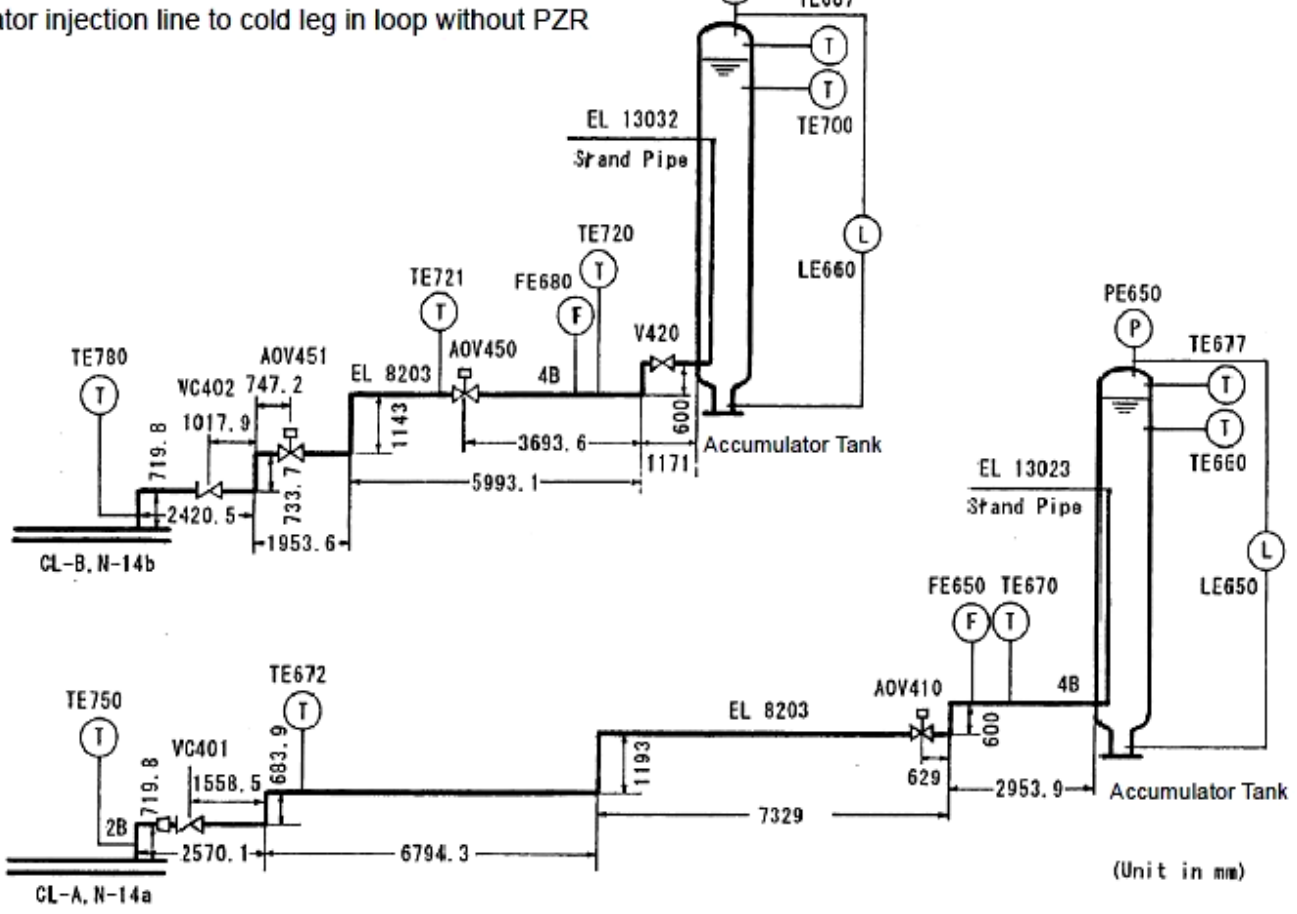

(b) Accumulator injection line to cold leg in loop with PZR

Figure 2.4 Accumulator injection line to cold leg in both loops.

It should be pointed out that some assumptions are put forward as the predetermined conditions as follows [4]:

1) The high pressure injection system fails and cannot inject any coolant into the system;

2) Loss of off-site power concurrent with the scram; 
3) Considering the conservativeness of system, the threshold temperature of the core protection logic and controlling system is increased by 50K compared with realistic operation conditions. The scheme of core protection logic used in the test is shown in Table 2.4.

Table 2.4 Core protection logic.

\begin{tabular}{|l|l|}
\hline Maximum fuel rod surface temperature $(\mathrm{K})$ & Cut down the power to be \\
\hline $958 \mathrm{~K}$ & $75 \%$ \\
\hline $968 \mathrm{~K}$ & $50 \%$ \\
\hline $969 \mathrm{~K}$ & $25 \%$ \\
\hline $970 \mathrm{~K}$ & $10 \%$ \\
\hline $973 \mathrm{~K}$ & $0 \%$ \\
\hline
\end{tabular}




\section{Simulation tool}

Safety codes play a critical role in assessing the safety of a nuclear power reactor. Due to the sophistication of modern nuclear reactor systems, whose response to some proposed perturbation cannot be explained or predicted by human reasoning and simple theoretical model. Advanced computational tools are therefore required and developed to simulate the reactor behavior during operational transient and other accident scenarios. So far, several codes for LWRs have been developed for the safety analysis, such as RELAP5, RELAP5/PARCS, TRAC-AAA, EAC, SAS4/SASSYS, and SIMMER [7]. Also, a lot of comparisons of the simulation results have been performed using different computing codes [8 - 10]. TRACE is an advanced and best-estimate reactor system code for analyzing steady-state and transient thermal-hydraulic responses in LWRs [11 - 16]. In this thesis, TRACE version 5.0 patch 2 is implemented to analyze the ROSA SBLOCA tests.

\subsection{TRACE code}

TRACE (TRAC/RELAP Advanced Computational Engine) developed by the USNRC, consolidates the capabilities of four codes (TRAC-P, TRAC-B, RELAP 5 and RAMONA) into one. The code is capable of analyzing of LOCAs, operational transients, accident scenarios and phenomena in experimental facilities. TRACE uses different types of components which could be further subdivided into various numbers of physical volumes (or cells), to model each physical piece of equipment comprised in the reactor system. Over each finite volume cells, the fluid, conduction and kinetics equations are averaged. The hydraulic components in TRACE include BREAKs, CHANs (BWR fuel channels), VESSELs, PIPEs, FILLs, PRIZERs (pressurizers), HEATRs (feedwater heaters), PLENUMs, PUMPs, SEPDs (separators), TEEs, TURBs (turbines), JETs (jet pumps) and VALVEs and so on. Models supplied in TRACE include multidimensional two-phase flow, such as critical flow model, offtake model and counter current flow model, non-equilibrium thermo-dynamics, reflood, level tracking, reactor kinetics and generalized heat transfer [11]. The models and correlations in the codes play a key role in the speed of calculation and the accuracy of the results.

\subsection{Characteristics of TRACE}

According to the manual published by U.S.NRC [11] [17], TRACE mainly possesses the following characteristics.

\section{Multi-Dimensional Fluid Dynamics}

The component VESSEL is a 3D component set up in three dimensions Cartesian- or cylindrical coordinate, while PIPE and TEE are 1D component which can be used to model the flows within a coolant loop. The complex multi-dimensional flow networks can be simulated accurately by the combination of $1 \mathrm{D}$ and 3D components. 


\section{Non-homogeneous, Non-equilibrium Modeling}

The six field conservation equations (gas-fluid) of hydrodynamic model are summarized as the following equation.

Time Averaged Mass Equation

$$
\begin{aligned}
& \frac{\partial[(1-\alpha)] \overline{\rho_{l}}}{\partial t}+\nabla\left[(1-\alpha) \overline{\rho_{l}} \overline{\overline{V_{l}}}\right]=-\bar{\Gamma} \\
& \frac{\partial\left(\alpha \overline{\rho_{g}}\right)}{\partial t}+\nabla\left[\alpha \overline{\rho_{g}} \overline{\overrightarrow{V_{g}}}\right]=\bar{\Gamma}
\end{aligned}
$$

Time Average Energy Equation

$$
\begin{gathered}
\frac{\partial\left[(1-\alpha) \overline{\rho_{l}}\left(\overline{e_{l}+V_{l}^{2} / 2}\right)\right]}{\partial t}+\nabla\left[(1-\alpha) \overline{\rho_{l}} \overline{\left(e_{l}+V_{l}^{2} / 2\right) \overrightarrow{V_{l}}}\right] \\
=-\nabla\left[(1-\alpha) \overrightarrow{\vec{q}_{l}^{\prime}}\right]+\nabla\left[(1-\alpha)\left(\overline{T_{l} \vec{V}_{l}}\right)\right]+(1-\alpha) \overline{\rho_{l}} \overline{\vec{g} \vec{V}_{l}}-\overline{E_{l}}+\overline{q_{d l}} \\
\frac{\partial\left[\alpha \overline{\rho_{g}}\left(\overline{e_{g}+V_{g}^{2} / 2}\right)\right]}{\partial t}+\nabla\left[\alpha \overline{\rho_{g}}\left(e_{g}+V_{g}^{2} / 2\right) \overrightarrow{V_{g}}\right] \\
=-\nabla\left[\alpha \overline{\overrightarrow{q_{g}^{\prime}}}\right]+\nabla\left[\alpha\left(\overline{T_{g} \vec{V}_{g}}\right)\right]+\alpha \overline{\rho_{g}} \overline{\vec{g} \overrightarrow{V_{g}}}-\overline{E_{l}}+\overline{q_{d g}}
\end{gathered}
$$

Time Average Momentum Equations

$$
\begin{gathered}
\frac{\partial\left[(1-\alpha) \overline{\rho_{l}} \overline{\overline{V_{l}}}\right]}{\partial t}+\nabla(1-\alpha) \overline{\rho_{l}} \overline{\overline{V_{l}}} \overline{\overline{V_{l}}}=\nabla\left[(1-\alpha) \overline{T_{l}}\right]+(1-\alpha) \overline{\rho_{l}} \vec{g}-\overline{M_{\iota}} \\
\frac{\partial\left[\alpha \overline{\rho_{g}} \overline{\overline{V_{g}}}\right]}{\partial t}+\nabla \alpha \overline{\rho_{g}} \overline{\overline{V_{g} V_{g}}}=\nabla\left[\alpha \overline{T_{g}}\right]+\alpha \overline{\rho_{g}} \vec{g}+\overline{M_{\iota}}
\end{gathered}
$$

In these equations, overbar represents time average, $\alpha$ is the probability that a point is occupied by gas phase, and $\Gamma, E_{i}$, and $M_{i}$ represent the contribution of time averaged jump conditions to transfer of mass, energy and momentum respectively. Besides, $q^{\prime}$ is conductive heat flux, $\mathrm{q}_{\mathrm{d}}$ is direct heating and $T$ is the full stress tensor. The subscripts of " $g$ " and " $l$ " represent gas and liquid term respectively. A series of approximations are needed to complete the closure of these field equations.

\section{Flow-Regime-Dependent Constitutive Equation Package}

The above thermal-hydraulic equations describe the balance of mass, energy and momentum between two phase flows. In order to simulate and calculate different flow topology and 
conditions which the two phase interactions depends a lot, a flow-regime-dependent constitutive equation package is incorporated into the code.

\section{Comprehensive Heat Transfer Capability}

Detailed heat transfer analyses of the components, i.e. vessel could be performed by TRACE. It means a 2D treatment of conduction hear transfer, quench fronts, fuel rod heat transfer, inner-surface and outer surface convection heat transfer even reactivity feedback could modeled.

\section{Component and Functional Modularity}

TRACE code uses the component-base approach. The hydraulic components in TRACE include BREAKs, CHANs (BWR fuel channels), VESSELs, PIPEs, FILLs, PRIZERs (pressurizers), HEATRs (feedwater heaters), PLENUMs, PUMPs, SEPDs (separators), TEEs, TURBs (turbines), JETs (jet pumps) and VALVEs and so on. All components are specified through input data. By the combination of the components, any LWR design or experimental configuration could be simulated. Besides, separate modules, such as heat transfer coefficient selection and basic hydrodynamics solution algorithm and other functions could be accessed and selected to perform different aspects of calculations.

\subsection{TRACE model theory}

\subsubsection{Component model}

TRACE uses a component-based approach to model reactor systems. Every physical piece of equipment could be represented as a component. All components used in the thesis are summarized in Table 3.1. 
Table 3.1 TRACE model description.

\begin{tabular}{|c|c|c|}
\hline Name & Description and application & Symbol \\
\hline BREAK & $\begin{array}{l}\text { To specify the pressure boundary conditions; other fluid } \\
\text { state properties could be specified as constants or defined } \\
\text { by signal variables or control blocks or trip. }\end{array}$ & \\
\hline FILL & $\begin{array}{l}\text { To impose boundary conditions, such as coolant velocity, } \\
\text { mass flow, fluid pressure, void fraction, temperature and so } \\
\text { on, without modeling a real physical component of the } \\
\text { system, i.e. feedwater flow. }\end{array}$ & \\
\hline VESSEL & $\begin{array}{l}\text { To model a light water reactor vessel within associated } \\
\text { internals, including the downcomer, fuel-assembly core, } \\
\text { upper head, upper plenum and lower plenum. For vessel } \\
\text { geometry, 1-,2- or 3D in Cartesian or cylindrical geometry } \\
\text { could be selected. All fluid flow area and volume faction } \\
\text { and fluid conditions are input dimensionally specified. }\end{array}$ & \\
\hline HTSTR & $\begin{array}{l}\text { To evaluate the dynamics of heat transfer, including } \\
\text { conduction, convection and radiation or heat loss; Usually } \\
\text { to model fuel rods inside a vessel or steam generator for } \\
\text { which temperature distribution could be computed. }\end{array}$ & \\
\hline PIPE & $\begin{array}{l}\text { Mostly to model general connectors between components } \\
\text { or part of other structures, i.e. reactor vessel control rod } \\
\text { guide tube (CRGT) or steam generator; also to } \\
\text { accumulators by initiating some options. }\end{array}$ & \\
\hline VALVE & $\begin{array}{l}\text { To model the flow through } 1 \mathrm{D} \text { pipe with predetermined } \\
\text { changing area or to model various types of valves, such as } \\
\text { check valve, trip controlled or controller activated valve. }\end{array}$ & \\
\hline PUMP & $\begin{array}{l}\text { To describe and evaluate the interaction two-phase fluid } \\
\text { with the simulation of centrifugal pump. }\end{array}$ & \\
\hline PRIZER & $\begin{array}{c}\text { To simulate a PWR 1D pressurizer reservoir, including } \\
\text { heater/sprayer logic to maintain the primary system } \\
\text { pressure. }\end{array}$ & 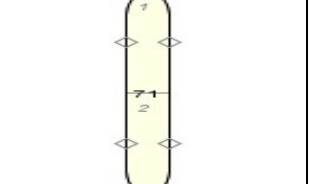 \\
\hline SEPD & $\begin{array}{l}\text { To model BWR separator and the secondary system of PWR } \\
\text { steam generator with TEE-like geometry by description of } \\
\text { phase separation model. }\end{array}$ & 然 \\
\hline POWER & $\begin{array}{l}\text { To supply power to solid structures, for example, HTSTR } \\
\text { component. }\end{array}$ & $\begin{array}{l}\text { 9. Power Components [2] } \\
\text { 9 Powers [2] }\end{array}$ \\
\hline
\end{tabular}




\subsubsection{Control procedure}

The TRACE control procedure is used to simulate the reactor control system and staff operation. It is flexible to specify a control procedure with desired control logic [17]. Table 3.2 summarizes the main control tools and its function. In the transient scenario, control systems are significant to accurately simulate the real situations.

Table 3.2 Description of main control tools.

\begin{tabular}{|c|c|c|}
\hline Name & Description and application & Symbol \\
\hline $\begin{array}{c}\text { Signal } \\
\text { Variables }\end{array}$ & $\begin{array}{l}\text { Some parameters whose value are sent to its own } \\
\text { output by a specialized control block }\end{array}$ & $\underbrace{\substack{\text { TANK LEV } \\
2}}_{\text {mode }=\text { exact value }}$ \\
\hline $\begin{array}{l}\text { Control } \\
\text { Blocks }\end{array}$ & $\begin{array}{l}\text { Functional operators to define the logic of a control } \\
\text { system }\end{array}$ & 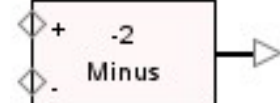 \\
\hline Trips & $\begin{array}{l}\text { ON/OFF switches to be used when: } \\
\text { 1) to evaluate a component hardware action; } \\
\text { 2) to define a status signal applied in a control block; } \\
\text { 3) to define a coincidence trip or a blocking. }\end{array}$ & $\begin{array}{l}\text { range type=1 } \\
\text { signal variable } \\
s 1=0.0, d t=0.0(s) \\
s 2=0.0, d t=0.0(s)\end{array}$ \\
\hline
\end{tabular}

\subsubsection{Critical flow model}

The determination of choked flow rate is of significance in safety analysis of nuclear reactors [18], especially in the break when critical flow conditions are expected to appear. For single phase flow, the choked point where the flow is critical, is characterized theoretically by: 1) the flow rate has the maximum possible value; 2 ) the pressure of downstream from the choked point does not influence the flow or the fluid properties upstream from the choked point; 3 ) there are limited derivations of most of the fluid properties at the choked point.

When developing a TRACE model, choked-flow model could be activated by input the value ' 1 ' or ' 2 ' for choked-flow model option variable ICFLOW in NAMELIST data cards [19]. In addition, cell-edge choked-flow model option ICFLG also needs to be actuated for the specific component, i.e. valve simulating the break. In both ICFLOW and ICFLG, value of ' 1 ' means default multipliers for choked-flow model calculations. Value of ' 2 ' in ICFLOW means optional NAMELIST variable defined multipliers by users is turned on and in ICFLG, from value ' 2 ' to ' 5 ', four different groups of multipliers could be chosen by user to calculate the choked flow.

In TRACE, if $\alpha \leqslant 1.0 \times 10^{-8}$, the coolant would be considered as subcooled liquid and the cell-edge velocity is calculated as the maximum of the Bernoulli-predicted velocity for 
homogeneous equilibrium sound speed [11]. If a sound-speed multiplier is specified in NAMELIST data by user, the final predicted liquid choking velocity is the product of maximum of the Bernoulli-predicted velocity with the multiplier.

For the cases of $1.0 \times 10^{-5} \leqslant \alpha \leqslant 0.999$, two-phase chocked flow, an extension of model developed by Ransom and Trapp [20] will be used for iteration and calculation. The predicted value is calculated by the equation below.

$$
\begin{gathered}
\mathrm{V}_{\mathrm{me}}^{\mathrm{p}}=\frac{\alpha_{\mathrm{e}} \rho_{\mathrm{ge}} V_{\mathrm{ge}}+\left(1-\alpha_{\mathrm{e}}\right) \rho_{\mathrm{le}} V_{\mathrm{le}}}{\rho_{\mathrm{mo}}} \\
\mathrm{V}_{\mathrm{le}}^{\mathrm{p}}=\text { CHMLT } 2 \cdot \frac{\mathrm{V}_{\mathrm{me}}^{\mathrm{p}} \cdot \rho_{\mathrm{mc}}}{\rho_{\mathrm{gc}} \alpha_{\mathrm{c}} \mathrm{S}+\rho_{\mathrm{lc}}\left(1-\alpha_{\mathrm{c}}\right)} \\
V_{g e}^{p}=S \cdot V_{l e}^{p}
\end{gathered}
$$

Where $\alpha_{\mathrm{e}}$ is the cell-edge void fraction; $\rho_{\mathrm{ge}}$ and $\rho_{\text {le }}$ are the cell-edge saturation densities determined by the cell-edge pressure; $\rho_{\mathrm{gc}}, \rho_{\mathrm{lc}}$, and $\rho_{\mathrm{mc}}$ are the cell-center steam/gas mixture, liquid and total mixture densities; CHMLT2 is a user-input chock-flow multiplier; $S$ is the slip ratio which is calculated by the momentum-solution steam/gas mixture velocities and liquid velocities:

$$
S=\frac{V_{g}}{V_{l}}
$$

If the mixture velocity determined by the momentum solution is less than the predicted maximum liquid choking velocity, the flow will be treated as non-choked flow and choking calculation will be ended. However, as long as the momentum-solution velocity is greater than the maximum choking velocity, the steam/gas mixture velocity will be reset to the maximum choking values.

\subsubsection{Junction loss coefficient}

At entries and exits, orifices and area-change edges, energy irreversibly dissipates which is known as hydraulic resistance [8]. Although they are minor losses, they account for a major portion of total pressure loss. TRACE provides special models to specify the loss coefficients associated with them. As Bernoulli's equation shows the wall fiction and local losses take up the pressure losses [21].

$$
\mathrm{p}_{1}+\frac{1}{2} \rho v_{1}^{2}+\rho g \mathrm{gh}_{1}=\mathrm{p}_{2}+\frac{1}{2} \rho v_{2}^{2}+\rho g \mathrm{gh}_{2}+\frac{\mathrm{fL}}{\mathrm{D}_{\mathrm{h}}} \frac{1}{2} \rho v_{2}^{2}+\sum \mathrm{K} \frac{1}{2} \rho v_{2}^{2}
$$

Where $\mathrm{K}$ is the coefficient of flow resistance, which is defined by:

$$
\text { Flow Resistance }=\frac{\text { Total Pressure Loss }}{\text { Dyniamic Pressure (Kineteic Energy) }}
$$

So K-fact in TRACE simulation could be calculated as:

$$
\mathrm{K}=\frac{\Delta \mathrm{p}_{\text {total }}}{1 / 2 \rho v_{\text {base }}^{2}}
$$

Where Base area refers to the smallest cross section and hence represents the largest velocity. Table 3.3 shows a list of configuration of different K-fact equation for main scenarios [21 - 23]. 
Table 3.3 List of different K-fact equation.

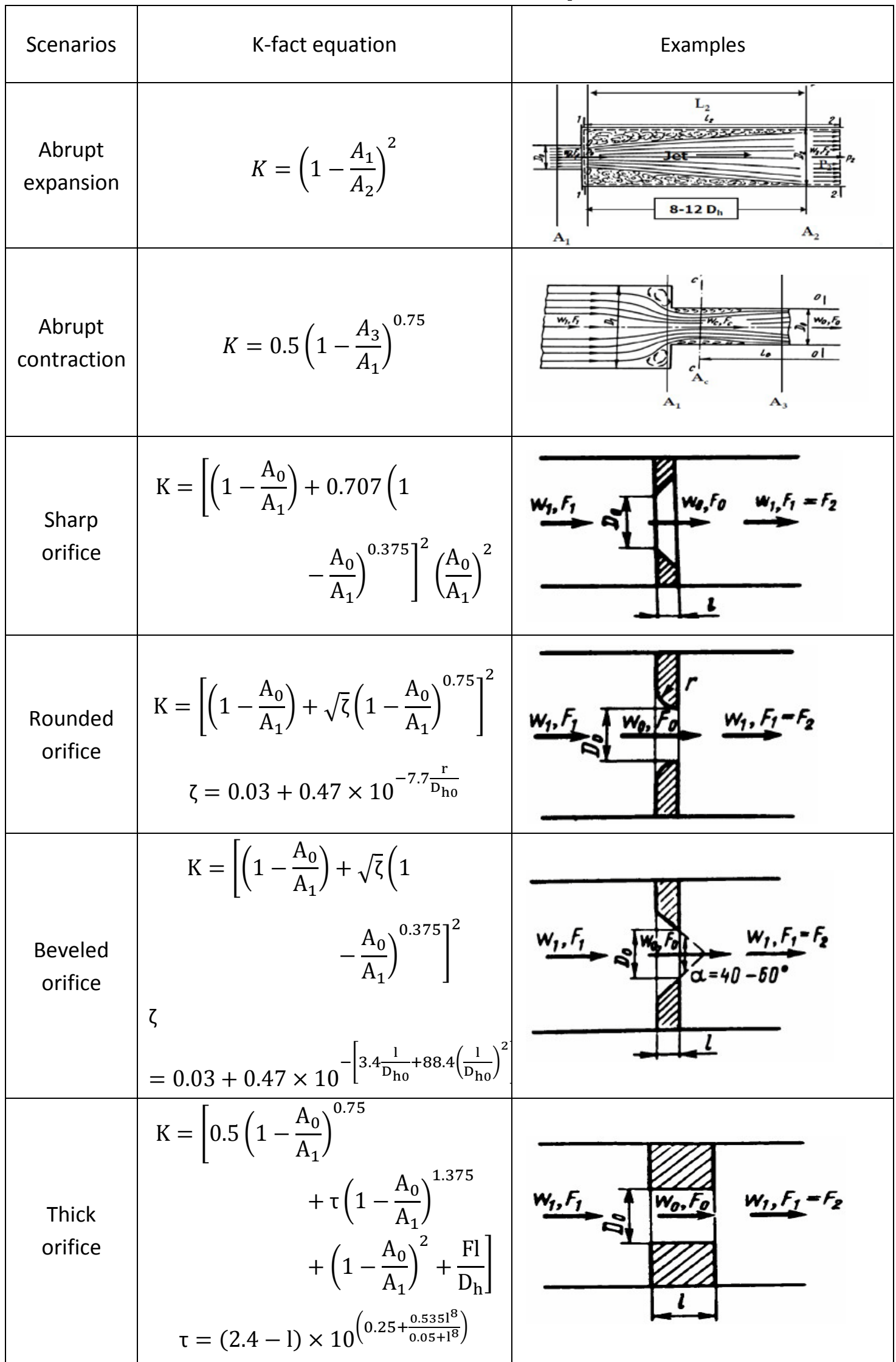




\subsection{TRACE range}

TRACE could best-estimate the physical phenomena of large-break LOCA and small-break LOCA. However, as a general rule, like the other computational codes, TRACE has its assessment range. The transients that have the following characteristics, are not appropriate for simulation by TRACE, such as too large momentum transfer at a localized level, too large changing asymmetries in core power, and too large viscous stresses which are equal to or larger than wall shear stress [15]. 


\section{Model simulation}

The graphical representation of the TRACE-Model using SNAP (Symbolic Nuclear Analysis Package software) is displayed in Figure 4.1. The LSTF has been modeled with 71 hydraulic components (8 BREAKs, 6 FILLs, 40 PIPEs, 2 PUMPs, 1 PRIZER, 11 VALVEs and 1 VESSEL). In order to represent the heat transfer processes, 28 Heat Structure components ( 2 for Steam Generator U-tubes, 12 for core power, 8 for PV and other main pipes heat losses and 3 for lower core plate heat transfer) have been designed. However, some unessential components are emitted to speed up the computation, such as the residual heat removal heat exchanger, jet condensers, break flow storage tank, high pressure injection system.

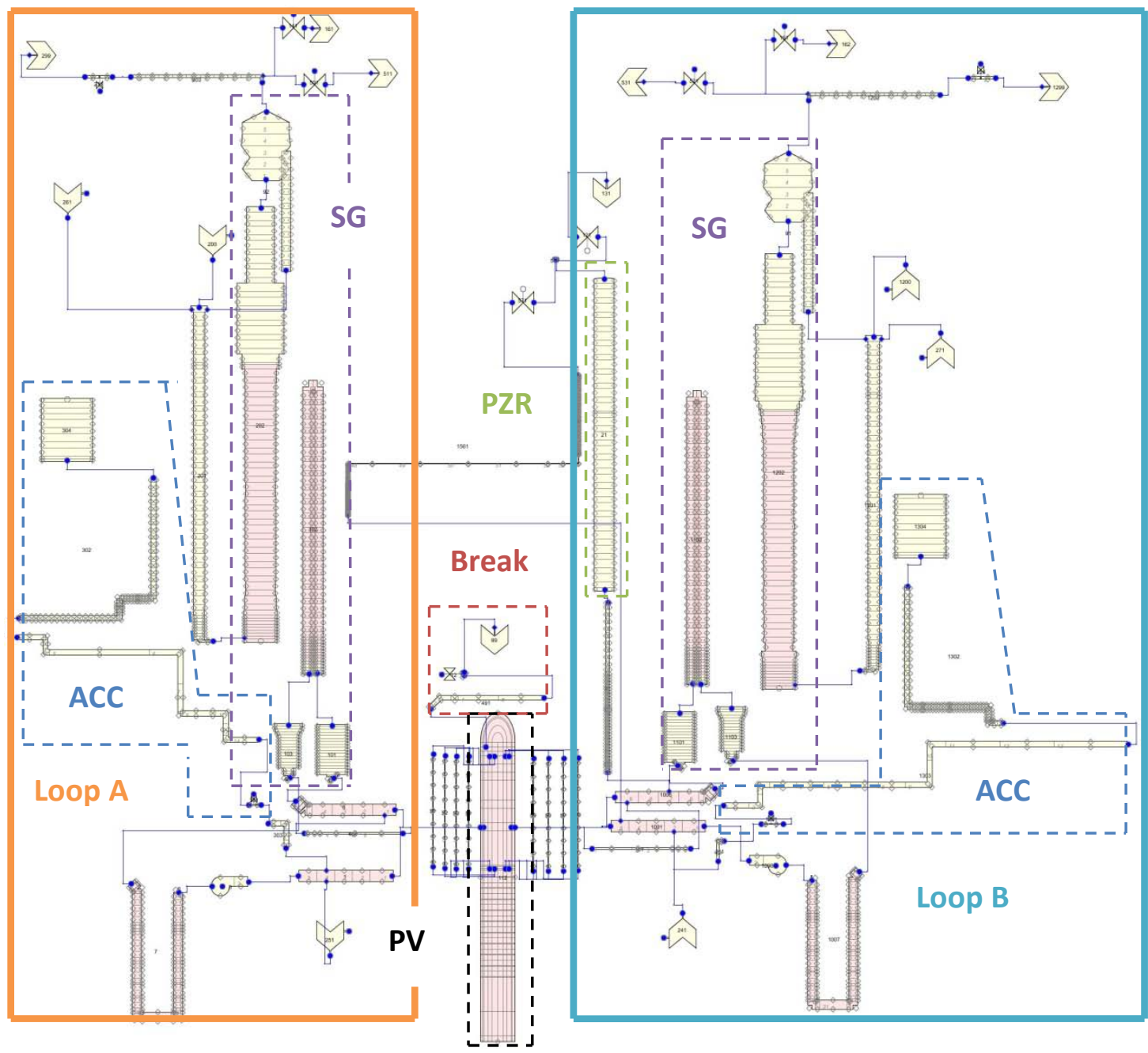

Figure 4.1 TRACE model of LSTF.

In addition, 63 control systems are built to simulate the complicated control systems and guide the transient scenarios. For example, problem time is set to be a signal variable, when it crosses $100 \mathrm{~s}$, a trip will be set to the state of On(For) by TRACE which activates break valve table. For accident management, the trip is initiated by the signal variables of the temperature at all core exit locations. Most trips are activated when the pressure of vessel lower plenum reaches the 
set points of the trips. All of the trips choose the type of On(For) ||OFF or OFF|| On(For). This kind of trips only have two possible states which are On(For) and OFF. When the status is On(For), the corresponding component-action table will be evaluated. With a status of OFF, the related component-action table is not evaluated. For the value of determining the status, the trips have two set points. They need large enough difference between subranges to avoid oscillating changes.

In order to execute the calculation, the minimum time step is set to be $1.0 \mathrm{E}-8$ for the first 2000 $\mathrm{s}$, and it is reduced to be $1.0 \mathrm{E}-9$ for the rest time until the end of the transient.

\subsection{Pressure vessel and its internals}

In the present thesis, a 3-D VESSEL component in cylindrical geometry $(r, \theta, z)$ is designed to simulate the PWR pressure vessel (PV), as shown in Figure 4.2. The meshes are defined by specifying the radial $r$, azimuthal $\theta$ and axial $z$ coordinates. In the thesis, the VESSEL is nodalized by $5 \times 4 \times 46$ for $r \times \theta \times z$. The VESSEL type uses the default option '[0] RPV' and '[0] No Flow Above or Below'. To model the heating rods and other metal structures, VESSEL component is coupled to HTSTR components and POWER component.

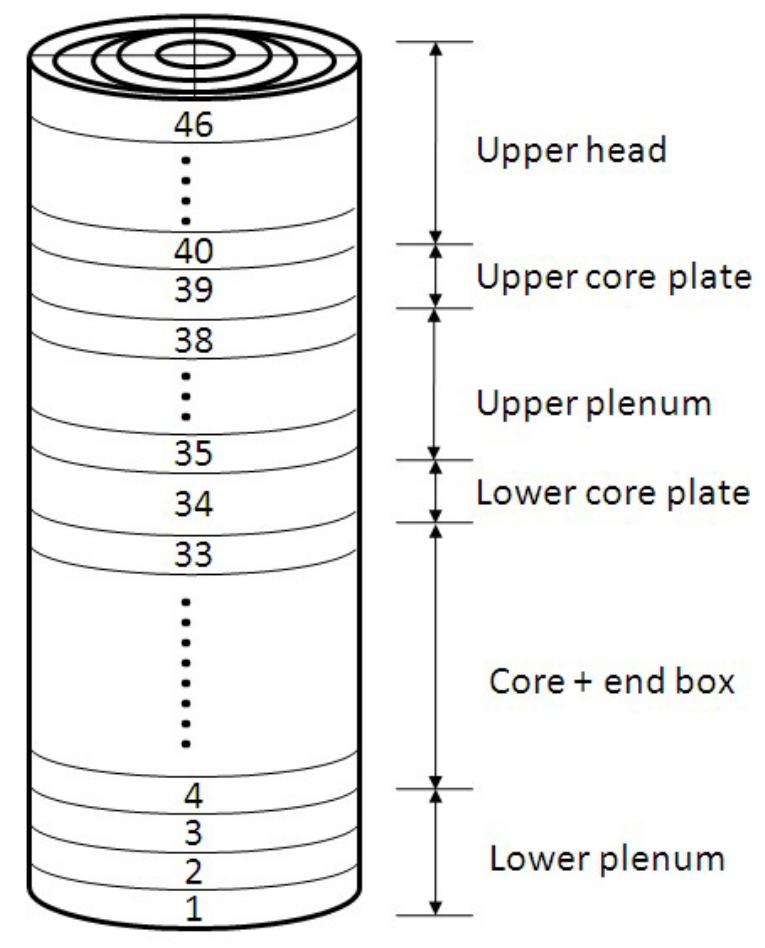

Figure 4.2 Cell nodding for PWR vessel.

As shown in Figure 4.2, there are 46 cells axially for the total height of $10.9574 \mathrm{~m}$. Inside of the $\mathrm{PV}$, it consists of the fuel-assembly reactor core, the lower plenum, the upper plenum, the upper head and the downcomer. All important elevations marked in the experiment are nodalized in different cells to finely represent the experimental phenomena. The first three cells are used to simulate the lower plenum while the 'core plus the end box' is modeled by the 
meshes from $4^{\text {th }}$ cell to $33^{\text {rd }}$ cell. The lower core plate is modeled by the $34^{\text {th }}$ cell. The upper plenum is modeled by the meshes from $35^{\text {th }}$ cell to $38^{\text {th }}$ cell. The upper core plate is modeled by the $39^{\text {th }}$ cell which exclude the flow path between the upper head and upper plenum except the ones provided by the eight CRGTs. At last, the upper head which is above the upper core plate is modeled by the meshes from $40^{\text {th }}$ cell to $46^{\text {th }}$ cell. In order to accurately represent the axial core power profile, as shown in Figure 4.3 , the core is finely nodalized with ten units. Each unit contains 3 cells whose length is $20 \mathrm{~cm}, 20 \mathrm{~cm}$ and $2 \mathrm{~cm}$ respectively. The $2 \mathrm{~cm}$-length cell is used to represent the core spacer whose flow area is much smaller than that of the core.

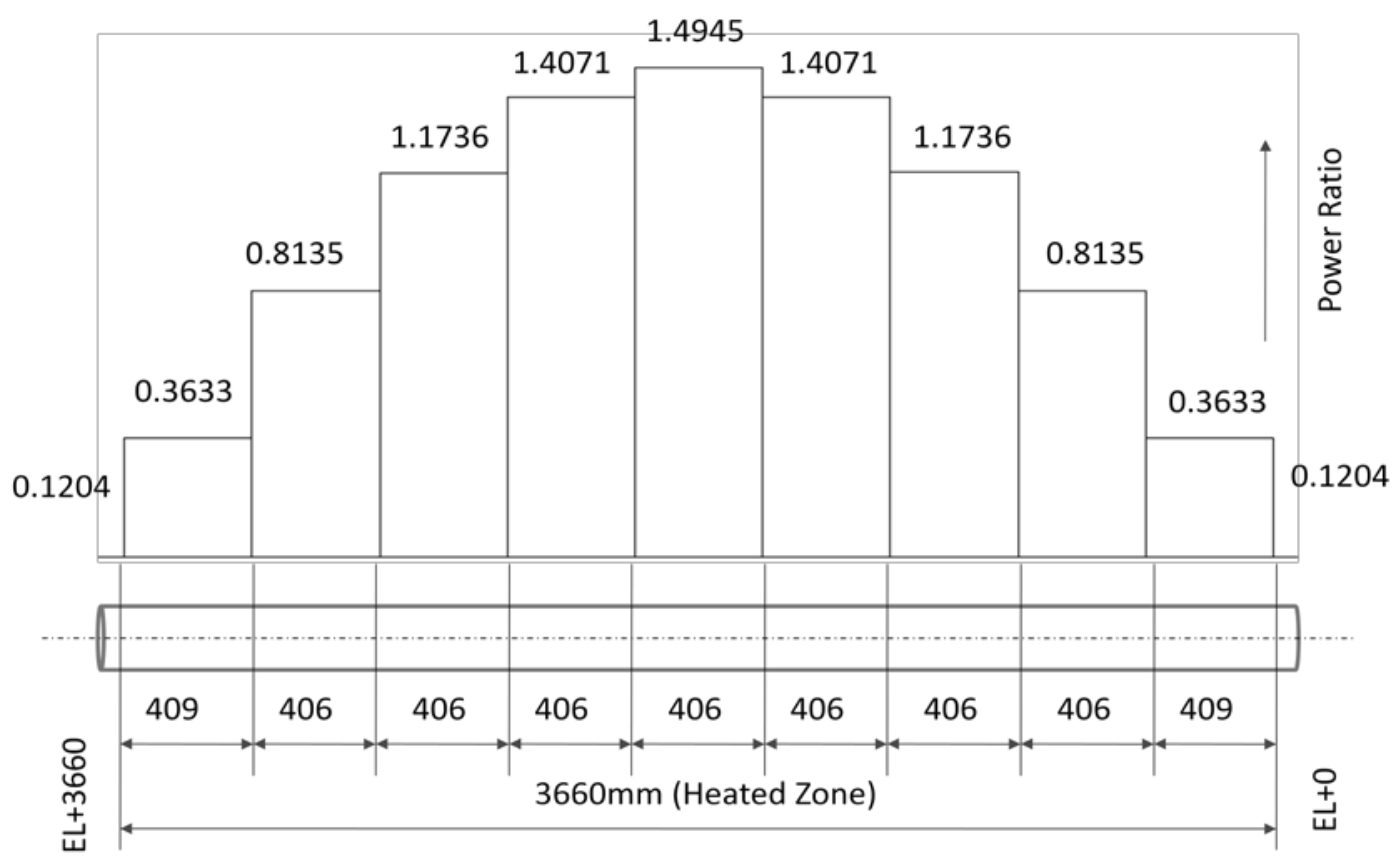

Figure 4.3 Axial power profile for high-power rods.

Figure 4.4 shows the radial sectioning and distribution of the PV. The inner diameter of PV is $0.64 \mathrm{~m}$ and it is divided into 5 rings in radial direction. The innermost three rings represent the lower plenum, the core and the upper plenum from the bottom until $40^{\text {th }}$ axial cell. The core barrel is simulated by the $4^{\text {th }}$ ring and it covers the cells from $1^{\text {st }}$ cell to $40^{\text {th }}$ cell in axial direction. The $5^{\text {th }}$ ring with the axial cells from $1^{\text {st }}$ cell to $40^{\text {th }}$ cell aims to simulate the downcomer. So the $4^{\text {th }}$ ring whose axial flow area is zero could prevent the flow in the core from mixing with the flow of downcomer. The upper head extends to encompass the highest 6 axial with all 5 radial levels.

Figure 4.4 also indicates the radial power distribution. As illustrated in Figure 4.4, the radial power distribution is realized by different numbers of the heating rods distributed to three heating zones in LSTF. The boundaries of the zones are indicated by red, blue and green lines respectively. According to the different peak factors each zone presented, the core is simulated by three rings. The area of each ring equals to the area of corresponding heating zones. For example, the first ring (painted in red) corresponds to the innermost 4 heating zones $(21,22,23$ and 24) whose peak factor is 1.00 and the radius of first ring is calculated by the square root of 
the area of the innermost four zones dividing pi. The radius of other core rings are calculated similarly and listed in Table 4.1. In addition, there are four HTSTR components coupled with each ring. In HTSTR components, the power fractions are defined in Powered Components table. For example, the first ring including 180 heating rods could be simulated by 4 HTSTR components with 45 rods each.
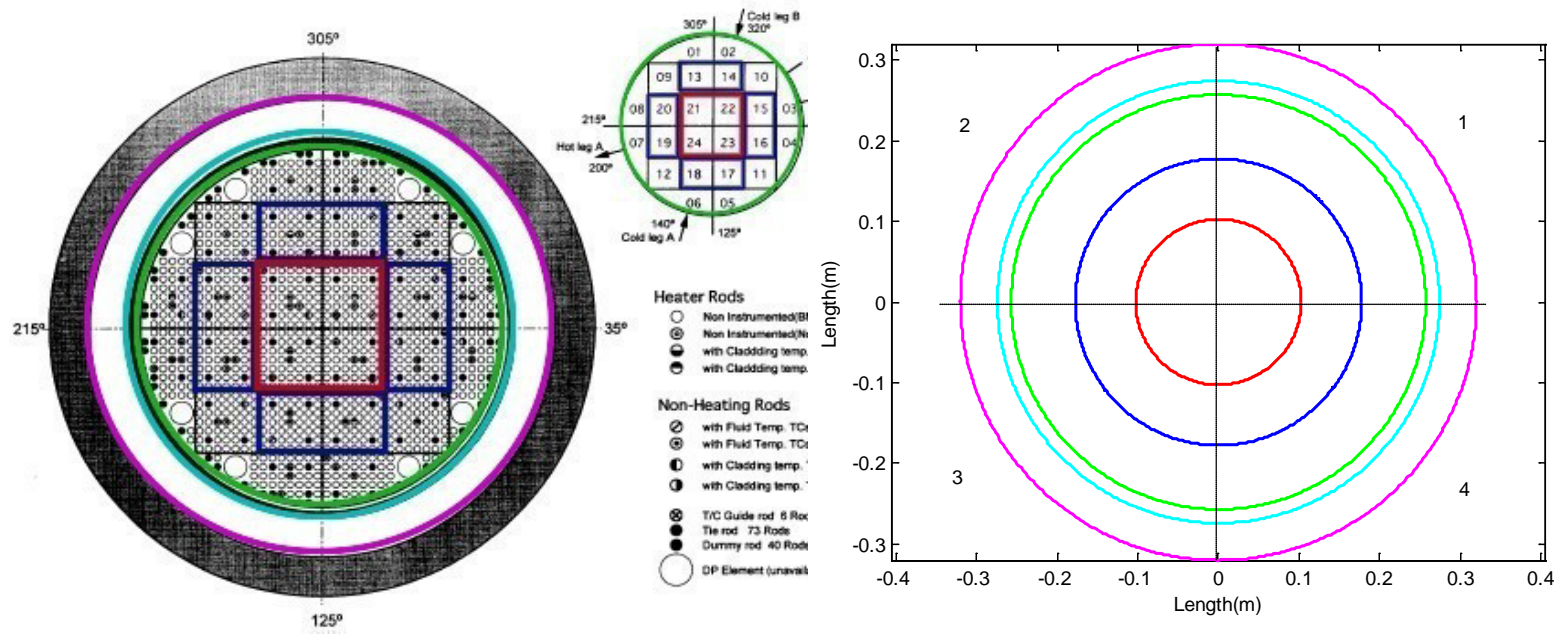

Figure 4.4 Radial sectioning and power distribution.

Table 4.1 Radial power distribution.

\begin{tabular}{|c|c|c|c|c|c|}
\hline Ring & Radius [m] & Heat zone & $\begin{array}{l}\text { Peak } \\
\text { factor }\end{array}$ & $\begin{array}{l}\text { Heated rod } \\
\text { number }\end{array}$ & $\begin{array}{l}\text { Heated power } \\
\text { fraction }\end{array}$ \\
\hline $\begin{array}{ll}\text { Core: } & \text { Inner } \\
\text { Layer } & \text { (red) }\end{array}$ & 0.1026 & $21,22,23,24$ & 1.00 & 180 & 0.174947 \\
\hline $\begin{array}{ll}\text { Core: } & \text { Middle } \\
\text { Layer } & \text { (blue) }\end{array}$ & 0.1776 & $\begin{array}{c}13,14,15,16,17,18,1 \\
9,20\end{array}$ & 1.435 & 360 & 0.5021 \\
\hline $\begin{array}{lr}\text { Core: } & \text { Outer } \\
\text { Layer } & \text { (green) }\end{array}$ & 0.257 & $\begin{array}{c}1,2,3,4,5,6,7,8,9,10 \\
11,12\end{array}$ & 0.71 & 468 & 0.322953 \\
\hline
\end{tabular}

In addition to the radial power distribution, the axial power distribution is also simulated. As shown in Figure 4.3, for different height of heating rod, the power ratio is different. In TRACE model, axial power distribution is realized by initiating the power shape option in which the power shape table could be input by different power ratio values at corresponding locations in POWER component. The power ratio values are listed in table 4.2.

In the model programmed by Gallardo [14] and Freixa [15-16], the vessel is divided by 10 sections in azimuthal direction. In order to speed the computation, four azimuthally subsections are applied in the thesis with 90 degree for each subsection. The PV connections with hot legs, cold legs and control rod guide tubes (CRGT) are modeled approximately in azimuthally sections.

Based on the experimental conditions, the connections between the PV and hot or cold legs should be attached to $37^{\text {th }}$ cell with different radial cells of the $3^{\text {rd }}$ (lower plenum) and $5^{\text {th }}$ ring 
(downcomer) respectively. In addition, a leakage between the hot leg $(\mathrm{HL})$ and the downcomer is simulated by a bypass PIPE connected between HL PIPE and the PV $5^{\text {th }}$ ring on the same PV axial level. The leakage is realized by two symmetrical lines and determined by two nozzles whose inner diameter is $3.5 \mathrm{~mm}$. In each line, a hand control valve is located to adjust the leakage mass flow rate which allows $0.2 \%$ bypass flow rate for each loop.

Table 4.2 Axial power distribution.

\begin{tabular}{|c|c|c|c|}
\hline Elevation $(\mathrm{mm})$ & \multirow{2}{*}{ Length $(\mathrm{mm})$} & \multicolumn{2}{|c|}{ Power ratio } \\
\cline { 3 - 4 } & & High-power rod & Low-power rod \\
\hline 0 & & 0.1204 & 0.1204 \\
\hline 409 & 409 & 0.3633 & 0.3628 \\
\hline 815 & 406 & 0.8135 & 0.8138 \\
\hline 1221 & 406 & 1.1736 & 1.1736 \\
\hline 1627 & 406 & 1.4071 & 1.4071 \\
\hline 2033 & 406 & 1.4945 & 1.4948 \\
\hline 2439 & 406 & 1.4071 & 1.4071 \\
\hline 2845 & 406 & 1.1756 & 1.1736 \\
\hline 3251 & 406 & 0.8135 & 0.8138 \\
\hline 3660 & 409 & 0.3633 & 0.3628 \\
\hline & & 0.1204 & 0.1204 \\
\hline
\end{tabular}

Control rod guide tubes (CRGT) which form the flow path between the upper head and the upper plenum are simulated by 8 PIPEs. The flow area is calculated according to the circular area between two rings whose inner diameters are $18 \mathrm{~mm}$ and $24 \mathrm{~mm}$ respectively. PIPEs are modeled with high $\mathrm{K}$-fact value, since the real geometry of CRGTs is more complex in experiment. In addition, the CRGTs are considered as evenly distributed in four azimuthally subsections.

In VESSEL component, all fluid flow areas and volumes are dimensioned and computed according to the geometric mesh spacing and the volume fraction. The mesh spacing could be specified in Geometry and Connection tables. The fraction can be set up in Volume and Edge data.

In addition, the rod distribution in the core and spacer is also considered to correctly simulate the core flow area. The flow area for free space in the core is calculated by following equation:

$$
\mathrm{A}_{\text {Core }}=\pi \cdot \mathrm{r}_{\text {Core }}^{2}-1008 \cdot \pi \cdot \mathrm{r}_{\mathrm{HR}}^{2}-136 \cdot \pi \cdot \mathrm{r}_{\mathrm{IR}}^{2}-8 \cdot \pi \cdot \mathrm{r}_{\mathrm{DP}}^{2}=0.1134 \mathrm{~m}^{2}
$$

$r_{\text {core }}$ the radius of core

$\mathrm{r}_{\mathrm{HR}^{-}}$the radius of heated rods

$r_{\mathbb{R}^{-}}$the radius of instrument rods

$r_{D P}$-the $r$ radius of differential pressure element

The core spacer flow area is calculated by:

$$
\mathrm{A}_{\text {Corespacer }}=\mathrm{A}_{\text {Core }}-\mathrm{A}_{\text {Spacer }}=0.0648 \mathrm{~m}^{2}
$$

Hydraulic diameters are calculated by: 


$$
\mathrm{H}_{\mathrm{D}}=\frac{4 \mathrm{~A}}{\mathrm{P}_{\mathrm{w}}}
$$

$\mathrm{H}_{\mathrm{D}}$-hydraulic diameter

A-flow area

$\mathrm{P}_{\mathrm{w}}$-the wetted perimeter

\subsection{Break unit}

In the TRACE model, a PIPE component with the same geometry as the experimental condition described in Section 2.3, a VALVE component and a BREAK component are connected with each other to simulate the break unit. In addition, the break trip which is controlled by problem time (when problem time $t$ is equal to $100 \mathrm{~s}$, the trip is activated) is coupled with the VALVE component. Totally, 13 different valve types are provided for simulation in TRACE. For the VALVE used in break simulation, 'Flow Area Table After Trip' type is chosen, because in this type, the valve opening time and size after the break trip could be specified by editing a flow area table. In the LSTF ROSA test $6-1$, the break valve is connected to a storage tank where the characteristics of choked point are met, so the choked flow model is activated by choosing default choke in choked flow model. In addition, a detailed break valve open table is defined in the TRACE model to ensure the consistency with the experimental integrated break mass. Because during the experiment, single phase mass flow is determined by measuring differential pressure across a venturi flow meter or a calibrated orifice; the two-phase flow rate is calculated by the values provided by venturi flow meter and gamma-ray densitometers (Figure 2.3) which measure the fluid density. But the two-phase flow measurements are not calibrated which means they are only for qualitative analysis. So to simulate the experimental conditions as close as possible, the integrated mass which is more reliable is considered as the main revision parameter. As it is mentioned in reference [3], the upper head break nozzle elevation is $8500.6 \mathrm{~mm}$ which locates at the point between $45^{\text {th }}$ cell and $46^{\text {th }}$ cell in the model, however, the break unit is approximately connected with the upper head at VESSEL $45^{\text {th }}$ cell in the simulation.

\subsection{Pressurizer}

In the TRACE model, the pressurizer reservoir is simulated by the PRIZER component while the surge lines are modeled by PIPE components. PRIZER could be connected to another 1D hydraulic components at both top and bottom junctions. In the present study, the top junction is connected with a VALVE component and a BREAK component to simulate the relief/safety valves. The bottom of the pressurizer is connected to the surge line, which is modeled by a PIPE component.

However, no relief valves or spray would be actuated in the transient, since the system pressure drops due to the LOCA at the upper head. In this case, the electrical heaters in pressurizer will be activated to produce more steam and increase the pressure. And the heater/sprayer logic is activated to simulate this phenomenon. By activating the logic, the system pressure could maintain the desired pressure specified by the user. For example, it is used to maintain the 
pressure of $15.5 \mathrm{MPa}$ in this work. Nonetheless, it cannot simulate the actual sprayer. Actual sprayers should be modeled by PIPE components with side junctions. Its status of off/on and mass flow rate is controlled by a predetermined table. The table would be evaluated once the corresponding trip is triggered. In the model, actual sprayers are omitted here, due to the complex setup and the fact that the pressure does not increase during the simulated transient scenario. But the spray line which could suck some coolant from cold leg to pressurizer is not omitted. It is simulated by a PIPE component. Although the spray water would not be actuated into the pressurizer in the transient, it might inject the coolant to the cold leg for cooling due to the natural circulation. So it is simulated and located besides the top of pressurizer with same geometry, bending and right elevation as the experiment.

\subsection{Steam generators (SG)}

Steam generators are the components to transfer the heat from the hot reactor coolant to the feedwater in secondary system. Both in primary system and secondary system, there are the components of the SG.

\subsubsection{SG primary side}

In TRACE, SGs in primary system are simulated by PIPE components by specifying different geometry parameters and orientation inputs for inlet plenum, out plenum and U-tubes. For example, U-tubes are bended to form U-shape. In the TRACE model, the heat exchange between primary system and secondary system is modeled by HTSTR component whose inner edge tied to the U-tubes while outer edge connected to the flow in SG secondary side. There are $141 \mathrm{u}$-tubes of nine different lengths which made up the tube bundles of LSTF. In the TRACE model simulated by S. Gallardo et al [14], it is claimed that the number of U-tube group does not change the final results significantly. In the present study, only one PIPE component with averaged conditions is used to simulate the $U$ tube bundles by setting the surface multiplier to be 141 .

\subsubsection{SG secondary side}

The SG secondary side consists of the boiler region which exchange heat with U-tubes in the primary side, downcomer pipes, feed water system and the upper region. The upper region includes steam separator, steam dryer, steam line, MSIVs and relief valves and so on. The boiler region is modeled by PIPE component which is coupled by HTSTR components to simulate the heat exchange with the primary system. The downcomer pipes and the feed water injection pipe are simulated by PIPE component. For the upper region, since TRACE 5.0 did not develop any pre-determined steam generator component, the steam separator and dryers are simulated by SPED component as suggested by the TRACE 5.0 user menu [16]. The other secondary system components such as the storage tank and turbine or condenser are simplified by using FILL or BREAK components just with the boundary conditions specified. 


\subsubsection{SG relief valves}

In the experiment, the opening and closing of steam relief valves is controlled by the secondary system pressure values and core exit temperature which triggers the accident management at $623 \mathrm{~K}$. In TRACE simulation, two VALVE components sharing the same geometry and initial conditions are combined to simulate SG RVs. One is activated by accident management trip which uses the core exit temperature as the signal variable while the other is controlled by secondary system pressure. When the signal of secondary system pressure exceeds 7.95MPa, the trip will turn to the status of On(For), and as a result, the valve table of fully opening of RVs will be evaluated. Due to the opening of RVs, the pressure suffers a drop. As soon as it drops down to $7.65 \mathrm{MPa}$, the trip turn to $\mathrm{ON}(\mathrm{Rev})$ which closes the valve. The valves switch off and on alternately until the accident management is activated.

\subsection{Other components of primary system}

Except PV, SG and pumps, all the other components in the primary system are modeled by PIPEs with same geometry as experimental conditions. For the PIPE type, 'no accumulator' type is chosen. The heat loss is modeled by coupling the PIPEs with unpowered HTSTR components.

The rotational speed of primary coolant pumps is the main controller of primary coolant mass flow. In TRACE simulation, for primary pump type option, the PUMP type of 'table controlled impeller rotation' is used. Corresponding to this type, the speed table is filled with the predefined rotational speed values as the experimental results. When editing the speed table, the trip connected with break valve opening is chosen as the controller trip. As a result, the speed table is evaluated when the break trip is triggered.

\subsection{Emergency core cooling system (ECCS)}

Emergency core cooling system supplies borated water into the primary system, hot leg, cold leg or directly to the pressure vessel to cool down the core and minimize fuel damage during LOCA. Besides, it also ensure the reactor remain shutdown after the cool down because it could provide the neutron poison. As mentioned in Section 2.3, only accumulators and Low pressure injection systems function normally in ROSA test 6-1.

\subsubsection{Accumulator}

In TRACE simulation, to accurately reflect the experimental setup, the accumulator system is modeled by three PIPE components and one VALVE component. The accumulator injection line is simulated by 'no accumulator' type PIPE component. The geometry parameters are set according to the data shown in Figure 2.5. 
The accumulator tank is modeled by one PIPE component which has to be specified as 'Accumulator type'. Actually, PIPE component type ' 1 ' to ' 3 ' could be used to simulate the accumulator tank. Take the geometry and later phase gas injection into consideration, '1 accumulator type' is chosen for simulation. Nitrogen gas, locating at the top of the accumulator tank, is defined by activating 'Non-condensable Gas Options' and choosing 'Nitrogen' in the 'Gas and Liquid species' table under 'Model Options'. It is carefully nodalized to make sure the $0.46 \mathrm{~m}^{3}$ non-condensable gas-nitrogen is at the top of the whole tank, below which there is $1.12 \mathrm{~m}^{3}$ water. When defining the initial conditions of accumulator tank, the cells filled with gas have to define the gas volume fraction and 'Non-condensable (NC) Partial Pressure'. In the present model, the stratification between gas and water exists in the $4^{\text {th }}$ cell. So the gas volume fraction of the top 3 cells is 1.0 while the gas volume fraction of $4^{\text {th }}$ cell is 0.499 , and the gas volume fraction of rest cells is 0 . Besides, the 'NC Partial Pressure' of rest cells is also 0 . Such a setting is suggested by reference [16] for accumulator tank.

For a SBLOCA, the depressurization of primary system is relatively slower than a LBLOCA and a periodical pressure rise may occur due to the clearing of loop seal. In the experiment, the accumulators discharge the coolant 3 times for short periods. To allow the accumulator check valve opening and closing alternately, the valve type is set to be 'Flow Area Table After Trip' and the trip setpoint data type should choose 'On(For) ||OFF||On(Rev)'. On(Rev) means the closure of the valve, while On(For) means the opening of the check valve. The status of the trip is controlled by the setpoint value ' 1 ' to ' 4 '. As Figure 4.5 shown, according to the trip logic, the valve keeps the status of closure when the signal is larger than value $S_{4}$. Until the signal is smaller than $S_{1}$, the valve will be opened and kept this status until the signal is larger than $S_{4}$ again which will set the trip to be reverse state to close the valve again. In the model, the pressure difference between accumulator injection line and primary system is set as the signal. The theory for accumulator activation is that when the primary pressure decreased lower than 4.5 MPa. From this, the differential pressure at activation time between accumulator injection line and primary pressure could be deduced and set as the trip $S_{1}$. As soon as the signal variable is small than $S_{1}$, the accumulator trip will be triggered. As a result, the valve of accumulator will be switched on and the coolant will be injected to the primary system driven by gravity and pressure difference.

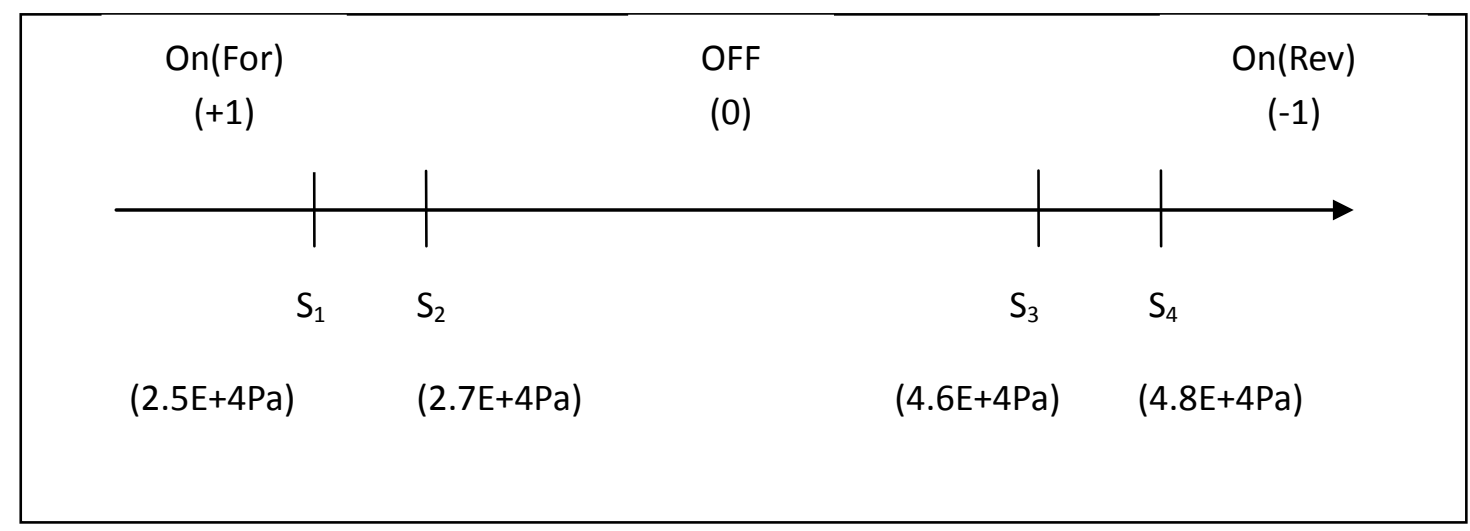

Figure 4.5 Schematic diagram of trip logic 'On(For) $\|$ OFF $\|$ On(Rev)'. 


\subsubsection{Low pressure injection system (LPIS)}

In the TRACE model, the low pressure injection system is simulated by a FILL component. The type 'Constant Mass Flow After Trip' is chosen for simulation. The corresponding LPIS trip is simulated by using 'ON (FOR) /IOFF' type with the set point 1 equal to $1.23 \mathrm{MPa}$, since in test 6-1, when the primary pressure drops down to $1.23 \mathrm{MPa}$, the LPIS will be activated and inject the coolant. 


\section{Results and discussions}

Before initiating the calculations, the model is validated by comparing the geometry input data of TRACE model with the experimental values. Afterwards, steady-state calculations are carried out. After all steady-state parameters are within the error bands of the measurement, the model is run under the transient calculation. The transient calculation results are presented and analyzed in the following sections. At last, the sensitivity study is conducted to investigate the influence of different parameters and setups.

\subsection{Model validation: components geometry comparison}

As the basic parameters in the fluid-dynamics and heat transfer, the geometry values of the main component are of paramount importance to the experimental results. In order to validate the model built by TRACE code in present study, firstly the simulation geometry values of the main component from the model will be compared with that of experiment. Table 5.1 summarizes the parameters comparison of main component geometry between the simulation and experiment, i.e. volumes. It can be seen from the comparison results that the experimental setup of main components is accurately modeled in the present thesis.

Table 5.1 Geometry parameters comparisons between experiment and TRACE model.

\begin{tabular}{|c|c|c|c|}
\hline \multirow{2}{*}{$\begin{array}{l}\text { Component } \\
\text { type and } \\
\text { number in } \\
\text { TRACE }\end{array}$} & \multirow{2}{*}{$\begin{array}{c}\text { Components in } \\
\text { LSTF }\end{array}$} & \multicolumn{2}{|c|}{ Volume $\left(\mathrm{m}^{3}\right)$} \\
\hline & & Experiment data & Simulation \\
\hline Pipe 1 & Cold leg & 0.1157 & 0.1157 \\
\hline Pipe 6 & Hot leg & 0.124 & 0.1242 \\
\hline Pipe 7 & Crossover leg & 0.2122 & 0.2133 \\
\hline Prizer 21 & Pressurizer & 1.2 & 1.19766 \\
\hline Pump 8 & $\begin{array}{l}\text { Main circulation } \\
\text { pump }\end{array}$ & 0.0235 & 0.0235 \\
\hline \multirow{5}{*}{ Vessel 112} & Upper head & 0.4963 & 0.4959 \\
\hline & Upper plenum & 0.4950 & 0.4948 \\
\hline & core & 0.4477 & 0.447 \\
\hline & Lower plenum & 0.4644 & 0.4639 \\
\hline & $\begin{array}{c}\text { Downcomer+ } \\
\text { Core bypass }\end{array}$ & 0.8504 & $0.85+$ \\
\hline \multirow{3}{*}{$\begin{array}{c}\text { Steam } \\
\text { generator A }\end{array}$} & Inlet plenum & 0.4351 & 0.4354 \\
\hline & Outlet plenum & 0.2115 & 0.2114 \\
\hline & U-tubes & 0.8384 & 0.8671 \\
\hline \multirow{3}{*}{$\begin{array}{c}\text { Steam } \\
\text { generator B }\end{array}$} & Inlet plenum & 0.4371 & 0.4354 \\
\hline & Outlet plenum & 0.2089 & 0.2094 \\
\hline & U-tube & 0.8384 & 0.8671 \\
\hline
\end{tabular}




\subsection{Steady state results}

The simulation results of steady state with TRACE model are shown in Table 5.2, where the experimental initial conditions data are also listed. All steady-state parameters are within the error bands of the measurement. Therefore, it can be believed that the input data is accurate to simulate the test.

Table 5.2 Steady state results comparison between experiment and TRACE model.

\begin{tabular}{|l|l|l|l|l|}
\hline Variable & Design Data & Experiment Data & Simulation & $\begin{array}{l}\text { Exp. } \\
\text { uncertainty }\end{array}$ \\
\hline Primary Pressure & $15.5 \mathrm{MPa}$ & $15.53 \mathrm{MPa}$ & $15.62 \mathrm{MPa}$ & $\pm 0.11 \mathrm{MPa}$ \\
\hline $\begin{array}{l}\text { Hot leg fluid } \\
\text { temperature }\end{array}$ & $598.1 \mathrm{~K}$ & $599.1 \mathrm{~K}$ & $599.8 \mathrm{~K}$ & $\pm 2.75 \mathrm{~K}$ \\
\hline Cold leg fluid temp. & $562.4 \mathrm{~K}$ & $563.6 \mathrm{~K}$ & $563.2 \mathrm{~K}$ & $\pm 2.75 \mathrm{~K}$ \\
\hline $\begin{array}{l}\text { Mass flow rate (per } \\
\text { arm) }\end{array}$ & $24.4 \mathrm{~kg} / \mathrm{s}$ & $24.8 \mathrm{~kg} / \mathrm{s}$ & $24.3 \mathrm{~kg} / \mathrm{s}$ & $\pm 1.25 \mathrm{~kg} / \mathrm{s}$ \\
\hline $\begin{array}{l}\text { Main feedwater } \\
\text { flow rate }\end{array}$ & $2.76 \mathrm{~kg} / \mathrm{s}$ & $2.74 \mathrm{~kg} / \mathrm{s}$ & $2.8 \mathrm{~kg} / \mathrm{s}$ & $\pm 0.1 \mathrm{~kg} / \mathrm{s}$ \\
\hline $\begin{array}{l}\text { Steam Dome } \\
\text { Pressure (SG) }\end{array}$ & $7.34 \mathrm{MPa}$ & $7.33 \mathrm{MPa}$ & $7.26 \mathrm{MPa}$ & $\pm 0.054 \mathrm{MPa}$ \\
\hline $\begin{array}{l}\text { Secondary Side } \\
\text { Liquid Level }\end{array}$ & $10.7 \mathrm{to} 14.28 \mathrm{~m}$ & $10.23 \mathrm{~m}$ & $10.94 \mathrm{~m}$ & $\pm 0.38 \mathrm{~m}$ \\
\hline Steam flow rate & $2.76 \mathrm{~kg} / \mathrm{s}$ & $2.65 \mathrm{~kg} / \mathrm{s}$ & $2.78 \mathrm{~kg} / \mathrm{s}$ & $\pm 0.1 \mathrm{~kg} / \mathrm{s}$ \\
\hline Pumps & $188.5 \mathrm{rad} / \mathrm{s}$ & $85.1 \mathrm{rad} / \mathrm{s}$ & $85.1 \mathrm{rad} / \mathrm{s}$ & $\pm 2.45 \mathrm{rad} / \mathrm{s}$ \\
\hline $\begin{array}{l}\text { Downcomer } \\
\text { Upper } \\
\text { Massflow }\end{array}$ & $\begin{array}{l}0.5 \text { of core } \\
\text { flow }\end{array}$ & $\begin{array}{l}0.3 \quad \% \quad \text { Target } \\
\text { Value) }\end{array}$ & $0.27 \%$ & Not measured \\
\hline $\begin{array}{l}\text { Downcomer - Hot } \\
\text { LegMassflow }\end{array}$ & $1 \%$ of core flow & $\begin{array}{l}0.2 \% \\
(=0.0496 \mathrm{~kg} / \mathrm{s})\end{array}$ & $\begin{array}{l}0.6 \% \\
(=0.1485 \mathrm{~kg} / \mathrm{s})\end{array}$ & Not measured \\
\hline
\end{tabular}

\subsection{Transient calculation}

In the following sections, transient results calculated by TRACE code are presented and analyzed. It can be seen that the code predicts most phenomena very well through the comparison between TRACE simulation and experimental data. The calculated parameters consist of break unit mass flow, system pressures, steam generator relief valve mass flow, core exit temperature, maximum fuel rod surface temperature, primary loop mass flow rate, collapsed liquid level in the core and upper head and ECCS mass flow. 


\subsubsection{Chronological sequence}

Table 5.3 lists the simulation results of chronological sequence of events during the transient. In order to better compare the simulation with experimental data, all experimental data are kept the same transient initiating time of TRACE modeling, which is corresponding to that in reference [6] of one hundred seconds later.

It can be seen from Table 5.3 that almost all the events in the simulation occur similarly as in the experiment. Discrepancies are kept within a reasonable range except the initiation time of LPIS, which would be discussed later in Section 5.3.9.2. Therefore, it can be concluded that the simulation of control systems is accurate and the TRACE model reproduces the whole experimental process. It is believed that the transient results calculate by TRACE are reliable.

Table 5.3 Chronological sequence of events comparison between experiment and TRACE model.

\begin{tabular}{|l|l|l|}
\hline Event & Experiment (s) & TRACE (s) \\
\hline Break valve open & 100 & 100 \\
\hline Scram signal & 122 & 121 \\
\hline SI signal & 128 & 127 \\
\hline $\begin{array}{l}\text { Break flow from subcooled to } \\
\text { two-phase flow }\end{array}$ & 150 & 147 (gas fraction $>1 \%)$ \\
\hline Primary coolant pump stop & 376 & 380 \\
\hline $\begin{array}{l}\text { Break flow to single-phase } \\
\text { vapor }\end{array}$ & 800 & 889 (gas fraction $>90 \%)$ \\
\hline $\begin{array}{l}\text { Primary pressure lower than } \\
\text { SG pressure }\end{array}$ & About 900 & 877 \\
\hline Full opening of SG relief valves & 1190 & 1137 \\
\hline Core protection activated & About 1300 & 1374 \\
\hline $\begin{array}{l}\text { Initiation of accumulator } \\
\text { system }\end{array}$ & About 1400 & 1440 \\
\hline Initiation of LPIS & About 3000 & 2003 \\
\hline End of test & $3265 \mathrm{~s}$ & $3265 \mathrm{~s}$ \\
\hline
\end{tabular}

\subsubsection{Break unit mass flow}

The simulation results of the break mass flow rate is shown in Figure 5.1, the integrated discharged inventory is illustrated in Figure 5.2, where the black line is the result of experiment and the red one is corresponding to the simulation result of TRACE model.

In Figure 5.1, the mass flow increases sharply after $100 \mathrm{~s}$ when the break valve opens and a high mass flow of coolant will be sprayed out due to the large pressure difference between PV and atmosphere. After a short while, the flow rate reaches the critical flow value of more than 
$12 \mathrm{~m} / \mathrm{s}$. After that, it decreases quickly because the break flow switches from single-phase liquid flow to two-phase flow. As there is no HPIS, steam is produced and starts to flow to the upper head due to the fast depressurization and core heating. Hence the upstream break void fraction increases and the break flow changes to be two-phase flow. This two phase flow stabilizes the break mass flow for about $600 \mathrm{~s}$ since a balance is built among the core power output, the break loss and the secondary side heat sink. At about $800 \mathrm{~s}$, the mass flow drops down again because the upper plenum is completely emptied. The phase of the flow changed to single-phase vapor. Finally, the mass flow is fluctuated between $0 \mathrm{~m} / \mathrm{s}$ and $2 \mathrm{~m} / \mathrm{s}$. The fluctuations are corresponding to vapor production and condensation due to the coolant injection in PV by ECCS.

As shown in Figure 5.2, the simulation results of integrated coolant mass through break are always close to that of the experimental data. At about $800 \mathrm{~s}$, the total mass is about $3600 \mathrm{~kg}$. After that, the rise of the total mass lost is slowed down until the end of test with the value of $5500 \mathrm{~kg}$.

It can be seen from the both figures that the TRACE results are comparable with the experimental values generally.

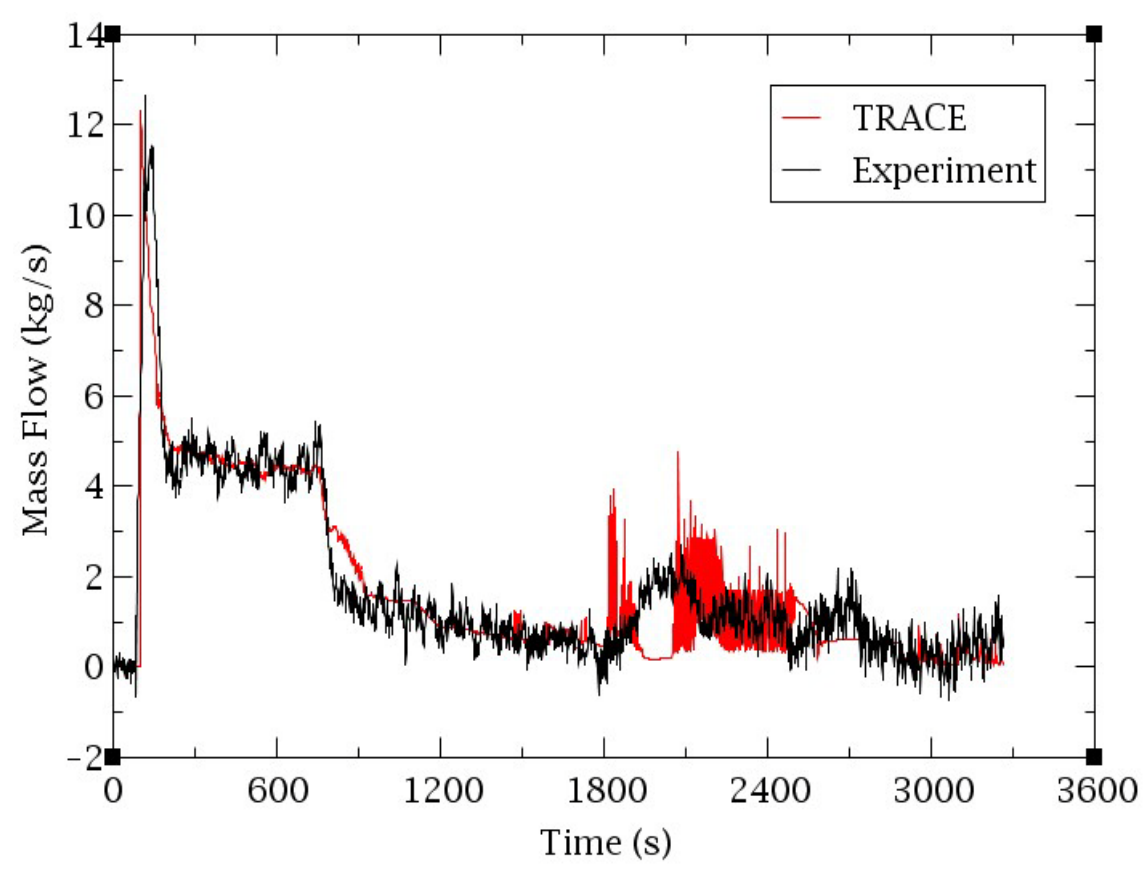

Figure 5.1 Break mass flow rate. 


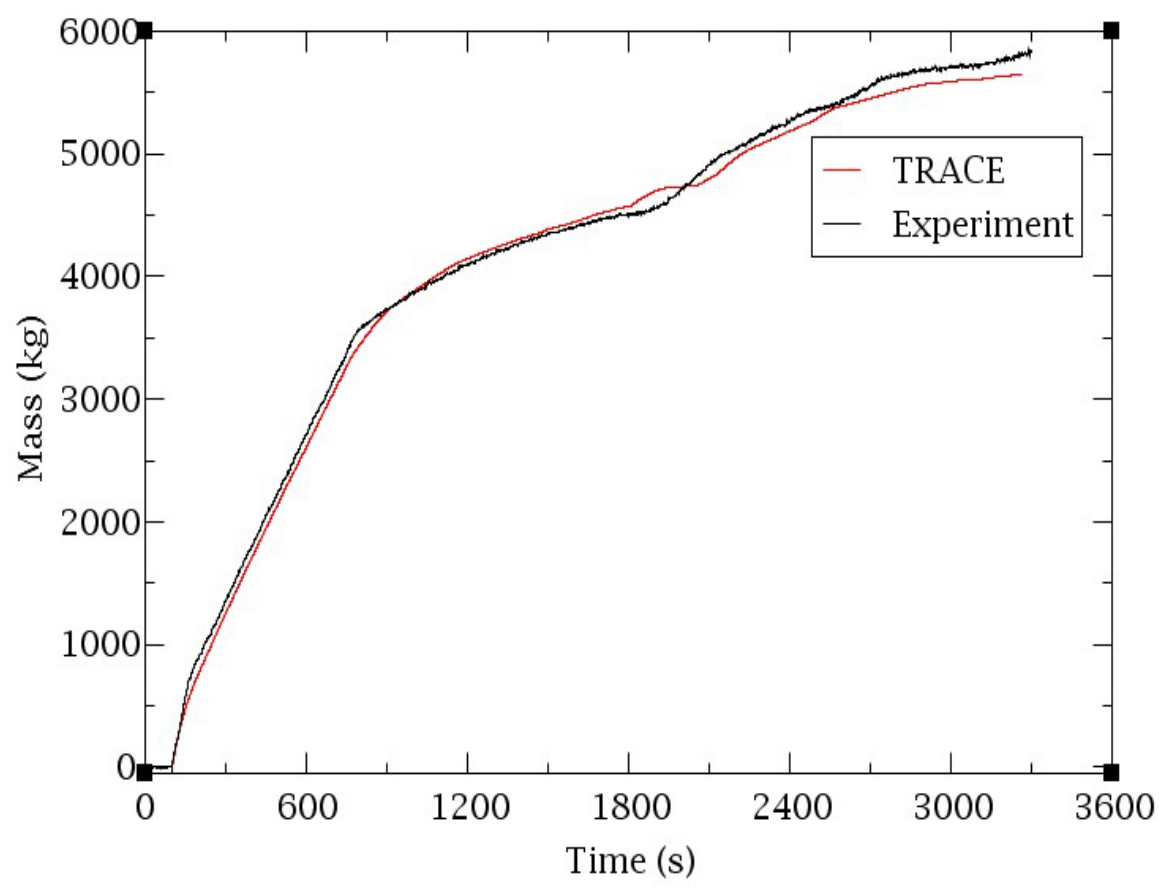

Figure 5.2 Integrated coolant mass through break.

\subsubsection{System pressure}

\subsubsection{Primary system pressure}

The primary pressures evolutions are calculated with the TRACE model, the results are plotted in Figure 5.3. The red line describes the simulated evolution while the black one represents the experimental data. When the break valve is switched on, there is a short period of fast depressurization of the primary system. When the break flow changes to two-phase flow, the primary pressure stabilizes at $8 \mathrm{MPa}$. After that, it decreases again since the break flow alternates to single phase vapor flow. Comparing with the experimental data, the TRACE calculation predicts a quicker drop of pressure at about $900 \mathrm{~s}$, because the corresponding break mass flow is predicted higher (Figure 5.1). During the depressurization, the pressure shows a rebound at $1500 \mathrm{~s}$ in the experiment which is around $100 \mathrm{~s}$ earlier than the simulation results. Such a difference is due to the different coolant injection process by the ECCS (accumulator injection) between the experiment and simulation, and hence a different time of clearing of loop seal. At time $2000 \mathrm{~s}$, there is a significant deviation between experimental data and TRACE simulation results. The difference decreases to a negligible level at the end of the test, since accumulators are empty of water and LPIS is actuated. 


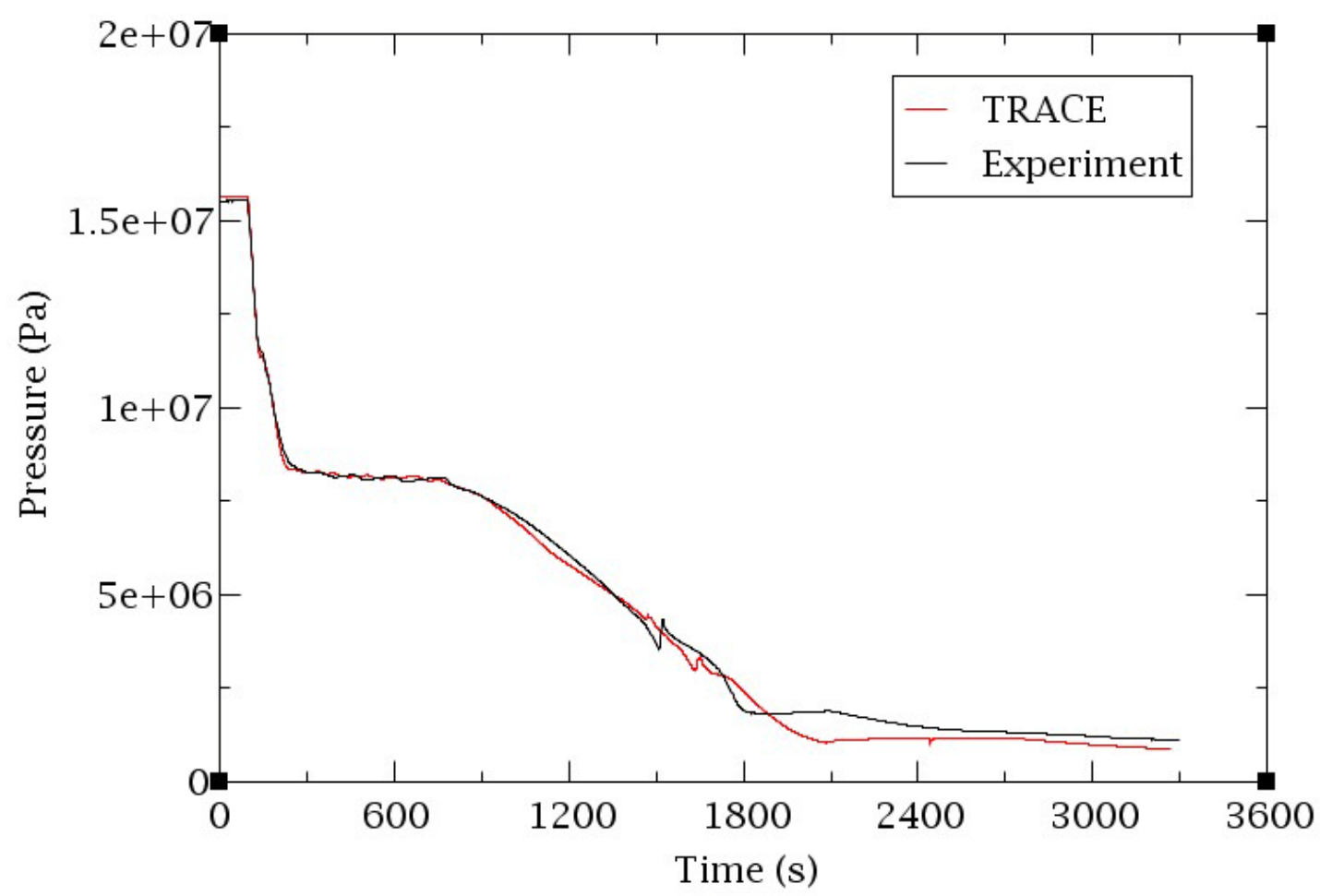

Figure 5.3 Primary pressure.

\subsubsection{Secondary system pressure}

Figure 5.4 shows the simulation result of secondary pressure in red line, the experimental data is also plotted in the figure with black line for comparison. After the break, the secondary pressure starts to rise due to the closure of MSIVs. But as soon as it reaches the value of 7.95 $\mathrm{MPa}$, the pressure of secondary system is maintained within $7.95 \mathrm{MPa}$ and $7.65 \mathrm{MPa}$ by SG relief valves (RVs). At about $1200 \mathrm{~s}$, the secondary side depressurizes gradually because of the initiation of the accident management of the permanent opening of SG RVs. It can be seen from the figure that the TRACE simulation reproduces the whole evolution very well, including the oscillation and slow depressurization. 


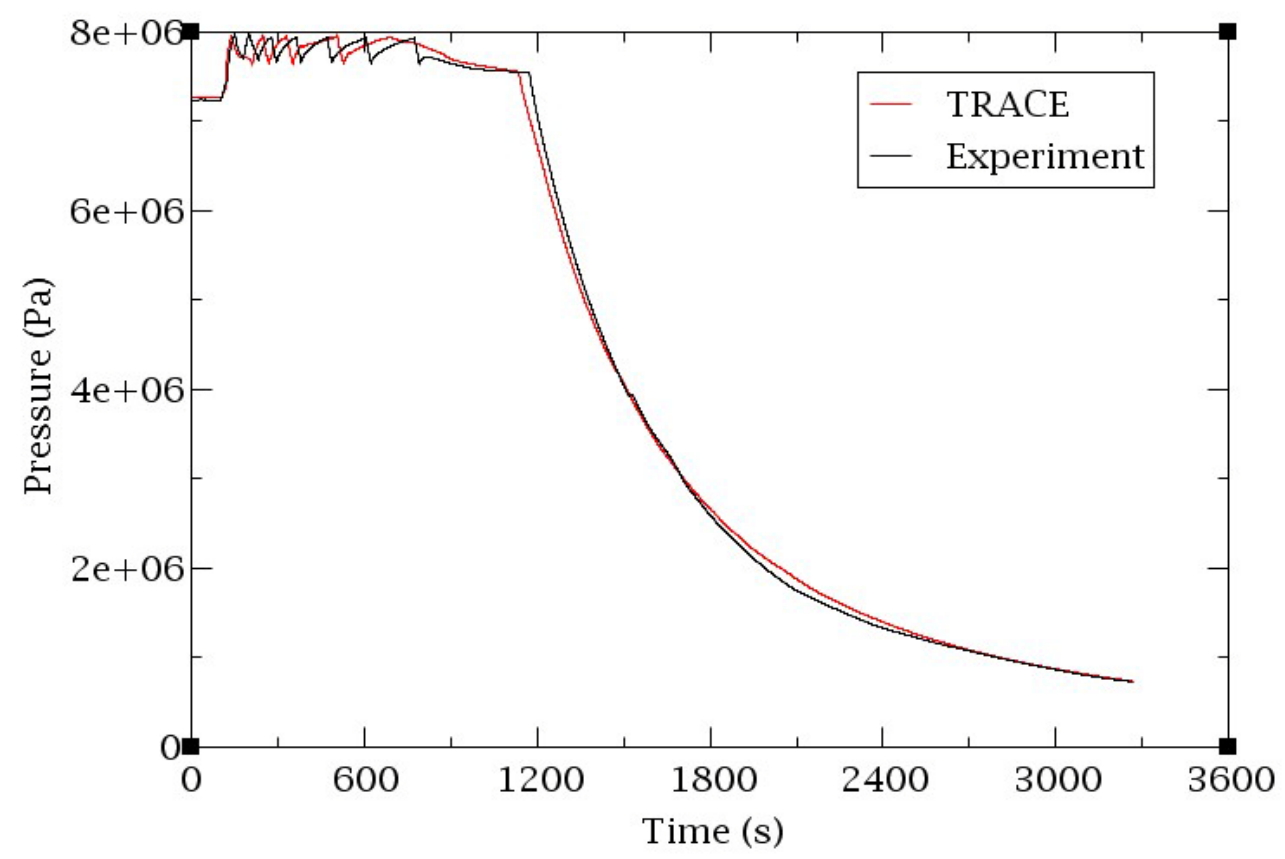

Figure 5.4 Secondary system pressure.

\subsubsection{Steam generator relief valves mass flow}

Figure 5.5 plots the mass flow rates of steam generator (SG) relief valves (RVs). Experimental data is presented by the black line and TRACE results are shown in the red solid line. Both have several periods of sharp increase and decrease of the mass flow rates of SG RVs. However, there is minor difference between TRACE prediction and experimental data. It may result from that the experimental data is not calibrated. If considering the initial value of all the experimental data as zero, the integrated value of rest data is almost the same as the TRACE simulated vapor inventory. So the simulation of SG relief valves which is connected to safety management shows reasonable agreement with the experiment. 


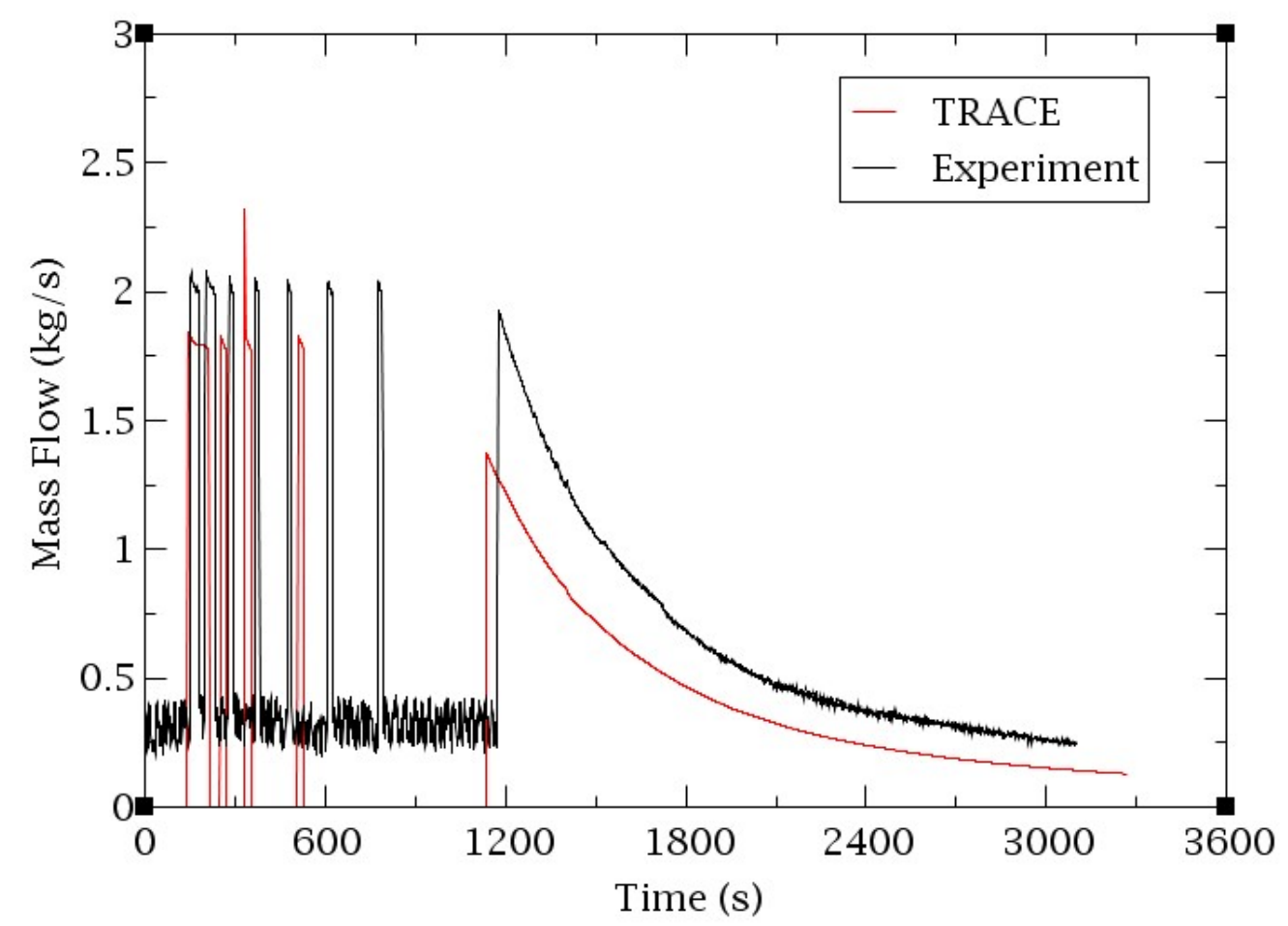

Figure 5.5 Steam generator relief valves mass flow rates.

\subsubsection{Core exit temperature (CET)}

CET is an important measurement parameter for the accident management [24]. So in present study, CET is calculated by TRACE code, and the result is shown in Figure 5.6. When the transient is initiated, the CET suffers a rather small drop followed by an increase and finally drops again. The possible reason for the fluctuation is because of the primary coolant mass flow which will be discussed in Section 5.3.7. After that, there is $600 \mathrm{~s}$ duration of a relatively steady period for CET. Then it starts rising again at about $1000 \mathrm{~s}$. It is obvious in Figure 5.6 that the TRACE simulation accurately reflects the rising time and trend of CET until $1300 \mathrm{~s}$. But the peak value of the simulation shows slightly higher than that of the experiment. This may due to the thermal-couple measuring point in the experiment locates at the bottom region of corresponding simulation cell. After the peak, the CET suffers a quick drop because the accumulator starts to inject coolant to the system. However, there is a steady phase of about $100 \mathrm{~s}$ duration after the first drop since the loop seal is clearing. It corresponds to the rebound of the primary pressure as shown in Figure 5.3. At about $1700 \mathrm{~s}$, the CET drops sharply again. In the TRACE simulation, the second drop of CET is much slower and finally to about $450 \mathrm{~K}$ which is $40 \mathrm{~K}$ lower than the corresponding experimental data.

In Figure 5.7, the primary pressure and secondary system pressure calculated by the TRACE model are plotted in the same figure, whose comparison could explain the CET rising. It can be seen that the primary pressure is higher than secondary system pressure before $900 \mathrm{~s}$, which ensures of the cooling of the core by natural circulation. However, when the primary pressure 
drops below the secondary system pressure due to the fast depressurization of primary system, the vapor in the primary system cannot be condensed any more, and the cooling of the core is ineffective. As a result, the core become uncover and CET begins rising steeply.

As shown in Figures 5.3, 5.4 and 5.6, the pressure prediction of TRACE code show the similar value to the experimental data at the end of test, but the CET prediction at the late phase is different with experimental data. It can be inferred that there might be other reasons for the significant CET difference. In fact, the core is still uncovered in late stage of experiment, while in TRACE simulation it is covered with coolant, which will be discussed in Section 5.3.8.

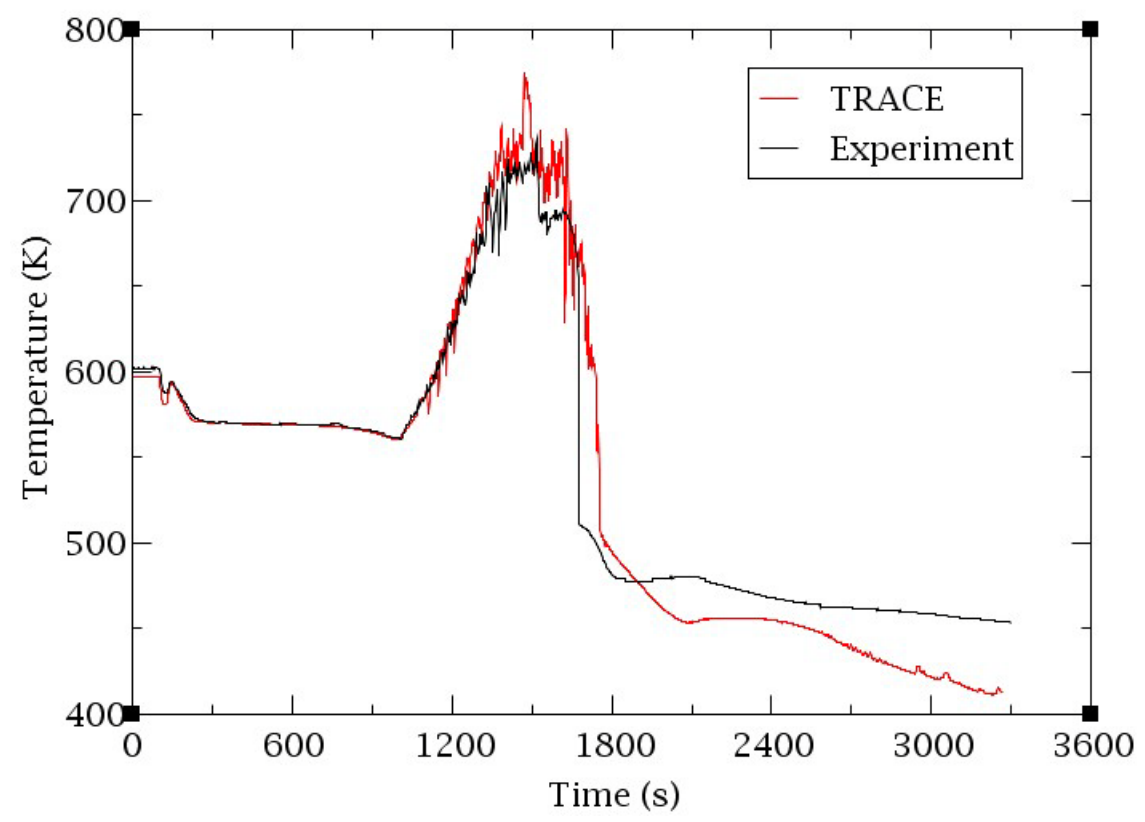

Figure 5.6 Core exit temperature.

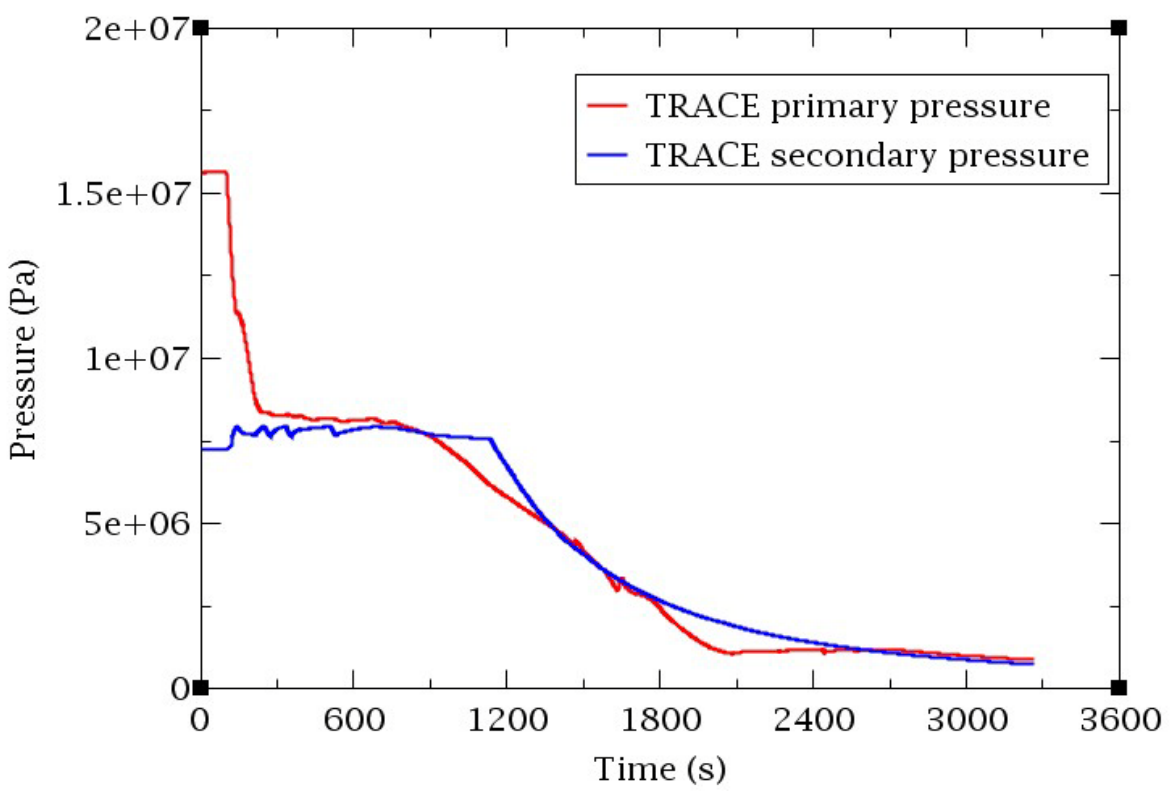

Figure 5.7 Primary and secondary pressures. 


\subsubsection{Maximum fuel rod surface temperature}

The maximum fuel rod surface temperatures are presented in Figure 5.8 with the black line for the experiment and the red line for simulation. The overall trend is similar to CET evolutions. After scram, it drops down a little because of the core power decay. Then the maximum fuel rod stabilizes until at round $1000 \mathrm{~s}$, when it starts to rise quickly to the allowable highest temperature of $958 \mathrm{~K}$. During this period, the discrepancies between the simulation results and the experimental data are kept within a reasonable range of less than $10 \mathrm{~K}$. The calculated maximum fuel rod surface temperature has the similar peak value as that of experiment, but simulated result show a delay comparing with the experimental data, since the predicted core collapsed water level shows a slower decrease than that of experimental data, as shown in Figure 5.12. After that, the temperature decreases because the core protection system is activated and the ECCS also starts to inject coolant. Finally, the temperature decreases down to $410 \mathrm{~K}$ at the end of the simulation while the corresponding experiment data is about $450 \mathrm{~K}$.

It can be seen from the figure that TRACE almost reproduces the evolution of the maximum fuel rod temperature especially in the early phase. However, since it spends more time to reach $958 \mathrm{~K}$, so there is a time delay for the activation of the core protection system and the temperature decrease at the late stage. In Figure 5.9, the total reactor power curves are plotted. It can be seen that the power follows the same decay curve in the simulation as that of the experiment until around $1300 \mathrm{~s}$. But the sudden cut down of the power is delayed for about $100 \mathrm{~s}$ in the simulation, due to the delay of core protection system between simulated results and experimental data.

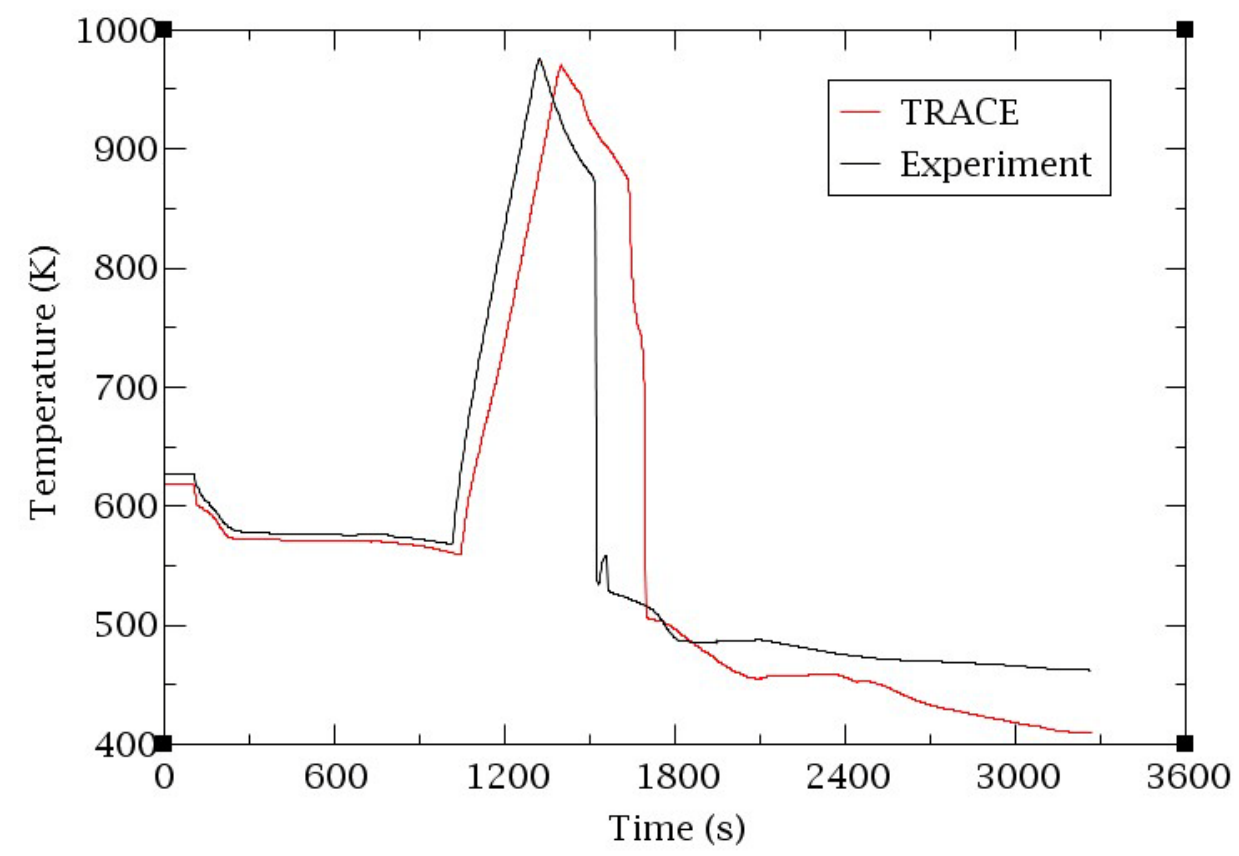

Figure 5.8 Maximum fuel rod surface temperature. 


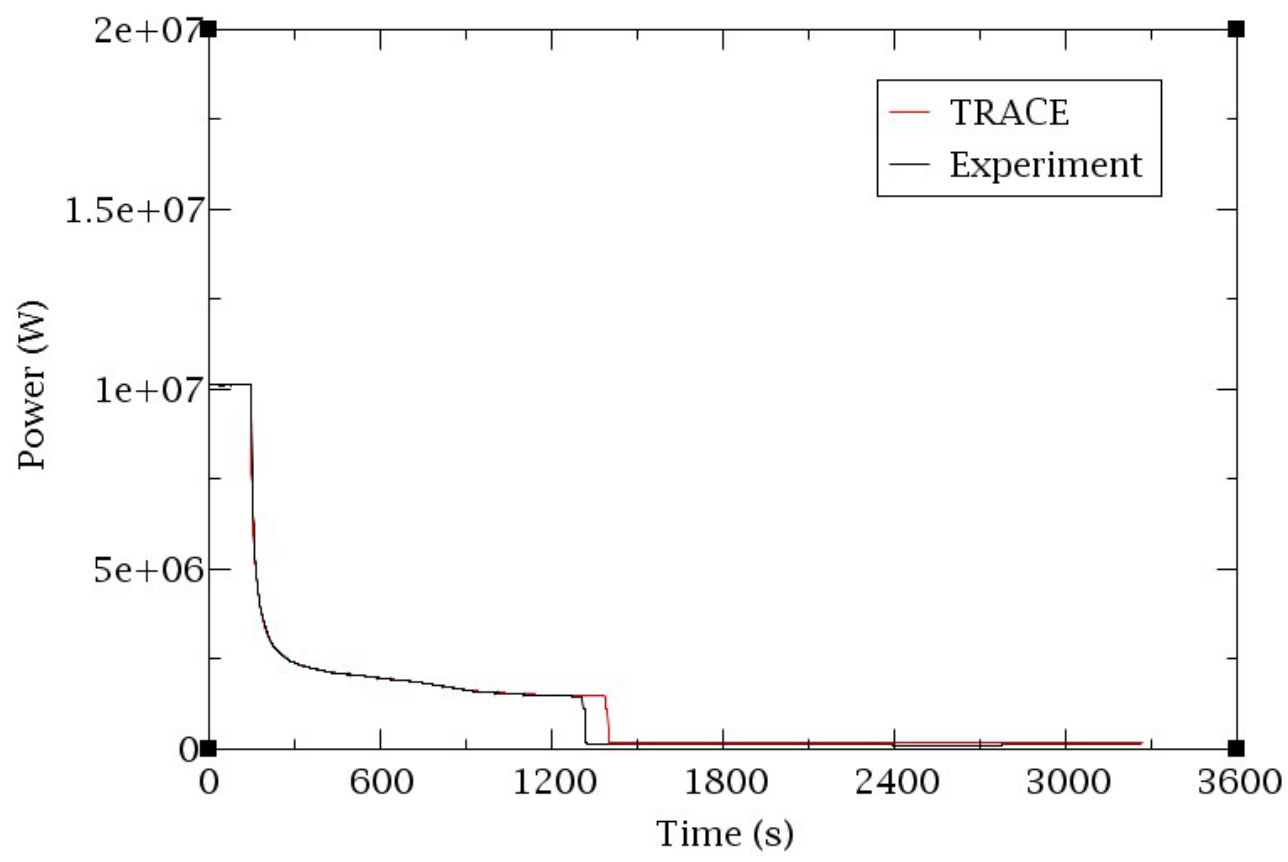

Figure 5.9 Reactor total power.

\subsubsection{Primary loop mass flow rate}

The mass flow evolutions of primary loop A and B calculated by TRACE code are presented in Figures 5.10 and 5.11 respectively. In general, the values and the trend of the mass flow rate through both loops are almost the same. After break valve is switched on, the mass flow increases sharply due to the large pressure difference between the pump and the PV caused by a large pressure drop in the PV. After the scram, the mass flow drops gradually to $0 \mathrm{~m} / \mathrm{s}$ because of the coast down of pump at about $350 \mathrm{~s}$. 


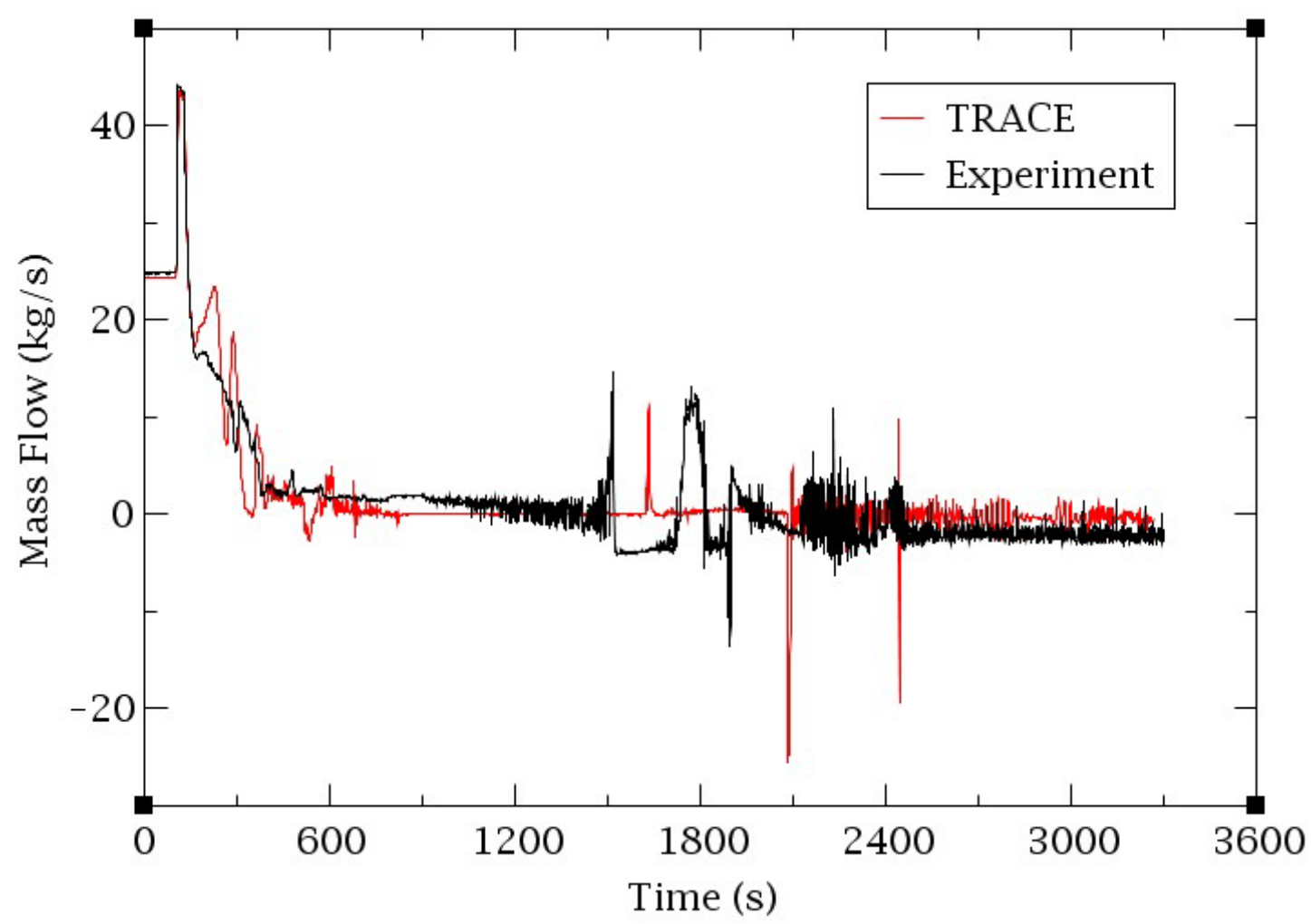

Figure 5.10 Primary mass flow rate in loop A.

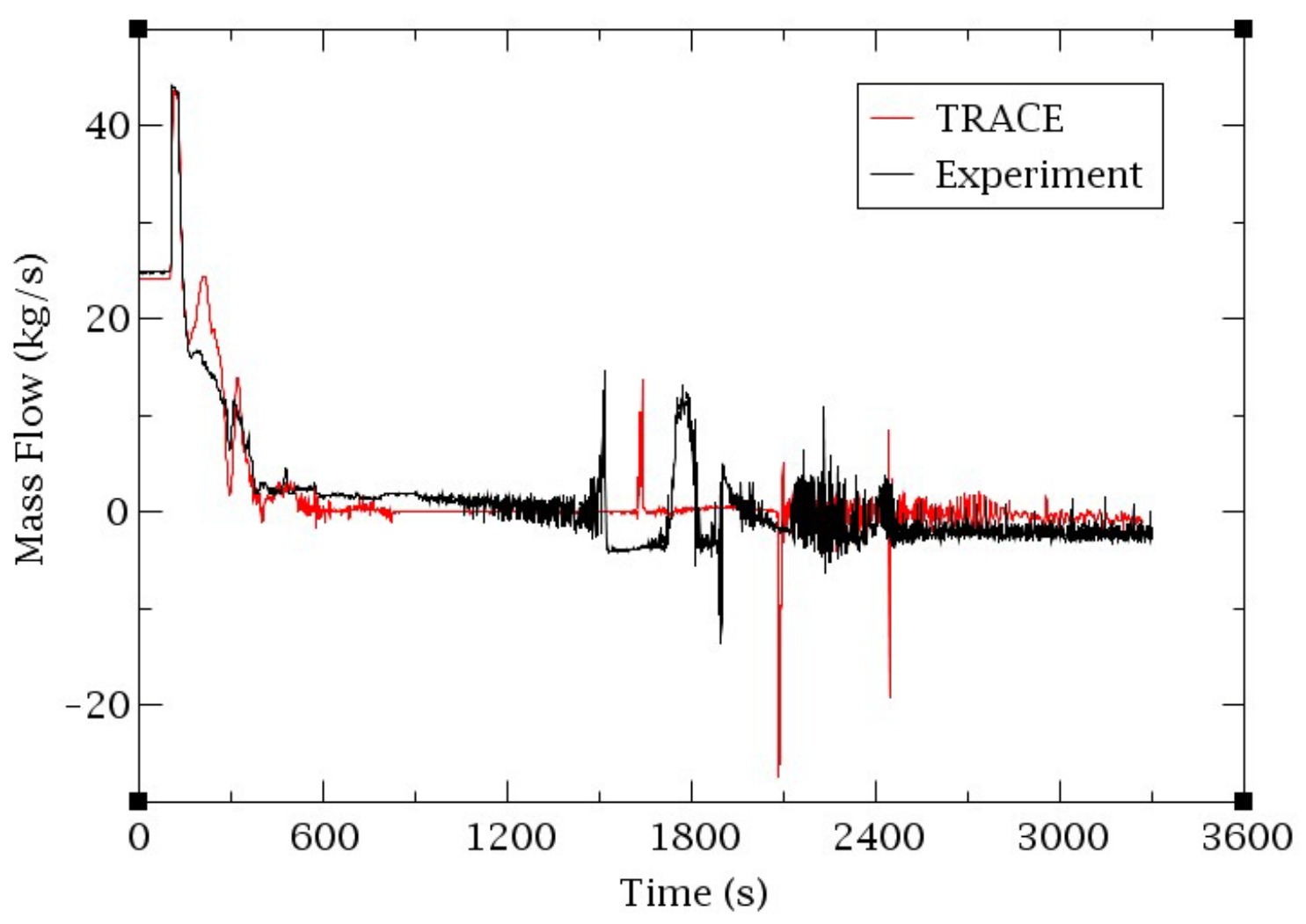

Figure 5.11 Primary mass flow rate in loop B. 


\subsubsection{Collapsed liquid level in the core and upper head}

The following Figures 5.12 and 5.13 show the collapsed water level results in the core and upper head. In Figure 5.12, the experiment value for collapsed water level in the core is about $4.6 \mathrm{~m}$ while the corresponding TRACE data is about $4 \mathrm{~m}$. After the break, experiment data increased to $6 \mathrm{~m}$ while the TRACE result is still about $4 \mathrm{~m}$. The possible reason is that the experimental value of collapsed liquid level is calculated from the pressure difference between the bottom and the top of the core and the pressure difference will be affected by the significant changes of the primary mass flow rate which may be not considered in the experiment calculation. After about $250 \mathrm{~s}$, the water level starts to decrease gradually. The decrease is accelerated at about $900 \mathrm{~s}$ when the upper plenum is empty. The experimental collapsed water level starts to rise at about $1500 \mathrm{~s}$, which is reproduced in TRACE although with a time delay of $100 \mathrm{~s}$. Since $2000 \mathrm{~s}$, the collapsed water level in TRACE simulation shows the same value as the steady state due to the ECCS injection. It is found from the experimental data that core is uncovered at the late phase of experiment. The different response of TRACE simulation leads to a lower prediction of the CET and maximum fuel rod surface temperature at the late phase.

Collapsed water level in the upper head is shown in Figure 5.13. The significant difference between TRACE and experimental data at steady state mainly results from the different measurement location. The experiment measures the data between elevation $7834 \mathrm{~mm}$ and $9653 \mathrm{~mm}$. Take the fact that the vessel bottom elevations is $-2357 \mathrm{~mm}$ into consideration, the data is measured at $12.01 \mathrm{~m}$ while the whole vessel height in TRACE simulation is $10.9574 \mathrm{~m}$. So it is measured at the very top of vessel which is neglected in TRACE simulation. In general, after the break, the water level suffers a decrease. It is decreased to $0 \mathrm{~m}$ at $1500 \mathrm{~s}$. After that, the collapsed water level in upper head increases to the relatively steady value of $1 \mathrm{~m}$ and 0.7 $\mathrm{m}$ for the simulation and the experiment respectively since $1800 \mathrm{~s}$. 


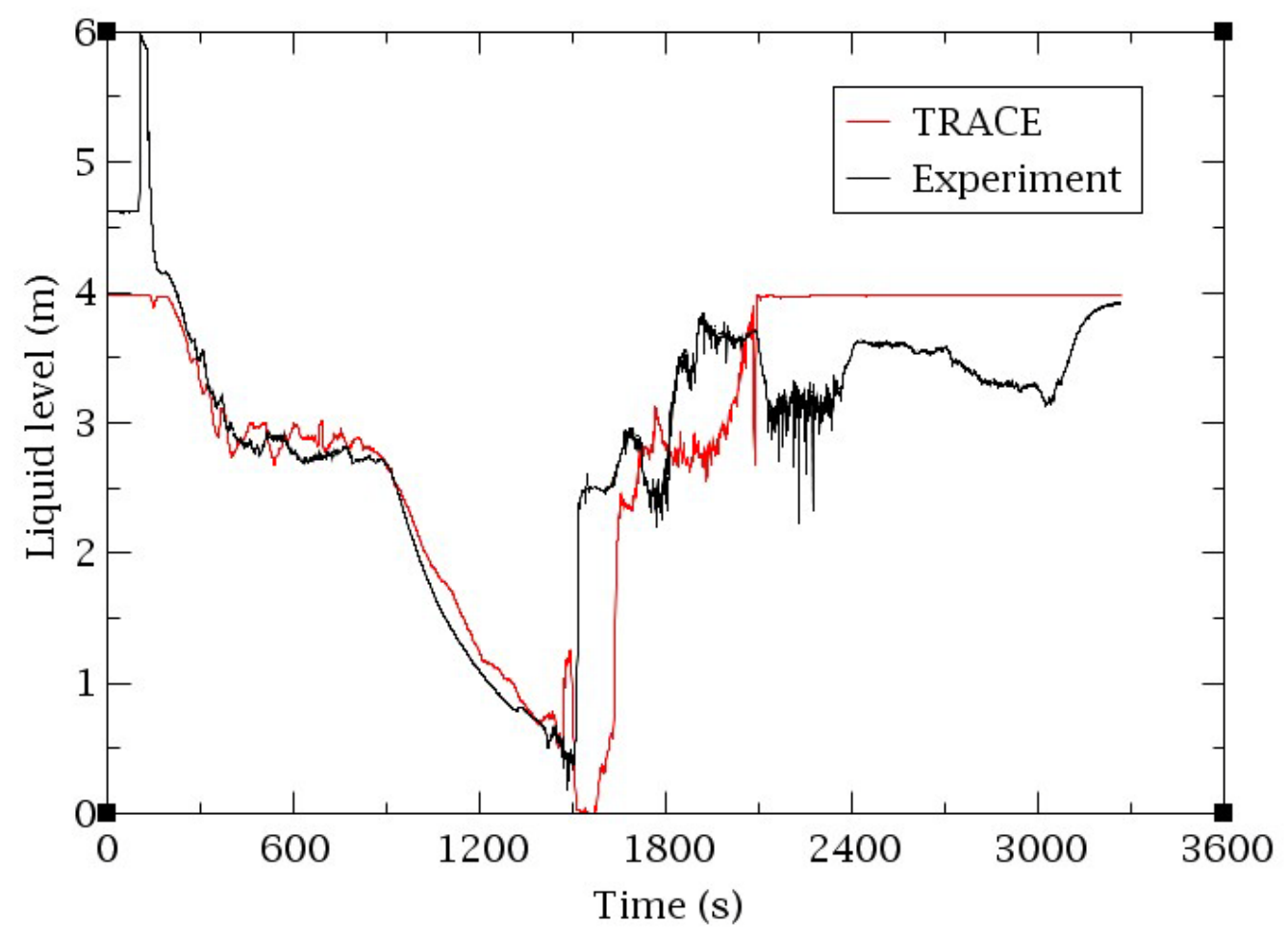

Figure 5.12 Collapsed water level in the core.

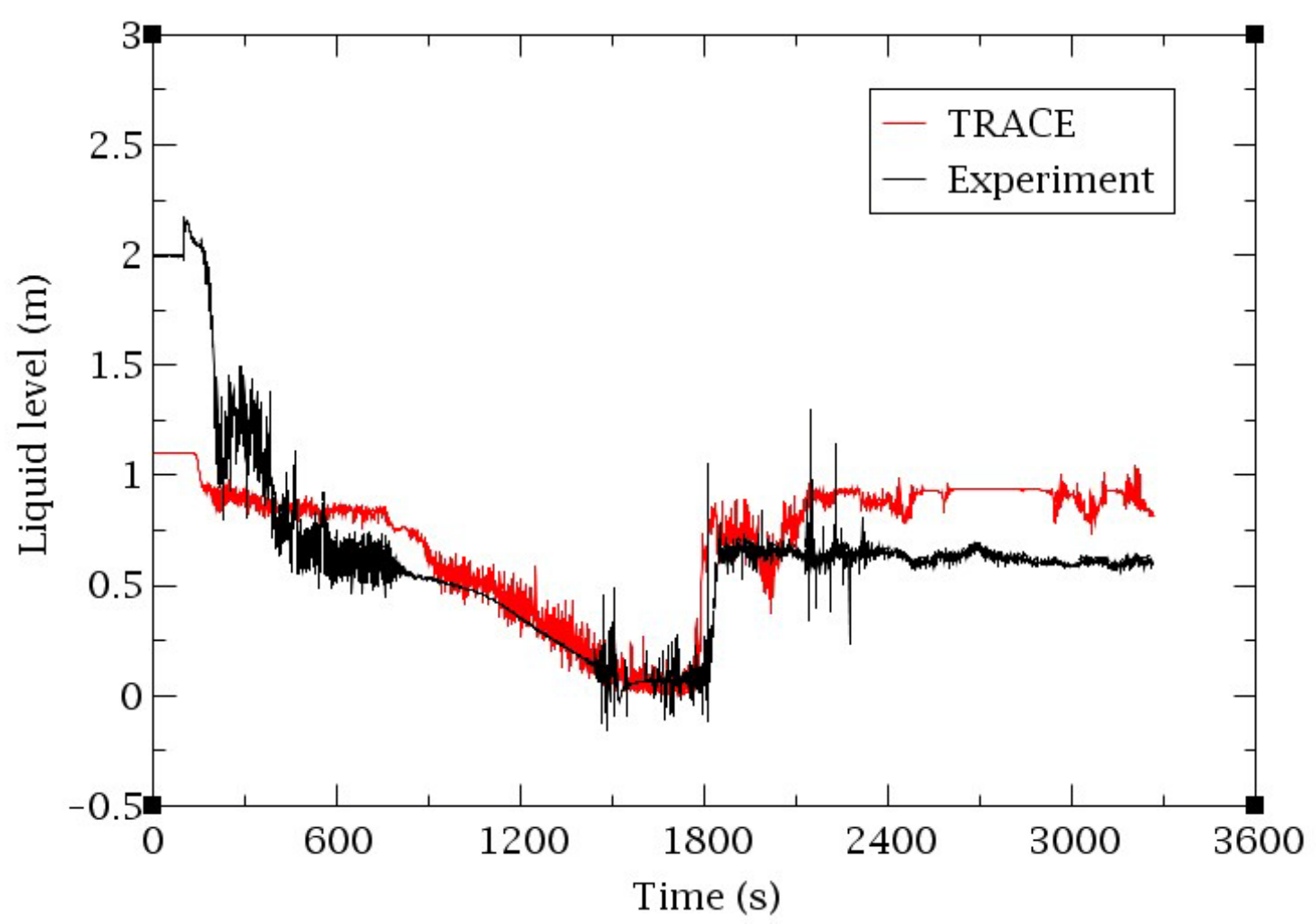

Figure 5.13 Collapsed water level in upper head. 


\subsubsection{ECCS injection mass flow}

Due to the assumption of the HPIS failure in the experiment, HPIS is omitted in the simulation. So only the accumulator injection mass flow and LPIS injection mass flow are calculated and presented in the following sections.

\subsubsection{Accumulator injection mass flow}

Figure 5.14 shows the TRACE results of accumulator injection mass flow. During the simulation, the accumulator is activated at around $1400 \mathrm{~s}$ with $1 \mathrm{~kg} / \mathrm{s}$ injection flow rate, which is almost same as that of the experiment. Because of the changes of pressure drop between accumulator system and primary system, the injection flow rate is shaking from $0 \mathrm{~kg} / \mathrm{s}$ to $3 \mathrm{~kg} / \mathrm{s}$ before 2200 $\mathrm{s}$.After that, there is little coolant flow out of accumulator since most coolant is already injected to the system. However, the experiment reaches a peak of $6 \mathrm{~kg} / \mathrm{s}$ at about $1800 \mathrm{~s}$ at the second injection. While the TRACE results increases to the highest value of $3 \mathrm{~kg} / \mathrm{s}$ at about 2000 s. After 2400s, the nitrogen is injected into the system in the experiment [4], but such a phenomenon is not reproduced in TRACE simulation.

For a SBLOCA, the depressurization of primary system is relatively slower than a LBLOCA. There will be periodical pressure rises due to the clearing of loop seal, which will divide the accumulator injection into several short periods. In the experiment, the accumulators discharge the coolant three times for short periods while it injects for more than three times of shorter periods in TRACE modeling. It may be the consequence of different pressure evolutions between TRACE prediction and experimental data. Another possible reason is that the control principle of simulated accumulator valve is different from that of experiment. 


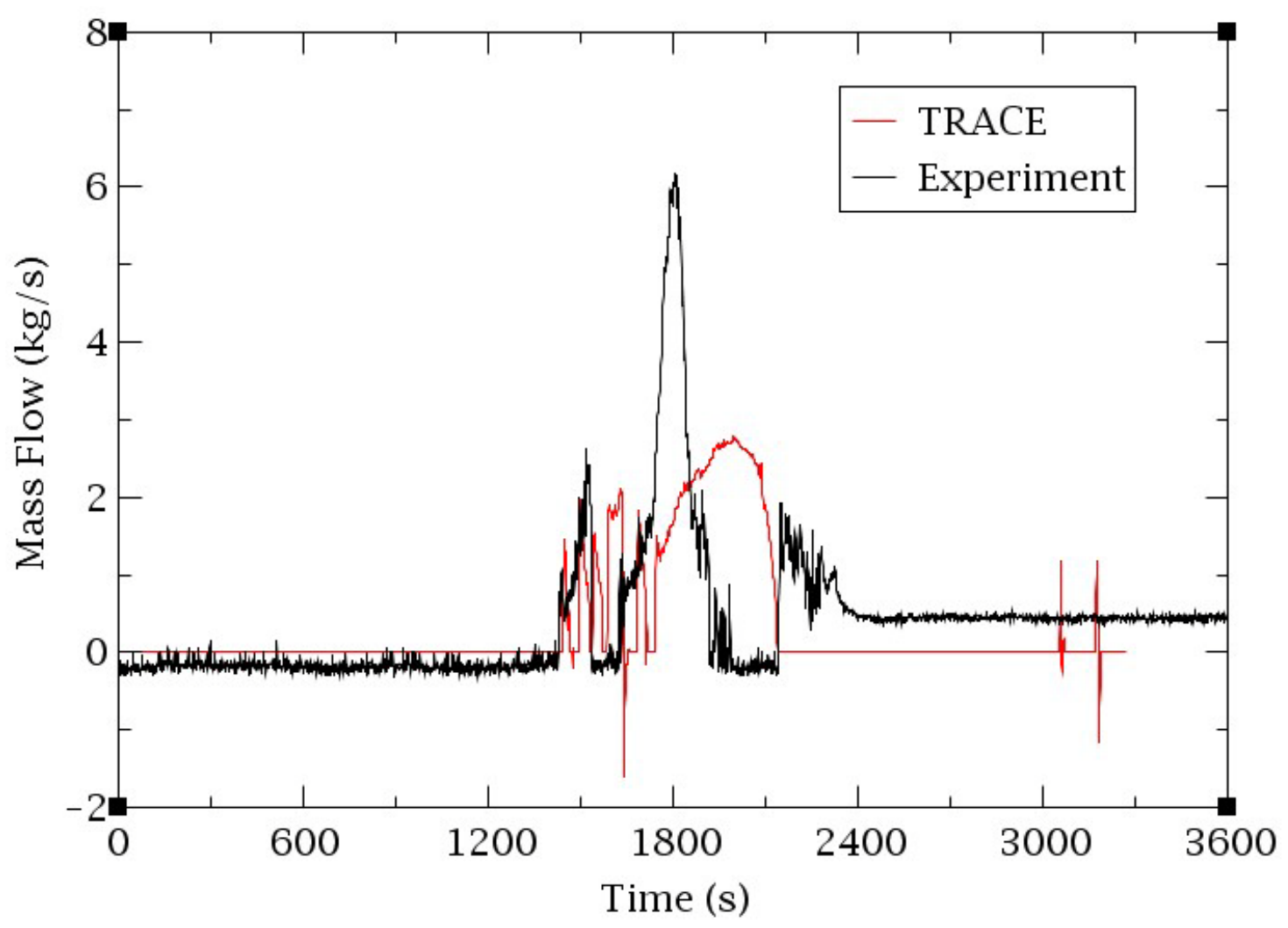

Figure 5.14 Accumulator injection mass flow rate.

\subsubsection{LPIS injection mass flow}

The LPIS injection mass flow rates are illustrated in Figure 5.14. The LPIS mass flow calculated by TRACE code increases from $0 \mathrm{~kg} / \mathrm{s}$ to $1.3 \mathrm{~kg} / \mathrm{s}$ at about 2000s. While the injection mass flow measured in the experiment is started from $3000 \mathrm{~s}$ and finally reaches the value of $1.5 \mathrm{~kg} / \mathrm{s}$. It can be seen from Table 5.3 and Figure 5.14, the lower pressure injection system in the TRACE model is activated earlier than that in experiment. 


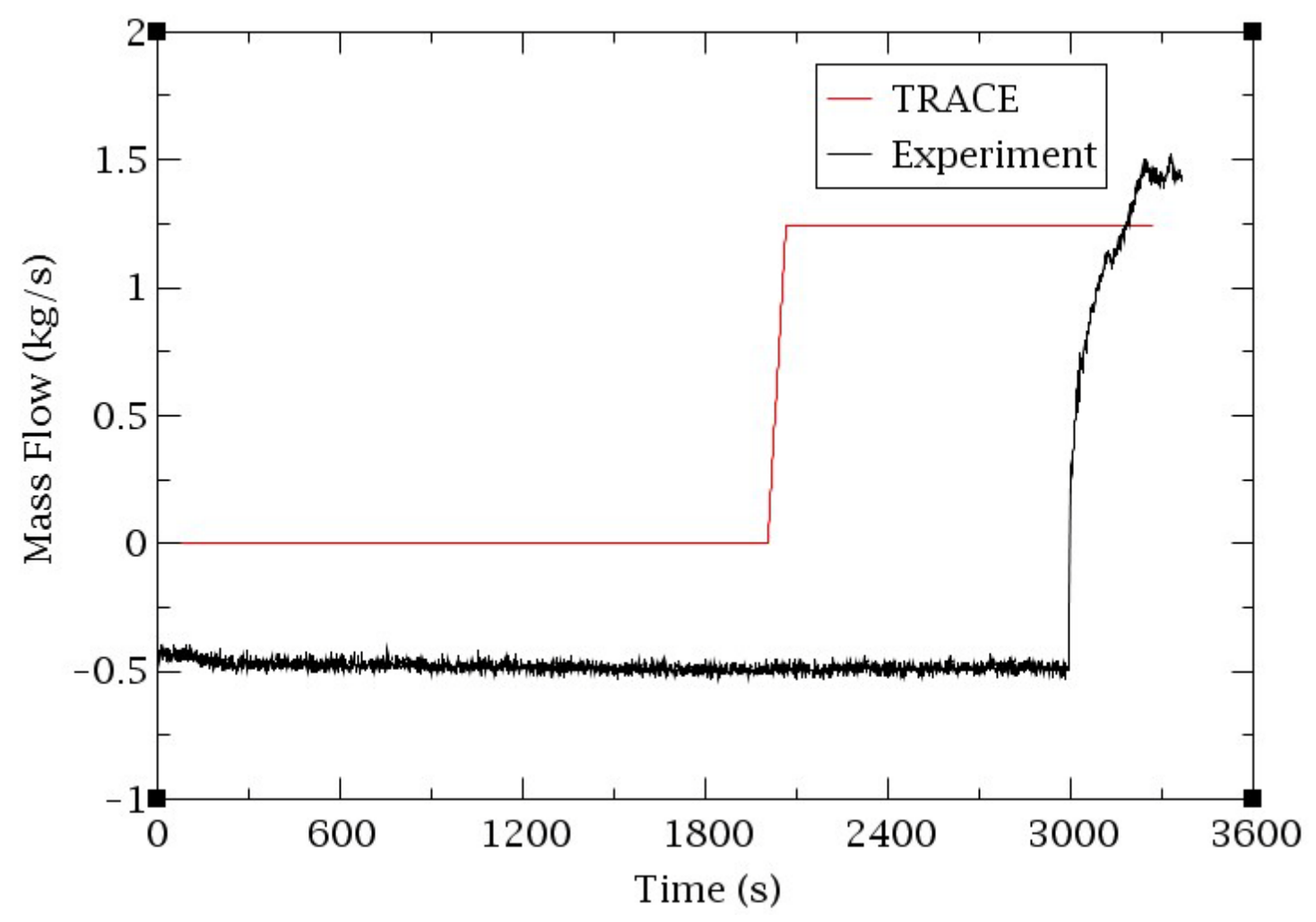

Figure 5.15 LPIS injection flow to CL.

\subsection{Sensitivity study}

The work is performed to improve the model and investigate the influence of different modeling. The improvement focused on two aspects: the simulation of break unit and leakage between downcomer and hot leg respectively. In addition, the effects of the break location, LPIS simulation and accumulator setup are also studied.

\subsubsection{Break unit simulation}

It is known that there is no choked flow multiplier for single vapor phase in TRACE code, which may result in some uncertainties during TRACE calculations. Figures $5.16-5.19$, show the simulation results of break mass flow rate, integrated break mass, CET at center and primary pressure, whose model use default choke for break mass flow and marked as 'TRACE break 1 '. It can be seen from the figures that the simulation results show a significant difference after 1200 $\mathrm{s}$ comparing with experimental data. To reduce the errors, a modified model is developed by refilling the break valve table with different array of values to control the flow area. The values are set just to follow the experimental evolution of integrated mass flow. The results of the modified model are also added in Figures 5.16 - 5.19 by red line. The principle for this modification is to make the simulated integrated mass flow as close as experimental data, since the measurement of mass flow in the experiment has higher uncertainty value, as discussed in Section 4.2. 
As shown in the figures, the model with default choked flow seems over-predicts the break mass flow especially when the coolant is in single phase superheated vapor. The reason may be that appropriate model cannot be actuated in TRACE for the break located at the upper head of PV. In the experiment, the break is above the upper head which could be considered as some kind of off-take geometry for PV. But in TRACE code, the off-take model can be actuated only for the scenario that LOCA is located at a branch pipe while not the one connected with VESSEL component. In addition, the single-phase vapor choking multiplier is not provided to reduce the uncertainties.

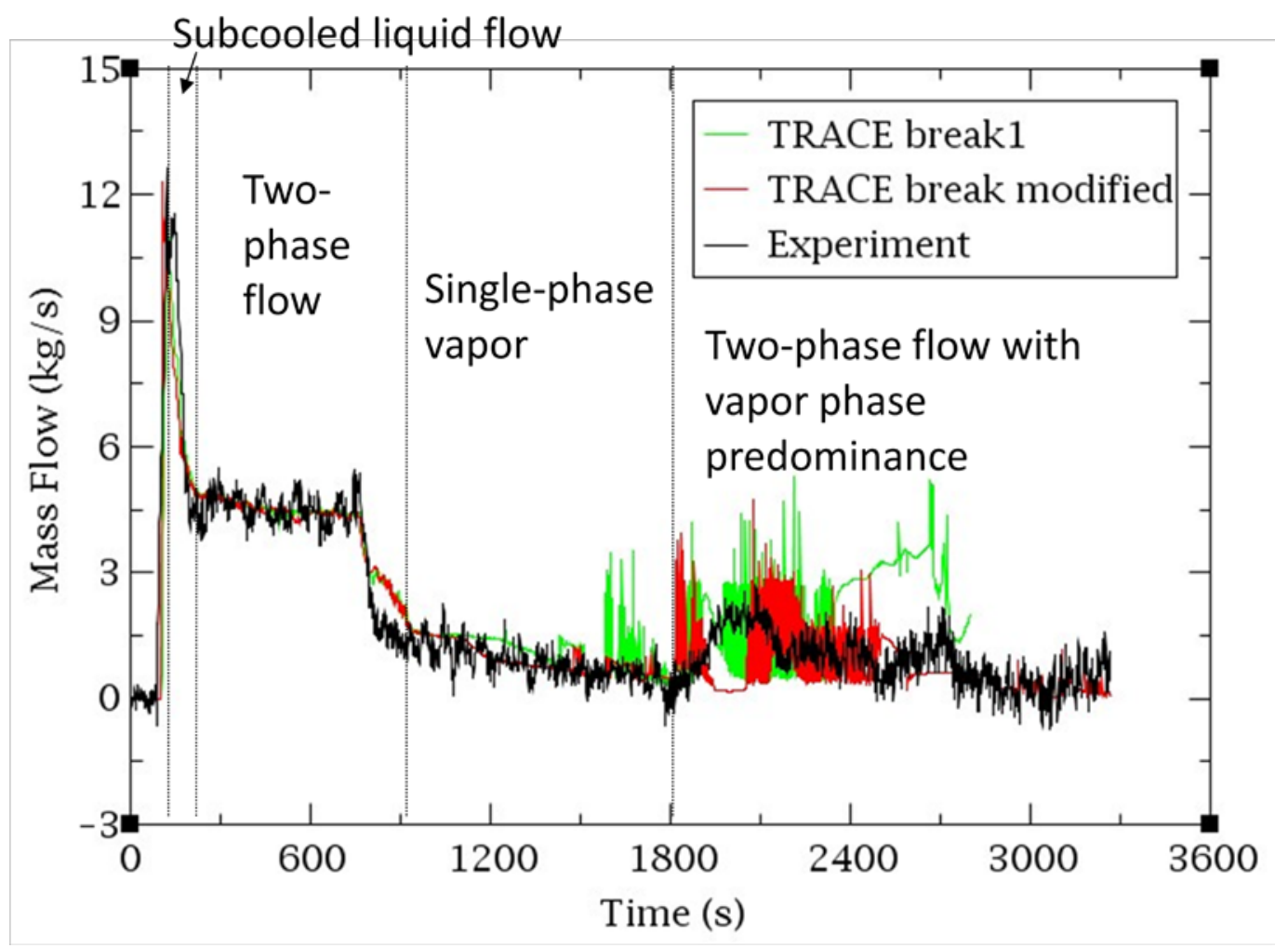

Figure 5.16 Break mass flow rate comparisons of different break simulation models. 


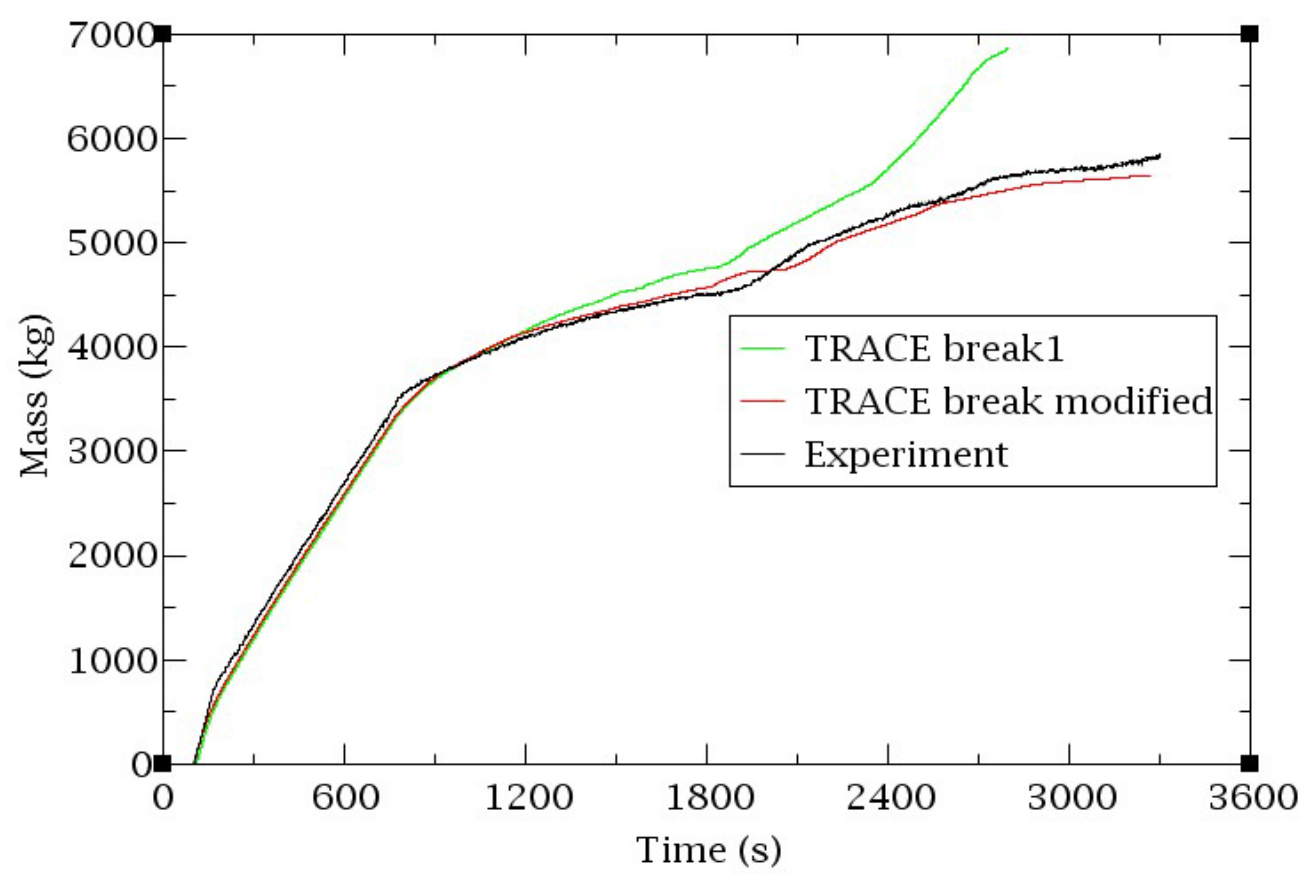

Figure 5.17 Integrated mass thought break comparisons of different break simulation models.

From Figure 5.18 (the CET prediction) and Figure 5.19 (the primary pressure results), it can be seen that the pressure in the PV simulated by the 'TRACE break 1' model suffers a quicker drop to final steady value with a small rebound at $1400 \mathrm{~s}$ and its CET cannot rise to higher value after about $1400 \mathrm{~s}$. The fast depressurization is caused by the high prediction of single-phase vapor loss rate. As a result, the accumulator is activated early and the coolant is injected to the system which prevents the CET from rising.

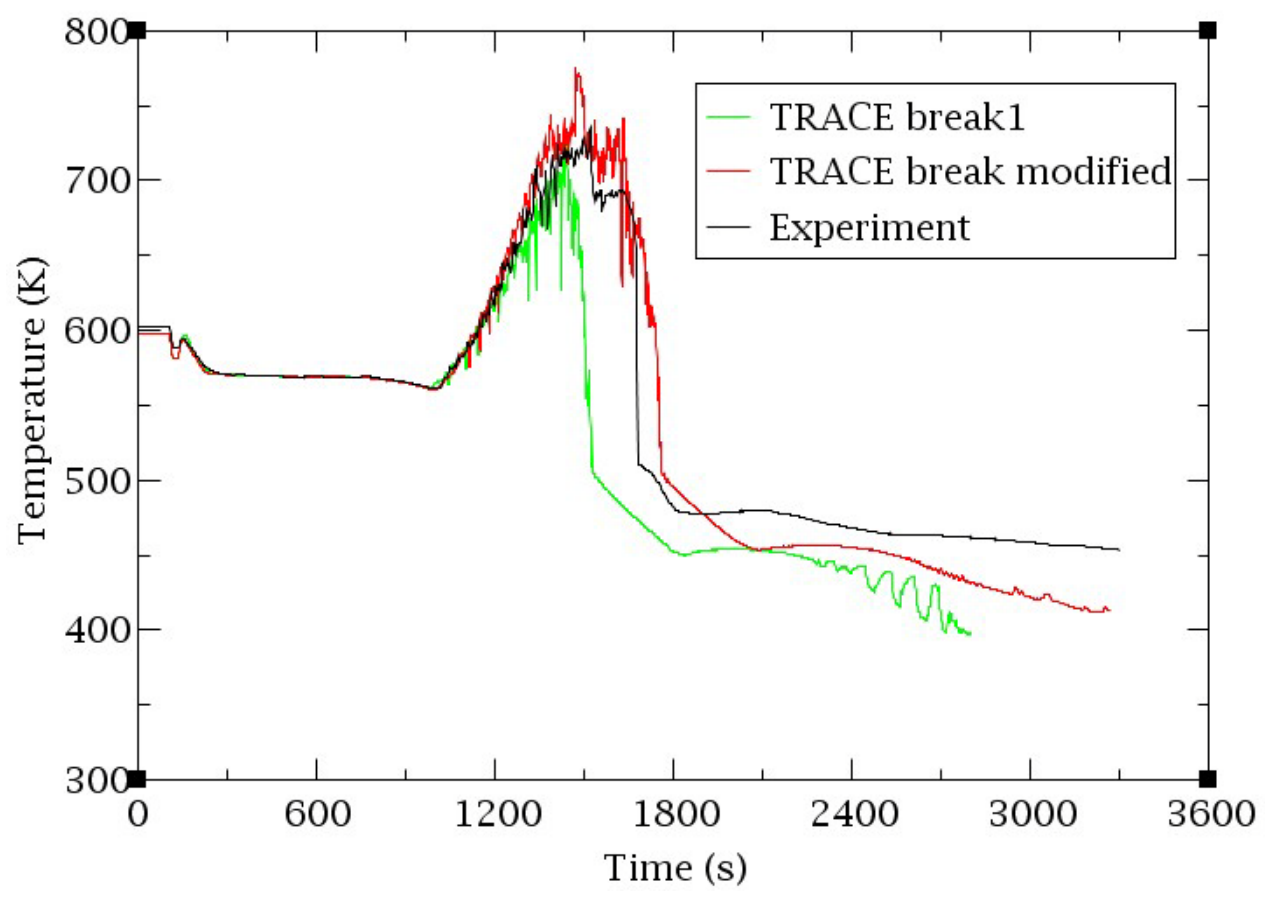

Figure 5.18 Core exit temperature. 


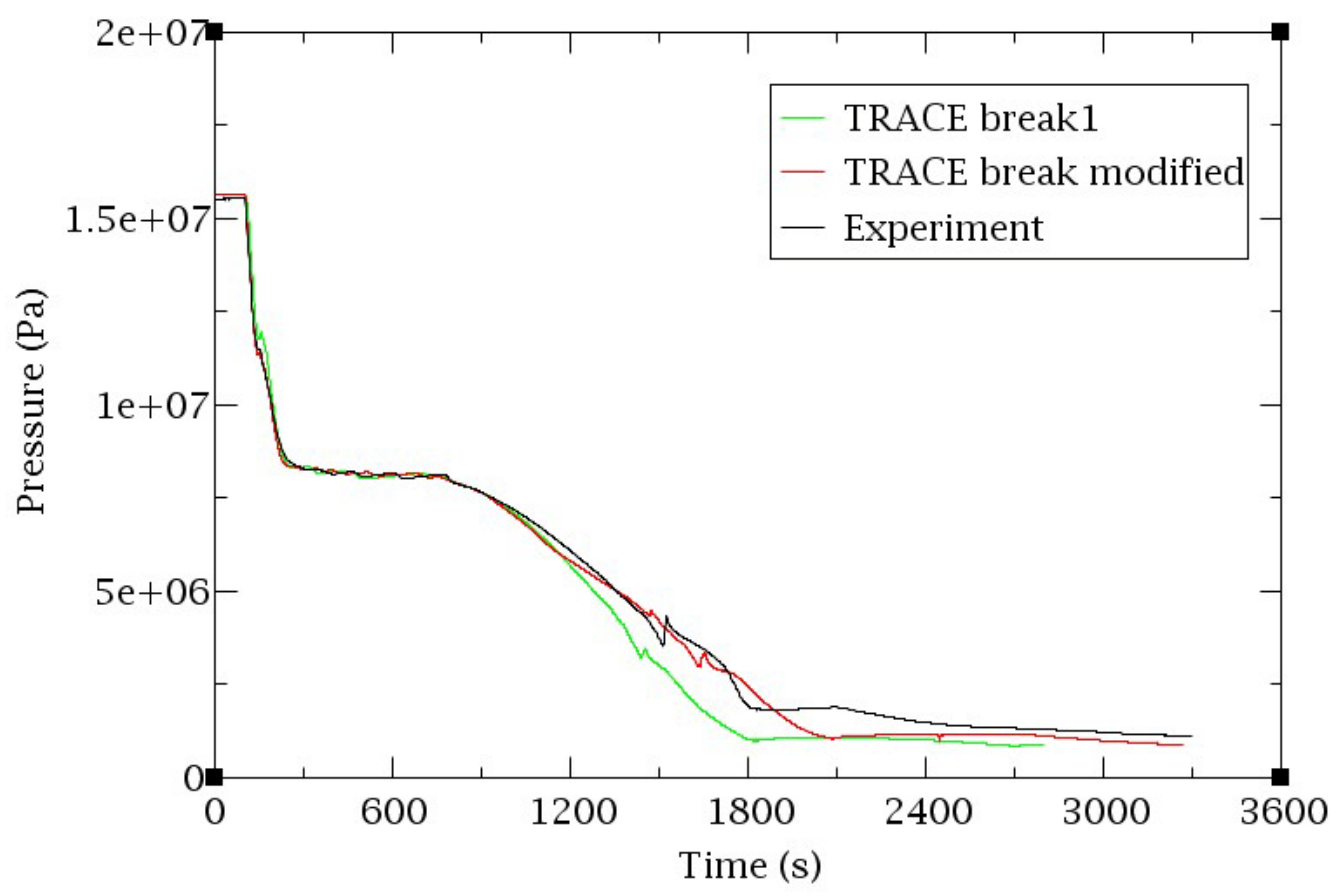

Figure 5.19 PV lower plenum pressure.

\subsubsection{Leakage between downcomer and hot leg}

In order to study the effect of leakage mass flow area between downcomer and hot leg on the simulation results, different models which manipulate different sets of leakage mass flow area are calculated and shown in Figures 5.20 - 5.22. The only difference among the TRACE models lies on the flow area of the leakage. For the edge flow area equals to $2 \mathrm{E}-5 \mathrm{~m}^{2}$, the model results are presented as the blue line. Other sets include $6 \mathrm{E}-5 \mathrm{~m}^{2}$ and $8 \mathrm{E}-5 \mathrm{~m}^{2}$ whose results are colored by red and green respectively. Black line presents the results of the experiment.

In Figure 5.20, the leakage mass flow rate under various leakage areas has two short increases due to the increasing mass flow of primary loop. After $250 \mathrm{~s}$, the leakage mass flows from the downcomer to the hot leg since the pump speed decreases to zero and the pressure difference drags them out of the PV. With the decrease of water level, the reverse mass flow drops down to $0 \mathrm{~m} / \mathrm{s}$ at about $900 \mathrm{~s}$. After that, the leakage mass flow fluctuates severely due to the ECCS injection and the temporary clearing of loop seal. Comparing the development of calculated leakage mass flow rate under various leakage flow areas, the one under the leakage flow area of $2 \mathrm{E}-5 \mathrm{~m}^{2}$ is closest to the experimental data at the steady state as shown in Figure 5. 20.

It can be seen from Figures 5.21 \& 5.22 that larger flow area could lead to larger drop of pressure and earlier rising of CET. It is reasonable because the larger flow area allows larger coolant mass flow rate leaking from PV and the corresponding pressure will be decreased faster. As a result, it causes the earlier CET rising. Although the leakage between downcomer and hot leg only occupy a rather small fraction of the total core mass flow, it exerts significant influence 
on the distribution of primary flow and primary pressure. But the different leakage flow areas do not affect the final steady temperature and pressure. All the predications stabilize at similar values both for CET and pressure.

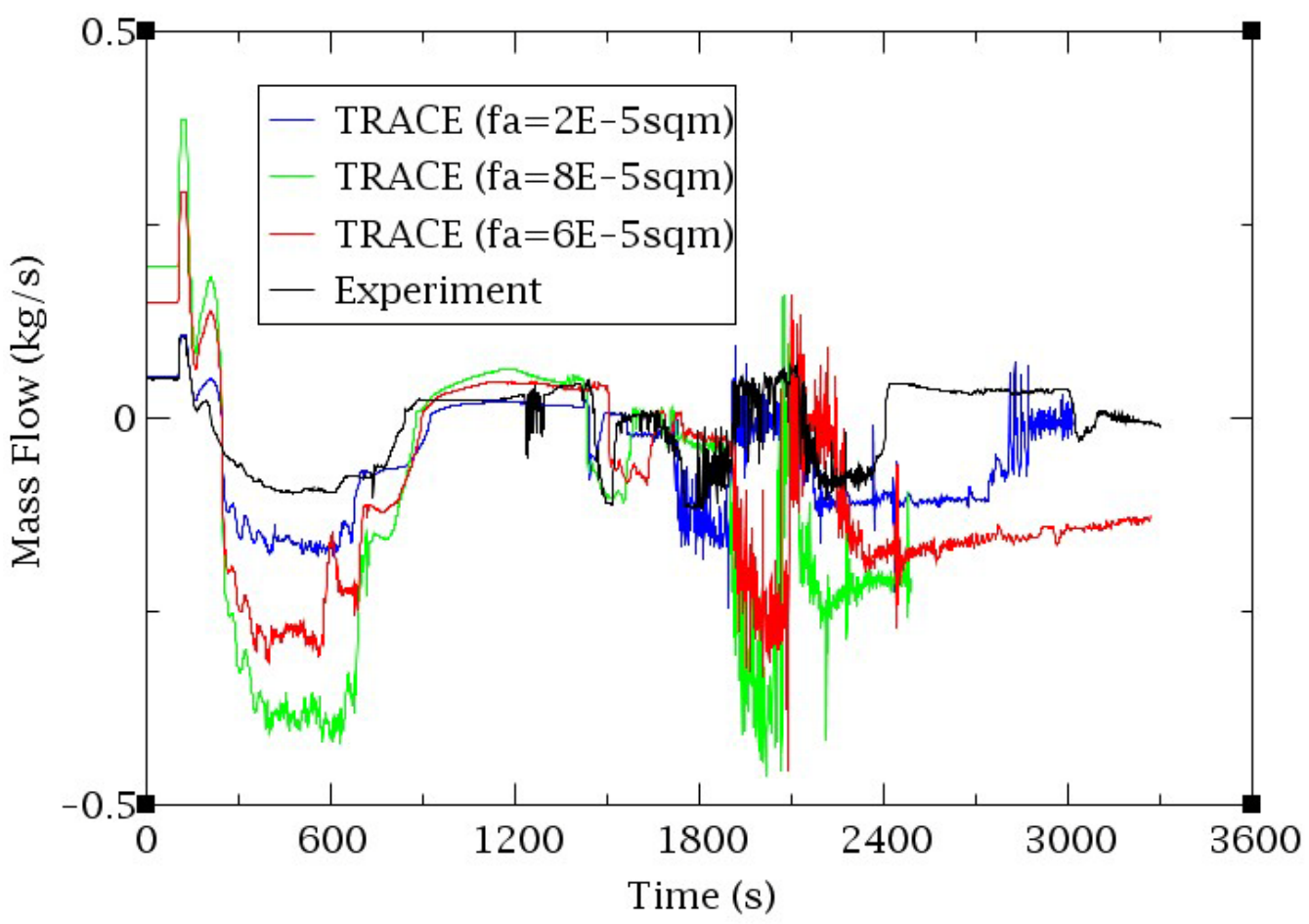

Figure 5.20 Leakage mass flow between downcomer and hot leg.

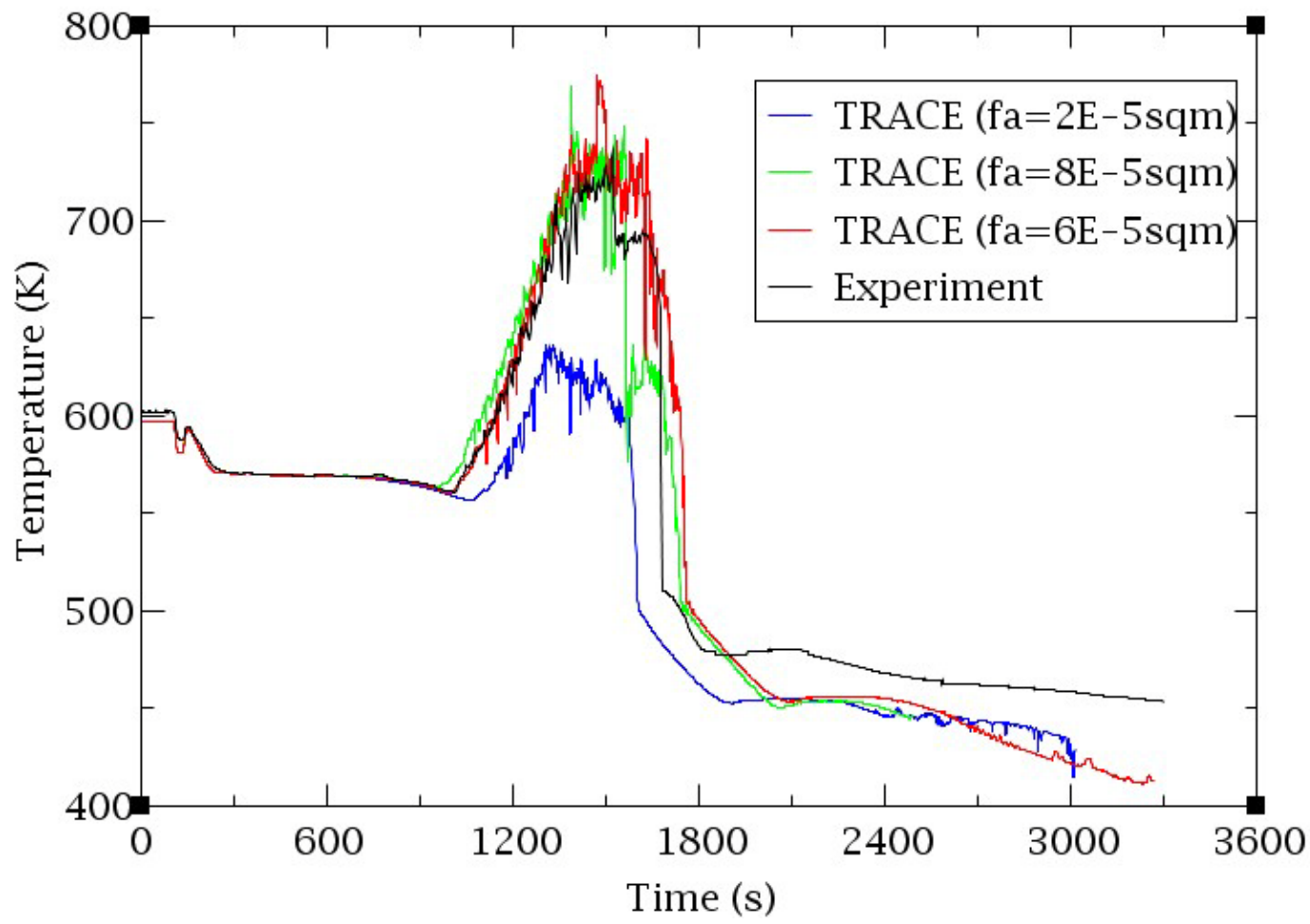

Figure 5.21 Core exit temperature. 


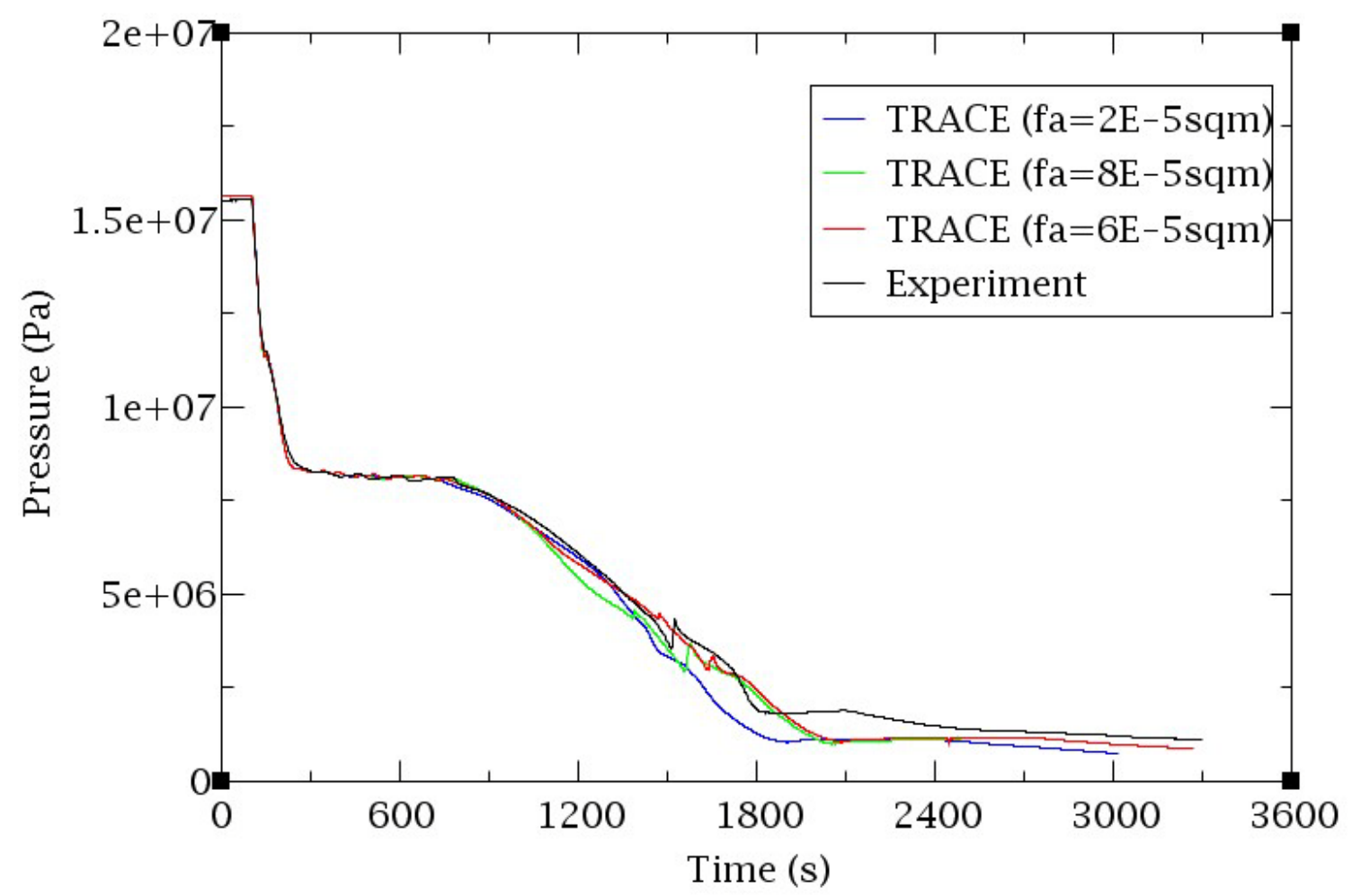

Figure 5.22 PV lower plenum pressure.

\subsubsection{Break location}

As mentioned in Section 4.2, the elevation of break nozzle is $8500.6 \mathrm{~mm}$, and it locates at the point between ' $45^{\text {th }}$ cell $3^{\text {rd }}$ ring' and ' $46^{\text {th }}$ cell $2^{\text {nd }}$ ring'. So the effect of break location is investigated. In Figures $5.23-5.25$, the green lines describe the results of the TRACE model whose break connection is at the ' $46^{\text {th }}$ cell $2^{\text {nd }}$ ring', while the red lines represent the simulation results of the model with the break pipe connection at the ' $45^{\text {th }}$ cell $3^{\text {rd }}$ ring'. The experimental data marked with black lines are also plotted for comparison.

From the Figure 5.23 - 5.25, it can be seen that the simulated results of the integrated break mass, the CET at center and the primary pressure, which predicted by two different models, have a minor difference. It means that the effect of break location on the integrated break mass, the CET at center and the primary pressure is very small. Therefore, although the simulated break location is not as precise as experimental setup, the result is reliable. 


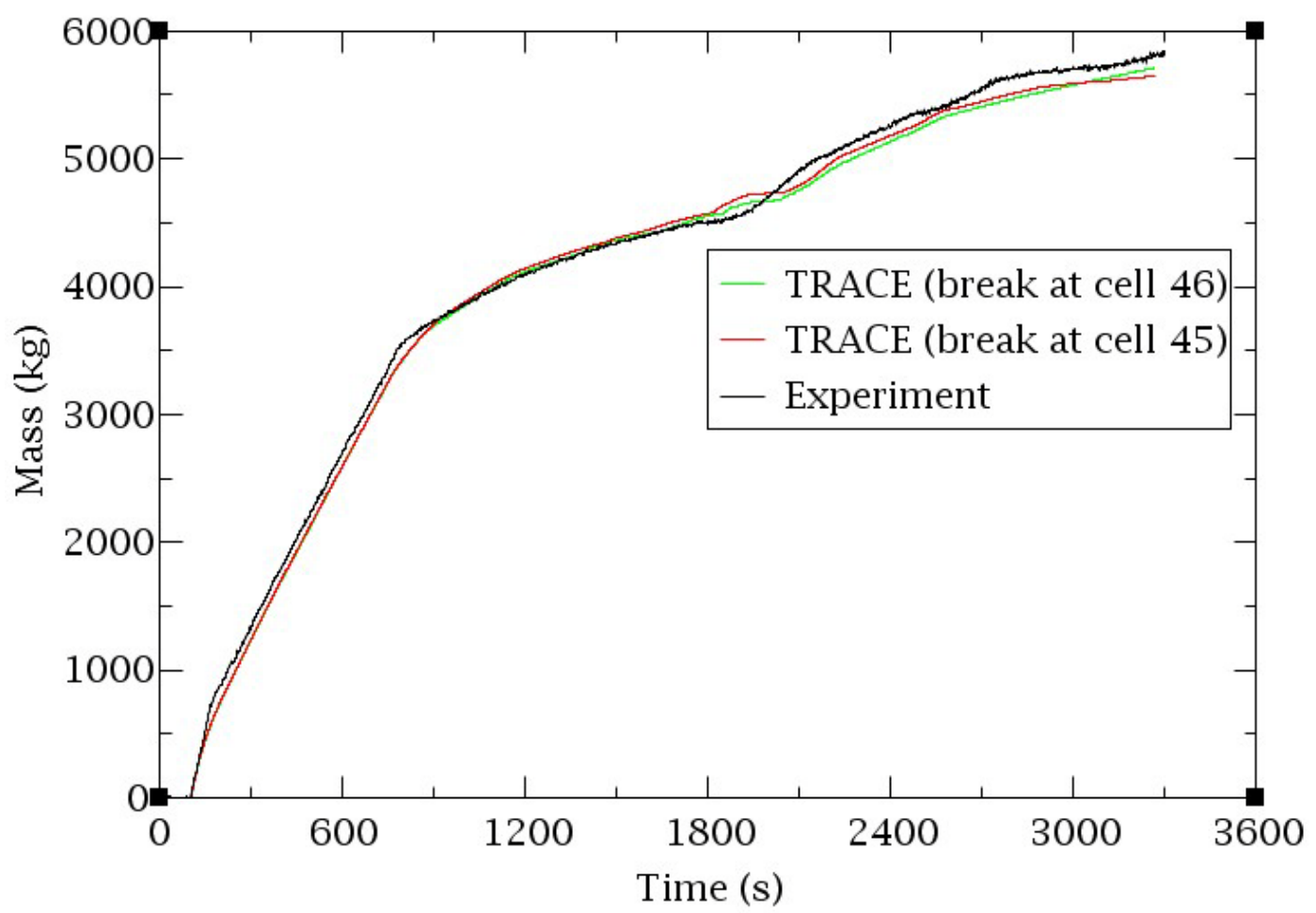

Figure 5.23 Integrated break mass.

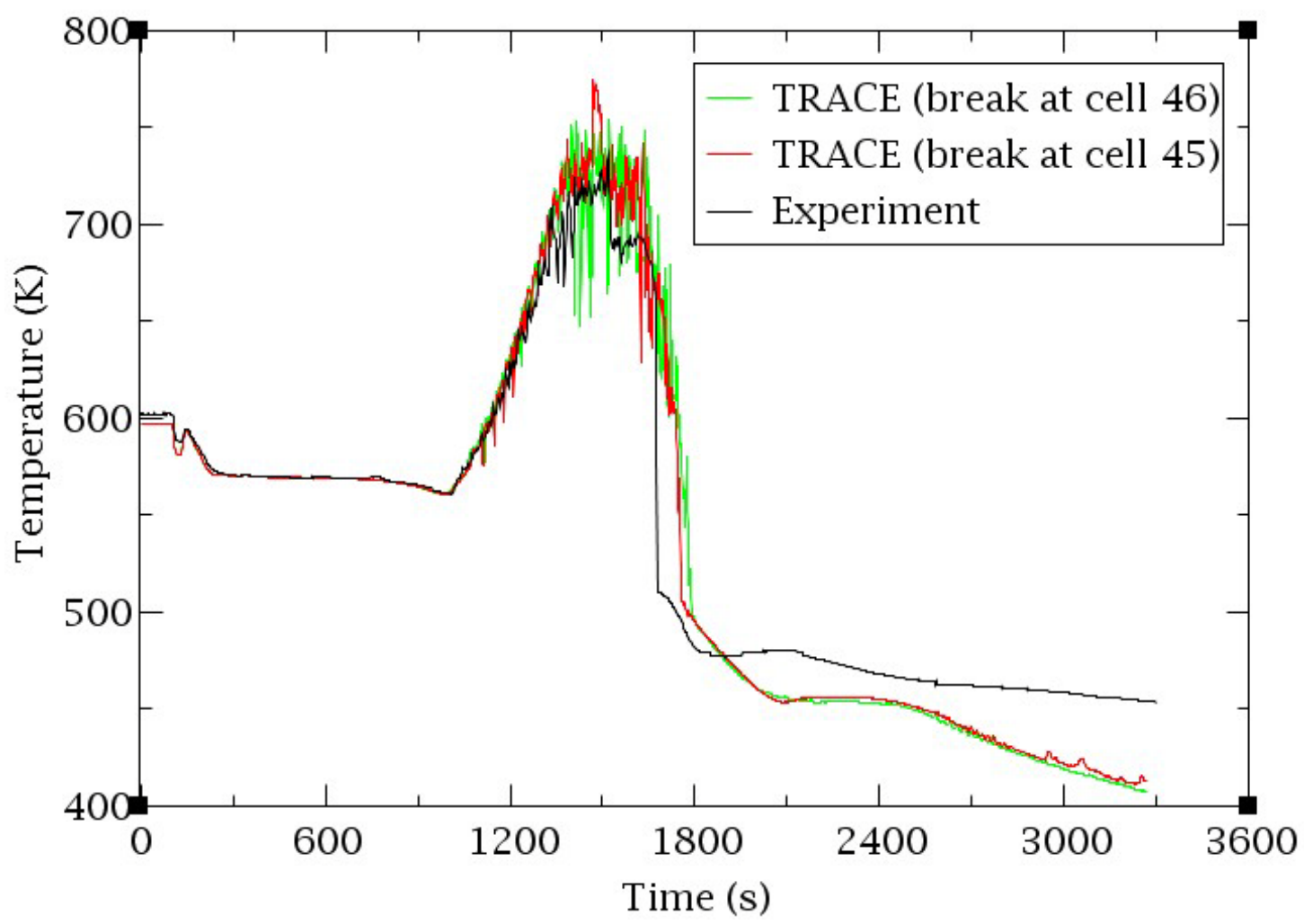

Figure 5.24 Core exit temperature. 


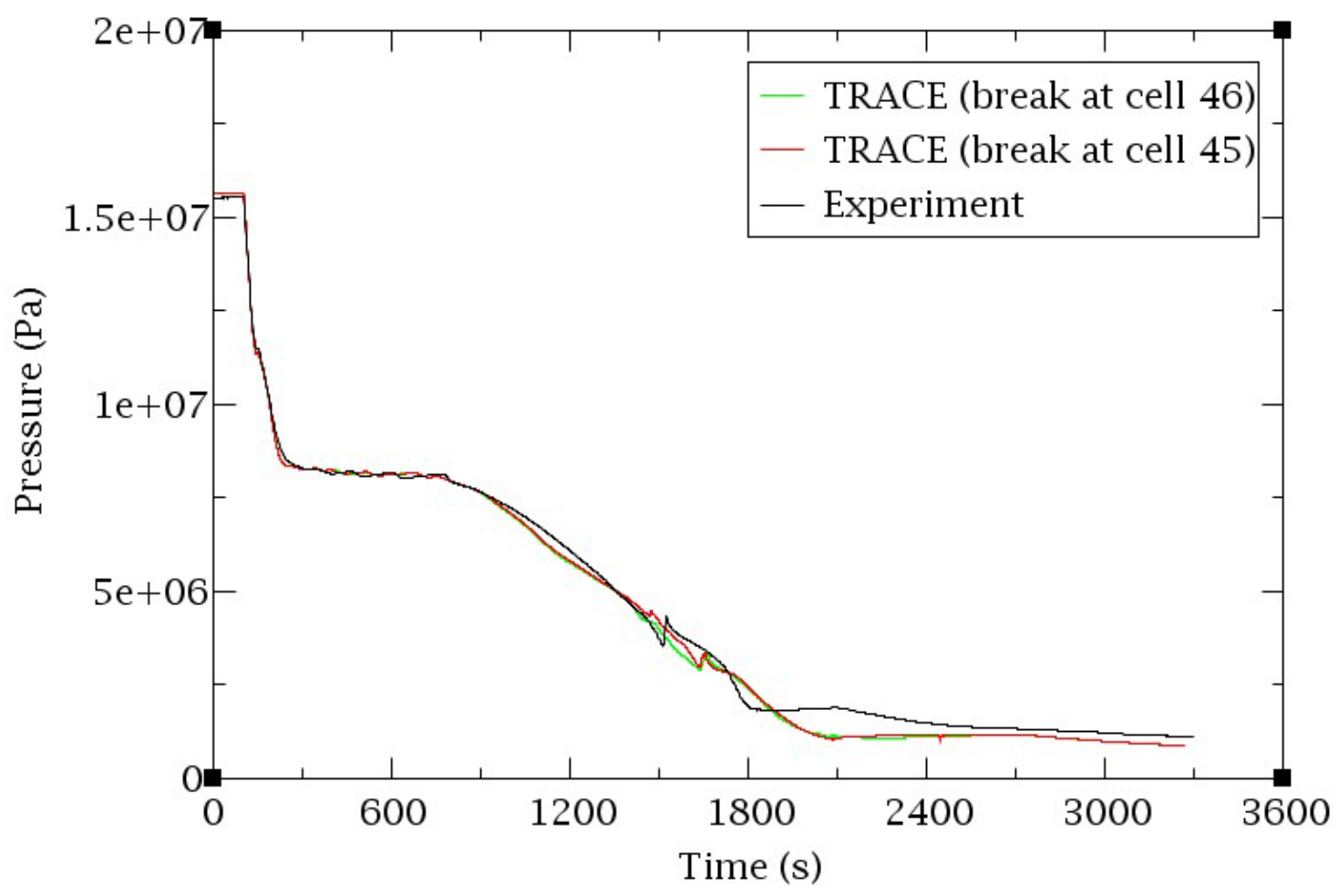

Figure 5.25 PV lower plenum pressure.

\subsubsection{Accumulator simulation}

The sensitivity effect of accumulator simulation is studied since it seems to be the main cause of the discrepancies at the late stage. Three different control logics ('time control model', 'no control model' and 'pressure control model') of accumulator injections valve are defined and tested in TRACE code. 'Time control model' means the opening and closing of accumulator valve are triggered at certain time instances. It is predetermined in the flow area table to keep consistent with that of experiment. 'The pressure control model' is that the accumulator is controlled by a trip whose status lay on differential pressure between accumulator system and primary pressure, as described in Section 4.6.1. In the 'no control model', no special controller is added.

The simulated results by different models are shown in Figures 5.26 - 5.28. In the figures, it shows small differences for the three models. In comparison, 'pressure control model' could predict a relatively higher mass flow rate of accumulator injection while the 'no control model' shows the worst prediction. But the data of core exit temperature and primary pressure are similar among three models, as shown in Figures 5.27 - 5.28. 


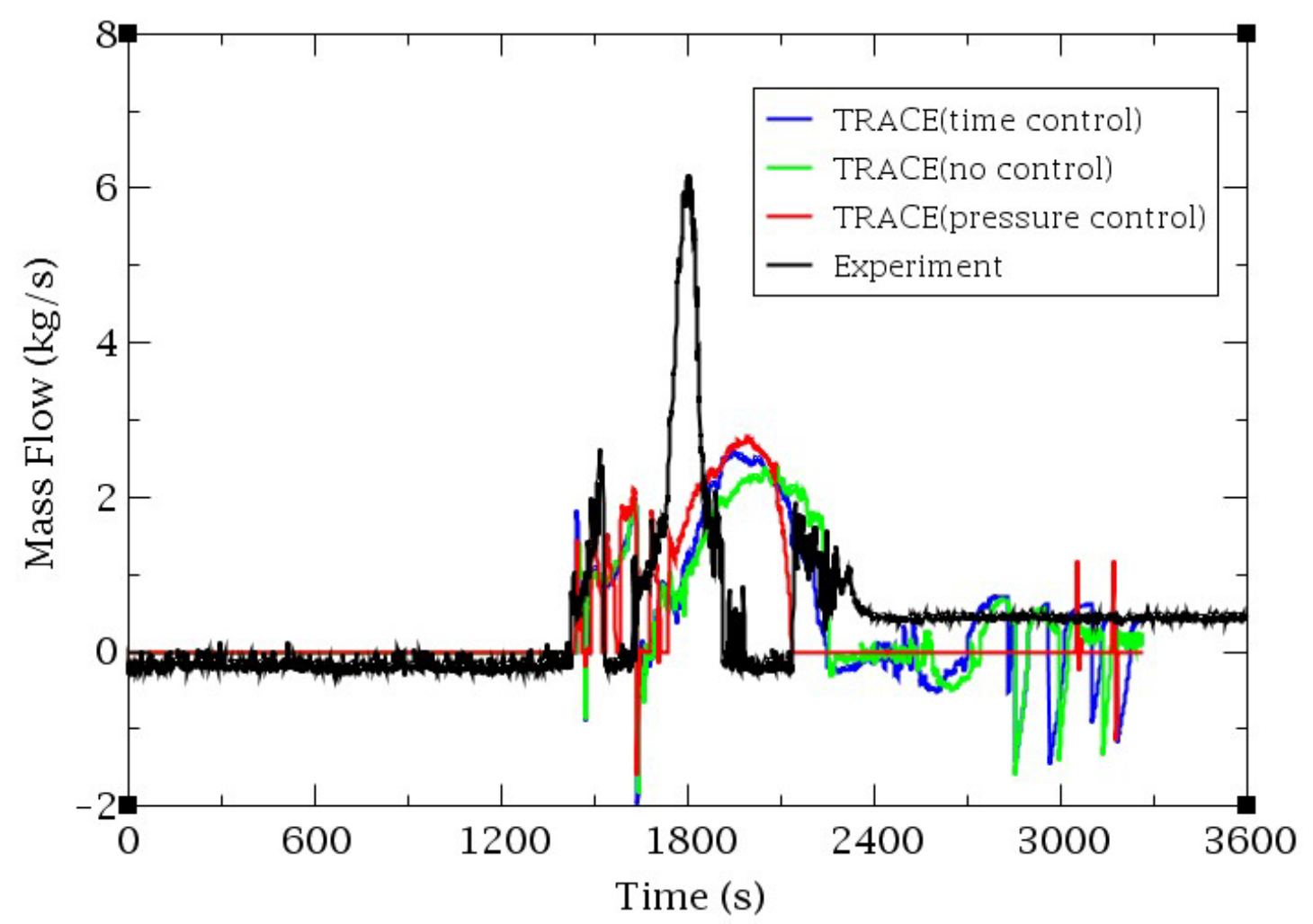

Figure 5.26 Accumulator mass flow.

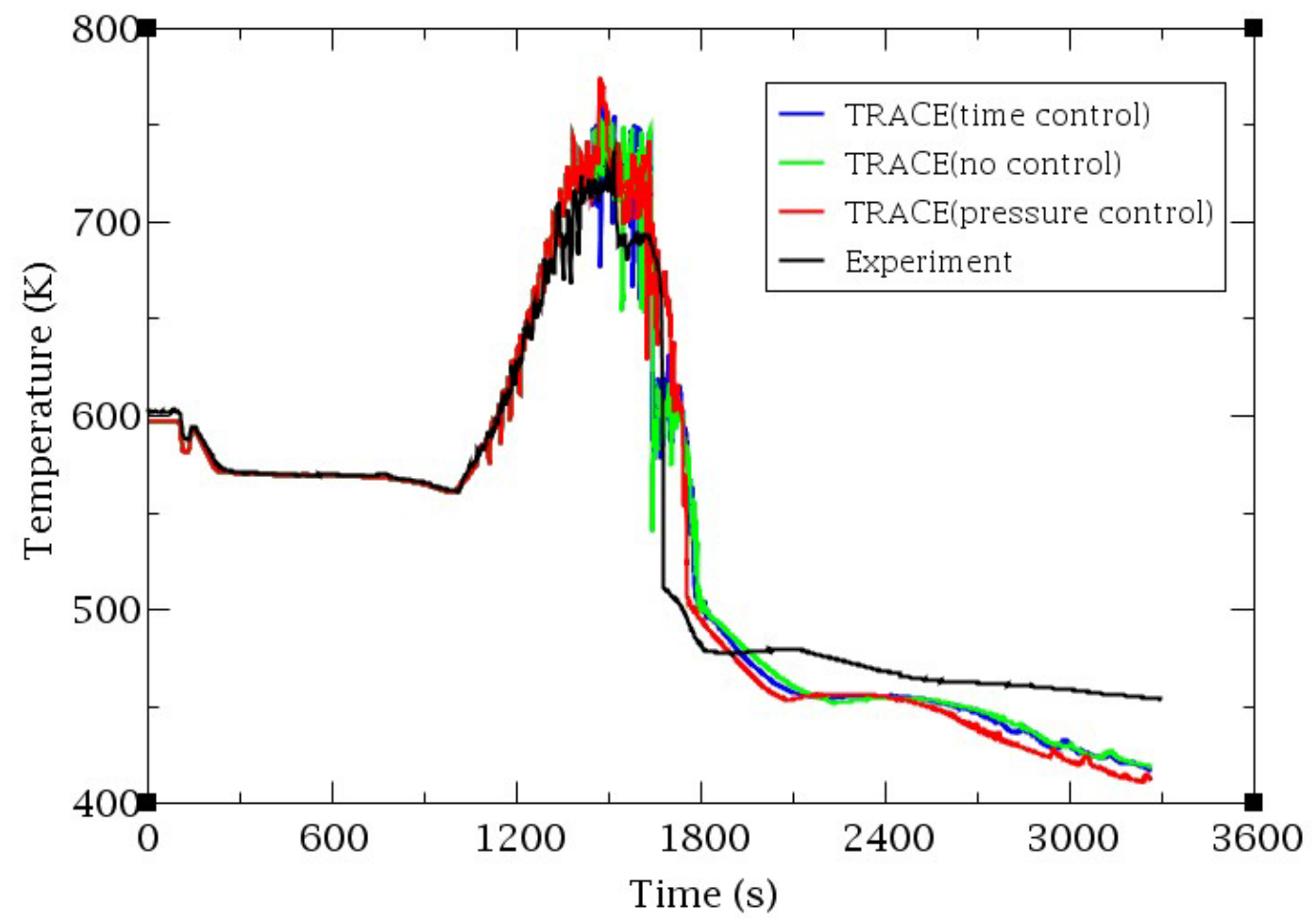

Figure 5.27 Core exit temperature. 


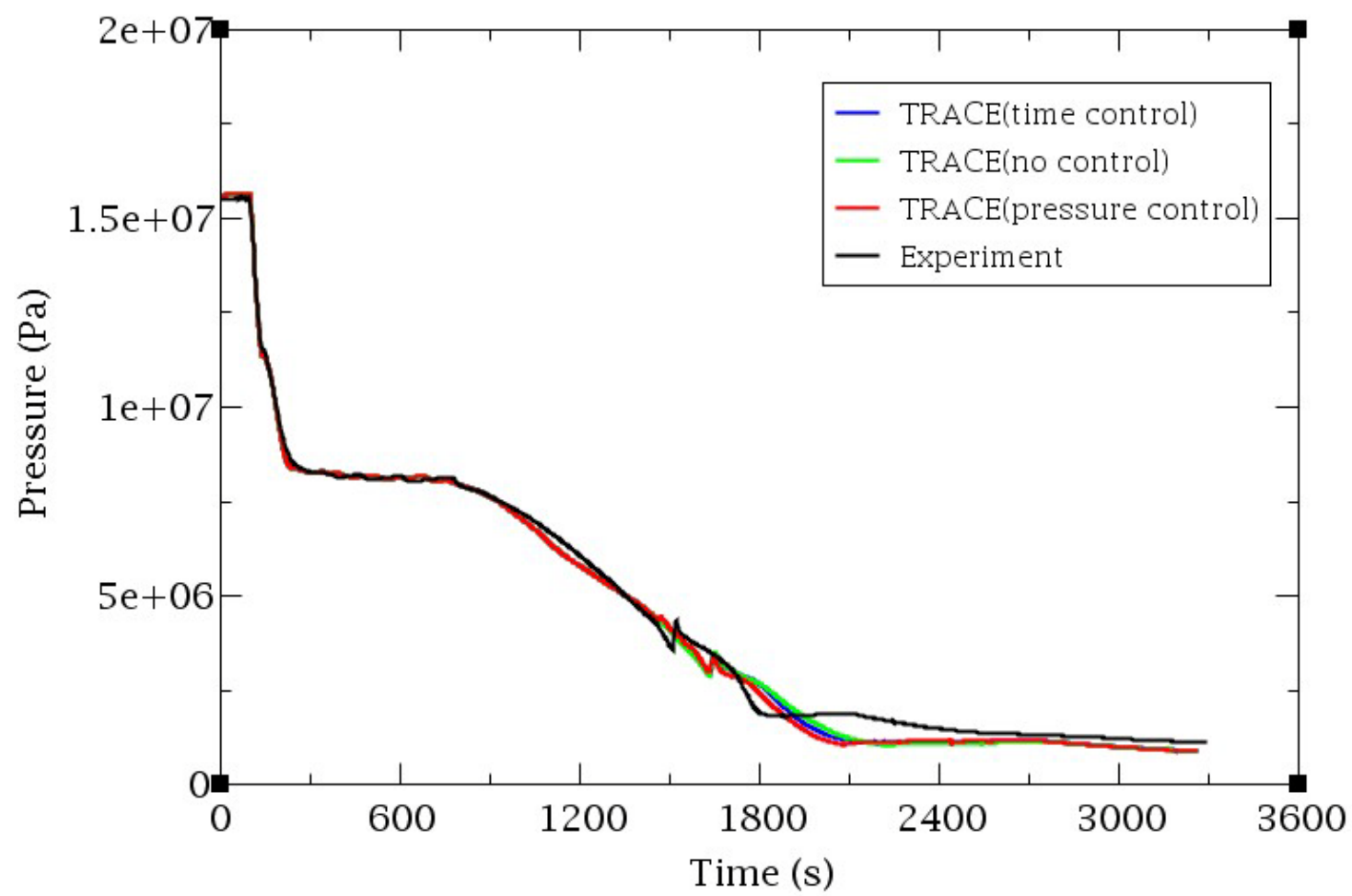

Figure 5.288 PV lower plenum pressure.

Since the pressure control logic shows better simulation result, different groups of the differential pressure set points are modeled and the results are compared in Figure 5.29 - 5.31. As pointed out in Section 2.3, when the primary pressure drops down to $4.5 \mathrm{MPa}$, the accumulator will be initiated. So the pressure difference set point of valve opening could be deduced. But the control of accumulator valve closure is unknown, so pressure difference between 'set point 1 ' and 'set point 4' (Figure 4.5) are designed by three values which are named DP large, DP small and DP middle. It can be seen from Figures 5.29 - 5.31 that the results do not show significant difference between different valve closure set points. The peak value may be increased a little by setting small DP, but the calculation cannot execute to the end of the transient under the current time step data. For example, for the DP small, the pressure difference between 'set point 1 ' and 'set point 4' is $1 \mathrm{E} 4 \mathrm{~Pa}$ and the calculation is interrupted at about $2200 \mathrm{~s}$. 


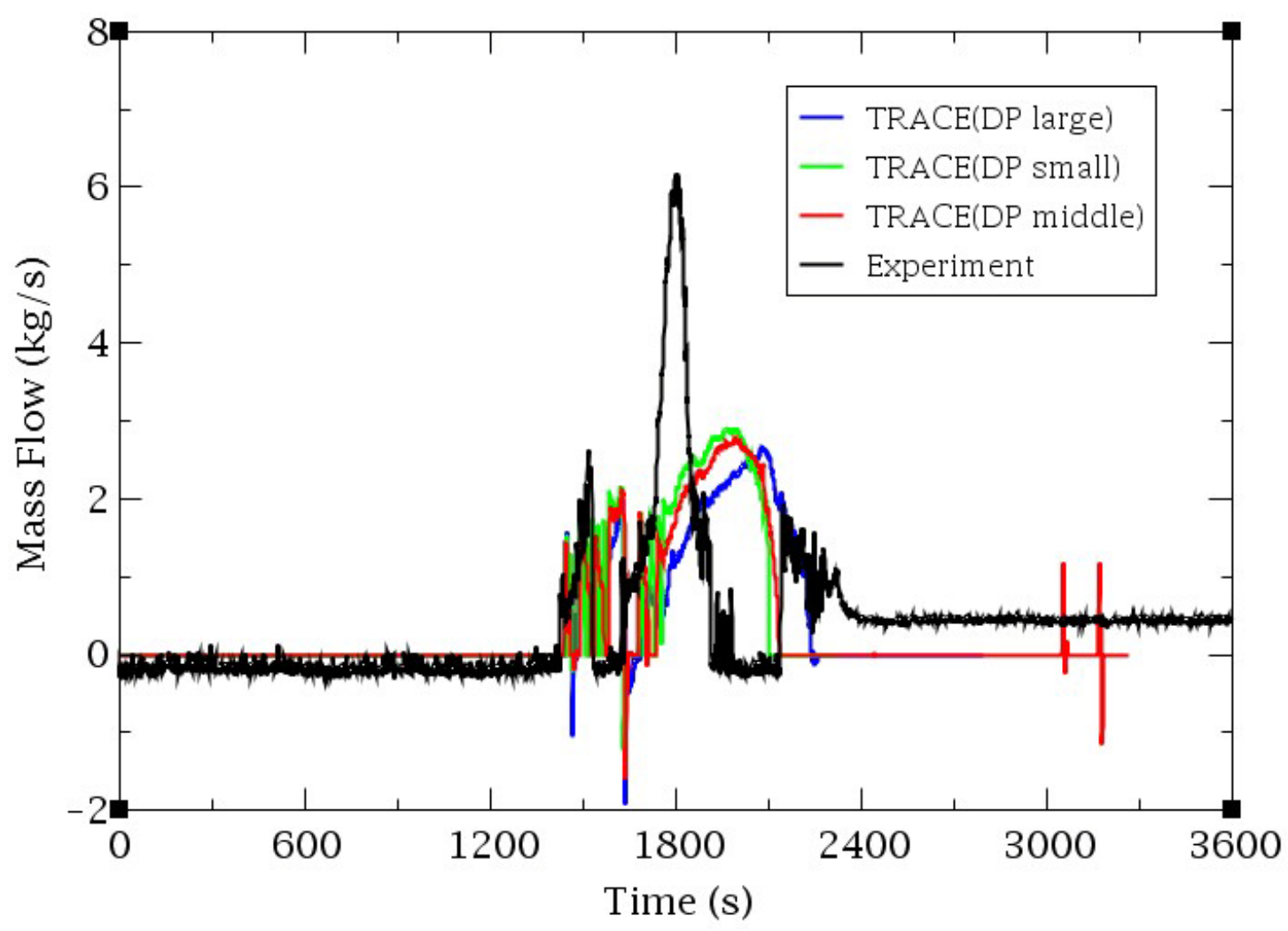

Figure 5.29 Accumulator mass flow.

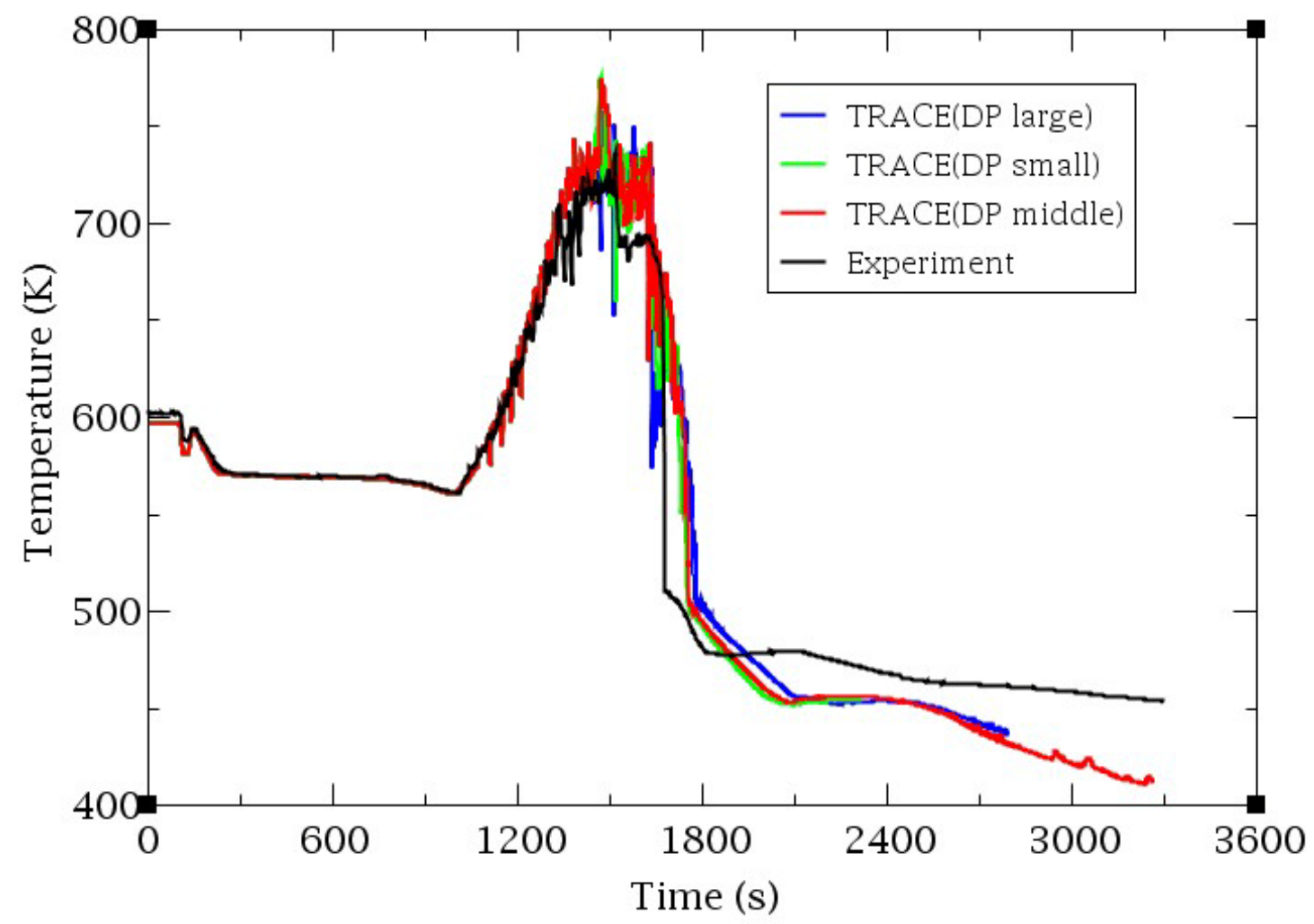

Figure 5.29 Core exit temperature. 


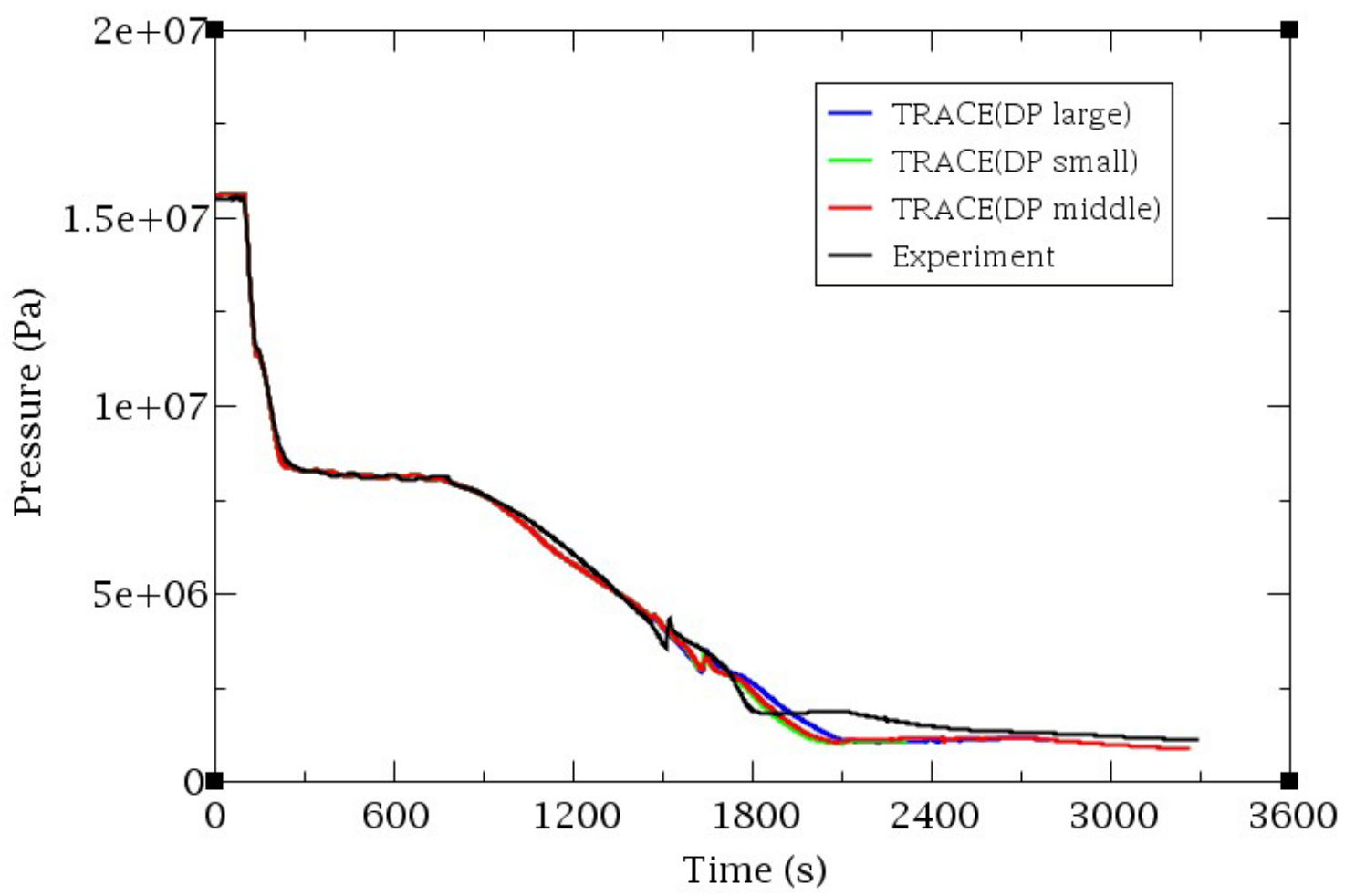

Figure 5.30 PV lower plenum pressure. 


\section{Conclusions}

Motivated by validation of TRACE code in simulating the SBLOCA at pressure vessel (PV) upper head, as well as trying to interpret the corresponding transient thermal hydraulic performance, a computational model is developed to simulate the ROSA-V project test 6-1 by using TRACE code 5.0 in this thesis.

Basically, the steady-state and transient-state of test 6-1 are simulated in present study, and the simulation results are compared with the corresponding experimental data to validate the TRACE code. The steady-state presents the initial conditions, while the transient process shows the development of some important parameters during the SBLOCA, such as the break mass flow rate, the pressure in both primary system and secondary system, the core exit temperature (CET), the maximum fuel rod surface temperature, the primary loop mass flow rate, the collapsed liquid level of the core and the emergency core cooling system (ECCS) injection. In addition, the sensitive study is also performed to improve the model and investigate the influence of different modeling for the simulations of the break unit, the leakage between downcomer and hot leg, and the ECCS system. It can be concluded as following:

In general, the simulation results of both the steady-state and the transient-state show good agreement with the experimental data. Discrepancies of chronological sequence are kept within a reasonable range except the initiation time of low pressure injection system (LPIS). It reveals that TRACE model could predict such SBLOCA with reasonable results.

However, at the late phase of simulation, there is a difference of primary pressure prediction due to higher break mass flow predicted in TRACE than that in experiment. It leads to the different coolant injection process by the ECCS (both accumulator and LPIS), which results in a fast depressurization and affects the primary pressure evolution again. In addition, the simulated results of the CET and the maximum fuel rod temperature are also different from experimental data at the late phase, since the core collapsed water level shows a slower decrease than that of experimental data and the core is still uncovered in the experiment at the end of test while it is covered by coolant in TRACE simulation.

From the sensitivity study, it is believed that the accurate prediction of the break mass flow rate and the flow area of the leakage between downcomer and hot leg exert significantly influences on the predicted results the CET and the pressure. When the coolant is in the single phase vapor, TRACE over-predicts the break mass flow for the break located at the upper head of PV and it is difficult to adjust the over-predicted results since the choked flow multiplier is unavailable for the single vapor phase in the code. In addition, the larger flow area between downcomer and hot leg could lead to larger drop of pressure and earlier rising of CET, so if the CET rising is too late, it will be helpful to adjust the leakage flow area. Furthermore, according to simulation results, it is shown that the difference of the break location between the experiment and the simulation at the VESSEL upper head cells due to the limited resolution has negligible effect on the integrated break mass, the CET and the primary pressure. As a result, it 
is unnecessary to renodalize the VESSEL component if the break connection does not locate exactly at the same point. Finally, the study of accumulator coolant injection is investigated which demonstrates that neither the different control logics of accumulator injection valves nor the different values of the differential pressure for activating the accumulator injection valves has great effect on the data of core exit temperature and the primary pressure. 


\section{References}

[1] P. Bengt, Light water reactor safety. Stockholm: Pergamon Press, 2009.

[2] B.K. Steven, H. L. Jay, B.K. Thomas, Nuclear Energy Encyclopedia: Science, Technology, and Applications. Wiley press, 2011.

[3] T. Mura, N. Gun, I. Gen, ROSA-V Group, ROSA-V Large Scale Test Facility (LSTF): System Description for third and fourth simulated fuel assemblies, Japan Atomic Research Institute, 2003.

[4] The thermo-hydraulic safety research group, Final Data Report of ROSA/LSTF Test $6-1$ (1.9\% Pressure Vessel Upper-head Small Break LOCA Experiment SB-PV-09 in JAEA).Japan Atomic Energy Agency, 2006.

[5] United States Nuclear Regulatory Commission, Nrc report NUREG/BR-0353, Davis-Besse Reactor Pressure Vessel Head Degradation-Overview, Lessons Learned, and NRC Actions Based on Lessons Learned, 2008.

[6] The ROSA-V Group, Experimental data of ROSA/LSTF Test 6-1, Japan Atomic Energy Agency, 2006.

[7] W.M. Ma, E. Bubelis, A. Karbojian, B.R. Sehgal, P. Coddington, Transient experiments from the thermal-hydraulic ADS lead bismuth loop (TALL) and comparative TRAC/AAA analysis, Nuclear Engineering and Design, Vol. 236, pp. 1422-1444, 2006.

[8] K. Bjorklund, Comparison between RELAP5 and TRACE for modeling different loads on pipe systems during transient conditions, ISSN: 1401-5757, UPTEC F10035, 2010.

[9] P. Davide, G. Davor, C. Antonio, E. R. Marco, Analysis of different containment models for IRIS small break LOCA, using GOTHIC and RELAP5 code, Nuclear Engineering and Design, Vol. 241, pp. 1152-1164, 2011.

[10] J. Suchoszek, F. Cadinu, T. Kozlowski, T.N. Dinh, RELAP5 and TRACE codes comparison and validation under steady-state and transient conditions on the basis of NUPEC data, 12th International Topical Meeting on Nuclear Reactor Thermal Hydraulics, NURETH-12, 2007.

[11] TRACE V5.0 THEORY MANUAL, Field Equations, Solution Methods, and Physical Models, Division of Safety Analysis, U.S. Nuclear Regulatory Commission, 2008.

[12] W. Wulff, Critical review of conservation equations for two-phase flow in the U.S. NRC TRACE code, Nuclear Engineering and Design, Vol. 241, pp. 4237-4260, 2011.

[13] Y.H. Cheng, C.K. Shih, J.R. Wang, H.T. Lin, An investigation of steam-water countercurrent flow model in TRACE, Annals of Nuclear Energy, Vol. 37, pp. 1378-1383, 2010.

[14] S. Gallardo, V. Abella, G. Verdú, Assessment of TRACE 5.0 against ROSA Test 6-1, Vessel Upper Head SBLOCA, NRC International Agreement Report, NUREG/IA-0245, 2011.

[15] J. Freixa, A. Manera, Remarks on Consistent Development of Plant Nodalizations: An Example of Application to the ROSA Integral Test Facility. Science and Technology of Nuclear Installations, Hindawi Publishing Corporation, 2011 (doi:10.1155/2012/158617).

[16] J. Freixa, A. Manera, Analysis of an RPV upper head SBLOCA at the ROSA facility using TRACE. Nuclear Engineering and Design, Vol. 240, pp. 1779-1788, 2010.

[17] TRACE V5.0 USER'S MANUAL, Volume 2: Modeling Guidelines, U.S. Nuclear Regulatory Commission, 2008. 
[18] T. Siikonen, A study of critical two-phase flow models, Nuclear Engineering and Design, Vol. 73, pp. 293-302, 1982.

[19] TRACE V5.0 USER'S MANUAL, Volume 1: Input Specification, Division of Safety Analysis, U.S. Nuclear Regulatory Commission, 2008.

[20] V. H. Ransom and J. A. Trapp, The RELAP5 Choked Flow Model and Application to a Large Scale Flow Test, ANS/ASME/NRC International Topical Meeting on Nuclear Reactor Thermal-Hydraulics (Saratoga Springs, New York), pp. 799-819, 1980.

[21] I. E. Idelchik, Handbook of hydraulic resistance. Begell House, 3rd edition, 2001.

[22] B. S. Massey, Mechanics of Fluids. New York: D. Van Nostrand Co, 1968.

[23] F. M. White, Fluid Mechanics. New York: McGraw-Hill Book Co, 1979.

[24] S. Oddbjörn, The role of the core exit thermocouples in accident management, presented in OECD-ROSA/LSTF Meeting in Paris, 31 May - 1 June, 2007. 